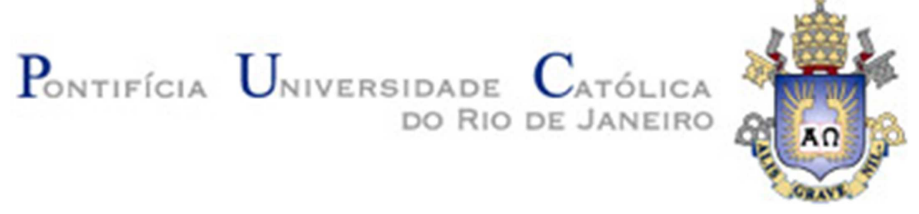

Sergio Paulo Gomes Pinho

Quebra de Gota no Escoamento através de um Orifício

Dissertação apresentada ao Programa de Pósgraduação em Engenharia Mecânica como requisito parcial para obtenção do título de Mestre em Engenharia Mecânica.

Orientador: Prof. Márcio da Silveira Carvalho 
Sergio Paulo Gomes Pinho

\title{
Quebra de Gota no Escoamento através de um Orifício
}

Dissertação apresentada como requisito parcial para obtenção do grau de Mestre pelo Programa de Pósgraduação em Engenharia Mecânica do Departamento de Engenharia Mecânica do Centro Técnico Científico da PUC-Rio. Aprovada pela Comissão Examinadora abaixo assinada.

\author{
Prof. Márcio da Silveira Carvalho \\ Orientador \\ Departamento de Engenharia Mecânica - PUC-Rio
}

Prof. Luis Fernando Alzuguir Azevedo

Departamento de Engenharia Mecânica - PUC-Rio

Prof. Geraldo Afonso Spinelli Martins Ribeiro Departamento de Engenharia Mecânica - PUC-Rio

Prof. José Eugenio Leal Coordenador Setorial do Centro Técnico Científico - PUC-Rio 
Todos os direitos reservados. É proibida a reprodução total ou parcial do trabalho sem autorização da universidade, do autor e do orientador.

\section{Sergio Paulo Gomes Pinho}

Sergio Paulo Gomes Pinho graduou-se em Engenharia de Fortificação e Construção pelo Instituto Militar de Engenharia em 2004. Concluiu o curso de pós-graduação em Engenharia de Petróleo pela Universidade Federal da Bahia em 2006. Trabalha desde 2005 na Petrobras nos projetos de desenvolvimento da produção na área de Elevação e Escoamento.

Ficha catalográfica

Pinho, Sergio Paulo Gomes

Quebra de gota no escoamento através de um orifício / Sergio Paulo Gomes Pinho; orientador: Márcio da Silveira Carvalho. - 2014.

125 f. : il. (color.) ; $30 \mathrm{~cm}$

Dissertação (mestrado) - Pontifícia Universidade Católica do Rio de Janeiro, Departamento de Engenharia Mecânica, 2014.

Inclui bibliografia

1. Engenharia mecânica - Teses. 2. Emulsão. 3. Orifício. 4. Quebra de gotas. I. Carvalho, Márcio da Silveira. II. Pontifícia Universidade Católica do Rio de Janeiro. Departamento de Engenharia Mecânica. III. Título. 
À minha esposa Rosana e meu filho Felipe, pelo apoio. 


\section{Agradecimentos}

A Deus pela saúde, capacitação e ajuda durante todo o tempo.

Ao meu orientador Professor Márcio Carvalho pelo estímulo e parceria para a realização deste trabalho.

A minha esposa Rosana pelo companheirismo, compreensão e apoio em todas as horas desta jornada.

Ao meu filho Felipe que alegrou os últimos meses deste trabalho.

Aos meus pais, pela educação, atenção e carinho.

Aos meus chefes na Petrobras Antônio Pinto, Geraldo Spinelli e Guilherme Peixoto que apoiaram em todo o tempo o meu desenvolvimento.

Aos meus colegas de trabalho Ana Gabriela, Denise, José Ricardo, Fabiano, Gustavo, Daniel, Fernando Coelho e Fernando César que compreenderam minhas ausências e me ajudaram no cumprimento das metas.

Ao Felicle pelos importantes conhecimentos passados no laboratório.

Aos meus colegas da PUC-Rio Ranena, Mildre, Tálita, Simone, Thiago, Danmer, Fred, Diego, Bruno e Jose pela ajuda e companheirismo no laboratório.

Aos professores que participaram da Comissão examinadora.

A todos os professores e funcionários do Departamento pelos ensinamentos e pela ajuda.

A todos os amigos e familiares que de uma forma ou de outra me estimularam ou me ajudaram. 


\section{Resumo}

Pinho, Sergio Paulo Gomes; Carvalho, Márcio da Silveira. Quebra de Gota no Escoamento através de um Orifício. Rio de Janeiro, 2014. 125p. Dissertação de Mestrado - Departamento de Engenharia Mecânica, Pontifícia Universidade Católica do Rio de Janeiro.

Na indústria do petróleo, durante a produção de um campo, é muito utilizada a injeção da água do mar para manutenção da pressão do reservatório. Com a injeção, há o aumento da fração de água no fluido produzido formando assim uma emulsão com uma determinada distribuição do tamanho de gotas. No sistema de produção, esta mistura sofre variações de pressão e temperatura que impactam na distribuição do tamanho de gotas da emulsão. As mudanças mais significativas nestes parâmetros ocorrem nos chokes instalados na chegada à planta de processo. O conhecimento desta distribuição é importante, pois influencia diretamente no dimensionamento dos separadores que serão instalados na plataforma, no caso offshore. O parâmetro considerado como o que melhor descrevia o processo de quebra de gotas era a potência dissipada no orifício. Nos experimentos desenvolvidos para avaliar a quebra de gotas nos chokes, foi observado que este termo possuía algumas limitações e um novo ajuste foi proposto para atender aos valores medidos. Nos testes foram utilizados dois tipos de óleos e diferentes orifícios que geraram os dados necessários para elaborar uma nova abordagem, onde a queda de pressão medida apresentou a melhor relação com os diâmetros das gotas após o orifício. Posteriormente, o efeito da viscosidade foi adicionado para que houvesse uma relação válida para ambos os óleos utilizados, tornando assim o modelo de quebra mais abrangente.

\section{Palavras-chave}

Emulsão; quebra de gotas; orifício. 


\section{Abstract}

Pinho, Sergio Paulo Gomes; Carvalho, Márcio da Silveira (Advisor). Droplet break-up in a flow through an orifice. Rio de Janeiro, 2013. 125p. MSc. Dissertation - Departamento de Engenharia Mecânica, Pontifícia Universidade Católica do Rio de Janeiro.

In the oil industry, during an oilfield development, the sea water injection is largely used to maintain the reservoir pressure. As a result of this injection, there is the increase of the water fraction in the produced fluid, forming an emulsion with a determined droplet size distribution. In the production system, this mixture flows under different conditions of pressure and temperature that impact the emulsion droplet size distribution. The most meaningful changes of these conditions occur in the chokes that are installed at the process plant arrival. The knowledge of the droplet size distribution is important, because it impacts the sizing of the separators that will be installed at the platform, in an offshore scenario. The parameter that was considered as the most appropriate to describe the droplet break-up process was the energy dissipation rate. During the experiments performed to evaluate the droplet break-up in the chokes, it was observed that this parameter had some limitations and a new adjustment was proposed to fit with the measured values. In the tests, two oils with different viscosities were used while varying orifices characteristics to obtain the needed data to elaborate a new approach. Thus, it was found that the measured pressure drop through the restriction presented the best relation with the droplets diameters measured downstream the orifice. After this, the effect of the oil viscosity was also added to the model so to create a correlation valid for both tested oils. In this way, the break-up model proposed would be more complete and useful for different conditions.

\section{Keywords}

Emulsion; droplets break-up; orifice. 


\section{Sumário}

1 Introdução 22

2 Revisão Bibliográfica 26

2.1. Emulsões 26

2.1.1. Conceitos Básicos 26

2.1.2. Formação da Emulsão $\quad 27$

2.1.3. Viscosidade da Emulsão 39

2.2. Quebra de Gotas no Escoamento 46

$\begin{array}{ll}\text { 2.2.1. Mecanismos de quebra de gotas } & 47\end{array}$

3 Experimentos $\quad 62$

3.1. Objetivos do Experimento 62

3.2. Descrição geral do experimento 63

3.3. Fluidos 73

3.3.1. Procedimento experimental de preparação e caracterização $\begin{array}{ll}\text { morfológica da emulsão concentrada } & 78\end{array}$

3.4. Obtenção dos Resultados 80

3.4.1. Procedimento para operação da bancada experimental e coleta de amostras 86

3.4.2. Procedimento para medição do tamanho de gotas no Mastersizer $2000 \quad 87$

4 Resultados Experimentais 89

4.1. Resultados Obtidos 89

4.1.1. Óleo $\mathrm{NH}-10 \quad 89$

4.1.2. Óleo 500PS 102

4.2. Discussão dos Resultados 108

4.3. Considerações Gerais 116

5 Conclusões e Recomendações 120 
5.1. Conclusões

120

5.2. Recomendações

121

6 Revisão Bibliográfica 


\section{Lista de figuras}

Figura 1 - Esquemático do sistema de injeção de água em um campo de petróleo [2]

Figura 2 - Representação das emulsões $\mathrm{O} / \mathrm{A}$ e $\mathrm{A} / \mathrm{O}$, respectivamente [9]

Figura 3 - Número de We crítico para quebra de gotas em um escoamento apenas sob a ação do cisalhamento em função da razão entre as viscosidade das fases dispersa e contínua [10].

Figura 4 - Diâmetro médio da gota, $d_{43}$, como função da energia adicionada $(\mathrm{P})$, para uma emulsão óleo-água produzido por vários equipamentos [12].

Figura 5 - Tamanho máximo da gota, $d_{95}$, em função da viscosidade da fase conínua. As curvas mostram as previsões teóricas para o tamanho máximo da gota [14].

Figura 6 - Efeito da viscosidade da fase dispersa, $\mu_{d}$ em mPa.s, no tamanho de gotas característico, $\mathrm{d}_{43}$, para várias máquinas [13]. De cima para baixo, as duas primeiras linhas representam o uso de turbomixer, a terceira um homogeneizador e a última, um gerador ultrassônico.

Figura 7 - Distribuição de volume cumulativa versus o diâmetro de gota característico, $d / d_{50}$. A fase dispersa é o hexadecano e a variação é no modo de preparo da emulsão [14].

Figura 8 - Comparação dos melhores ajustes entre as funções de volume cumulativo para óleos de diferentes viscosidades versus o diâmetro de gota característico, $\mathrm{d} / \mathrm{d}_{50}$. Os óleos utilizados foram o Hexadecano ( $\left.\mu_{d}=3 \mathrm{mPa} . \mathrm{s}\right)$, o SBO $\left(\mu_{d}=27 \mathrm{mPa} . \mathrm{s}\right)$ e o óleo siliconado ( $\left.\mu_{d}=95 \mathrm{mPa} . \mathrm{s}\right)$ [14].

Figura 9 - Efeito da concentração total de surfactante no tamanho de gotas médio resultante. Quatro surfactantes usados neste experimento [10].

Figura 10 - Diagrama do efeito Gibbs-Marangoni agindo em duas 
gotas que se aproximam durante a emulsificação. As moléculas do surfactante estão representadas pela letra Y [10].

Figura 11 - Diâmetro de gota característico d95 para os três óleos avaliados em função do teor da fração interna [14].

Figura 12 - Diâmetro de gota característico $d_{32}$ para os três óleos avaliados em função do teor da fração interna [14].

Figura 13 - Viscosidade do óleo puro e de uma emulsão água/óleo com $30 \%$ de água, em função da temperatura [8].

Figura 14 - Viscosidade da Emulsão a $20^{\circ} \mathrm{C}$ versus fração da fase dispersa. Neste caso, o ponto de inversão de fase é 70\% [8].

Figura 15 - Formação das camadas quando as partículas são sujeitas a tensão cisalhante [17].

Figura 16 - Efeito da Temperatura e da taxa de cisalhamento na viscosidade da emulsão. A influência do cisalhamento é mais significativa quando a temperatura do fluido está abaixo de $20^{\circ} \mathrm{C}$ [20].

Figura 17 - Representação esquemática da inversão de fases [22].

Figura 18 - Gradiente de pressão relativo ao caso sem água, no duto de aço na velocidade de mistura de $2,1 \mathrm{~m} / \mathrm{s}$ [24].

Figura 19 - Esquemático dos campos de pressão e escoamento através de um orifício. A linha preta, que corta a região azul no ponto mais estreito, indica o ponto de ocorrência da Vena Contracta [4].

Figura 20 - Mapa de quebra de gota de uma solução nheptano/água em função do $\mathrm{Re}$ e da razão de restrição, $\beta$. Acima da reta inclinada não foi verificada quebra de gotas [6].

Figura 21 - Comparação entre os diâmetros $d_{32}$ e $d_{95}$ a jusante do choke, com os dados experimentais de Percy e Sleicher, em função do comprimento característico $\mathrm{L}_{0} . \mathrm{O} \Delta \mathrm{P}_{\text {máx }}$ é igual ao $\Delta \mathrm{P}_{v c}$ das equações anteriores [6].

Figura 22 - Relação entre o $d_{95}$ e o parâmetro $L_{0}$, para quebra de gotas em orifícios entre 1,0 e 3,0 mm. Os dois óleos usados são o Vitrea 9 e Vitrea 46 , com viscosidade de 18 e $140 \mathrm{mPa} . \mathrm{s}$ a $22^{\circ} \mathrm{C}$, 
respectivamente [4].

Figura 23 - Características geométricas dos Orifícios testados. Medidas apresentadas estão em mm [4].

Figura 24 - Visão Esquemática da Zona do jato a jusante do Orifício, neste ponto a velocidade do fluido é superior à verificada no duto.

Figura 25 - Relação entre o $d_{95}$ e o parâmetro de quebra devido ao movimento turbulento, em orifícios entre 1,0 e $3,0 \mathrm{~mm}$. Os dois óleos usados são o Vitrea 9 e Vitrea 46 [4].

Figura 26 - Efeito da distribuição do tamanho de gota injetado na distribuição a jusante do orifício. Usado o óleo Vitrea 9 [7].

Figura 27 - Relação entre o $d_{\max }$ e o parâmetro de quebra devido ao movimento turbulento, em orifícios entre 1,0 e 3,0 mm, com o ajuste linear dos três óleos analisados ( $\mathrm{n}$-heptano, Vitrea 9 e Vitrea 46) [7].

Figura 28 - Tamanho de gotas a jusante da restrição em função do diâmetro de entrada. A quebra ocorre em um orifício e em dois orifícios postos em série [7].

60

Figura 29 - Visão Esquemática da bancada experimental utilizada.

Figura 30 - Imagem da ligação do cilindro com emulsão concentrada a bomba de seringa, à esquerda. Observa-se que a saída da bomba é conectada ao topo do cilindro. Atrás do cilindro, observa-se o tanque de água.

Figura 31 - Conexão entre o circuito de água e o de emulsão concentrada. Na parte superior esquerda observa-se a mangueira plástica para visualização da injeção de emulsão e ao final desta a check valve.

Figura 32 - Pontos de coleta de amostras com as válvulas pretas, manômetro e alojador de orifícios no centro.

Figura 33 - Vista do Mastersizer 2000 e a direita, o Hydro2000MU.

Figura 34 - À esquerda, as peças que compõem o conjunto alojador/orifício, e à direita os orifícios disponíveis para utilização no experimento. 
Figura 35 - Montagem do alojador com orifício, com corte representativo. O orifício é a peça azul escura mostrada no corte.

Figura 36 - Projeto dos Orifícios construídos, com as cotas em $\mathrm{mm}$. As cotas $A$ e $C$ referem-se aos diâmetros utilizados e a $B$ aos comprimentos menores de $30 \mathrm{~mm}$.

Figura 37 - Visão da bancada desde o ponto de mistura, canto inferior esquerdo, até a válvula de fechamento, canto direito, passando pelos pontos de amostragem, manômetro e alojador de orifícios. O equipamento circular azul é o medidor de vazão.

Figura 38 - Emulsões O/A preparadas para avaliação de estabilidade. Os teores volumétricos óleo/água ilustrados são 30/70, 50/50 e 70/30.

Figura 39 - Emulsão com a água livre totalmente segregada e verificação de estabilidade da amostra 20 dias após a drenagem.

Figura 40 - Imagem dos equipamentos utilizados no procedimento de formação de emulsão - Balança de precisão, Misturador e Ultrarrax.

Figura 41 - Medição de tamanho de gotas. As linhas verde e vermelha são, respectivamente, as medições de fundo e topo da Amostra 3 , e as linhas rosa e azul são, respectivamente, as de fundo e topo da Amostra 4. Observa-se homogeneidade nas duas amostras.

Figura 42 - Mudança do tamanho das gotas desde o tanque até o ponto antes do orifício, na vazão de $312 \mathrm{ml} / \mathrm{min}$, para a Amostra 5 (azul para vermelho) e Amostra 6 (rosa para o verde).

Figura 43 - Mudança do tamanho das gotas desde o tanque até o ponto após o orifício, na vazão de $312 \mathrm{ml} / \mathrm{min}$, para a Amostra 5 (vermelho para o azul) e Amostra 6 (verde para o rosa).

Figura 44 - Mudança do tamanho das gotas desde o tanque até o ponto antes do orifício, na vazão de $156 \mathrm{ml} / \mathrm{min}$, para a Amostra 5 (vermelho para o azul) e Amostra 6 (verde para o rosa).

Figura 45 - Distribuição do tamanho de gotas após preparo das Amostras 8 (linha verde) e 10 (linha vermelha). 
Figura 46 - Distribuição do tamanho de gotas para a Amostra 8 na vazão de $1040 \mathrm{ml} / \mathrm{min}$, na condição de tanque (linha vermelha), antes do orifício (linha verde) e após o orifício (linha azul).

Figura 47 - Distribuição do tamanho de gotas para a Amostra 10 na vazão de $800 \mathrm{ml} / \mathrm{min}$, na condição de tanque (linha vermelha), antes do orifício (linha verde) e após o orifício (linha azul).

Figura 48 - Distribuição do tamanho de gotas para a Amostra 11 na vazão de $2000 \mathrm{ml} / \mathrm{min}$, na condição de tanque (linha vermelha), antes do orifício (linha verde) e após o orifício (linha azul).

Figura 49 - Distribuição do tamanho de gotas para a Amostra 12 na vazão de $2000 \mathrm{ml} / \mathrm{min}$, na condição de tanque (linha vermelha), antes do orifício (linha verde) e após o orifício (linha azul).

Figura 50 - Mudança do tamanho das gotas desde o tanque até 0 ponto após o orifício, na vazão de $1600 \mathrm{ml} / \mathrm{min}$, para a Amostra 13 (vermelho para o azul) e Amostra 18 (verde para o rosa).

Figura 51 - Mudança do tamanho das gotas desde o tanque até o ponto após o orifício, na vazão de $480 \mathrm{ml} / \mathrm{min}$, para a Amostra 13 (vermelho para o azul) e Amostra 18 (verde para o rosa).

102

Figura 52 - Mudança do tamanho das gotas desde o tanque até o ponto após o orifício, na vazão de $1040 \mathrm{ml} / \mathrm{min}$, para a Amostra 14 (vermelho para o azul) e Amostra 17 (verde para o rosa).

Figura 53 - Mudança do tamanho das gotas desde o tanque até o ponto após o orifício, na vazão de $800 \mathrm{ml} / \mathrm{min}$, para a Amostra 14 (vermelho para o azul) e Amostra 17 (verde para o rosa).

Figura 54 - Mudança do tamanho das gotas desde o tanque até 0 ponto após o orifício, na vazão de $1360 \mathrm{ml} / \mathrm{min}$, para a Amostra 15 (verde para o rosa) e Amostra 16 (vermelho para o azul).

Figura 55 - Mudança do tamanho das gotas desde o tanque até o ponto após o orifício, na vazão de $1120 \mathrm{ml} / \mathrm{min}$, para a Amostra 15 (verde para o rosa) e Amostra 16 (vermelho para o azul).

Figura 56 - Diâmetro $d_{50}$ a jusante do orifício em função da Potência Dissipada.

Figura 57 - Gráfico log-log com o ajuste do diâmetro $d_{50}$ após a 
restrição em função da Potência Dissipada para cada orifício avaliado com o óleo $\mathrm{NH}-10$.

Figura 58 - Diâmetro $d_{50}$ após a quebra em função do Re em cada orifício.

Figura 59 - Diâmetro $d_{50}$ após a quebra em função da velocidade no orifício.

Figura 60 - Equação de ajuste do diâmetro $d_{50}$ após o orifício em função da velocidade no orifício.

Figura 61 - Relação entre o diâmetro $d_{50}$ após a quebra e a queda de pressão no orifício, com a equação de ajuste para as emulsões do óleo $\mathrm{NH}-10$, e a faixa de confiança de $95 \%$.

Figura 62 - Relação entre o diâmetro $d_{50}$ após a quebra e a queda de pressão no orifício, com a equação de ajuste para as emulsões do óleo 500PS, e a faixa de confiança de $95 \%$.

Figura 63 - Ajustes obtidos com os dois óleos testados no experimento.

Figura 64 - Novo ajuste para os dois tipos de emulsão em função do termo de queda de pressão e viscosidade.

Figura 65 - Ajuste de todos os pontos coletados em função do parâmetro de queda de pressão e viscosidade, e as linhas de confiança de 95\% (vermelha) e 99\% (amarela). 


\section{Lista de tabelas}

Tabela 1 - Tempos medidos para diferentes volumes amostrados. $\quad 64$

Tabela 2 - Vazões calculadas a partir dos tempos medidos acima. 64

Tabela 3 - Vazões lidas no medidor 65

Tabela 4 - Diferença entre as Vazões médias Lidas e Calculadas $\quad 65$

Tabela 5 - Características dos Orifícios Construídos 71

Tabela 6 - Propriedades dos Óleos NH-10 e 500PS. 74

Tabela 7 - Emulsões concentradas utilizadas no experimento 77

Tabela 8 - Tempo e Velocidade de agitação para formação das emulsões

Tabela 9 - Variação de pressão, em psi; Comprimento do orifício = $30 \mathrm{~mm}$.

Tabela 10 - Variação de pressão, em psi; Comprimento do orifício $=10 \mathrm{~mm}$.

Tabela 11 - Variação de pressão, em psi; Comprimento do orifício $=5 \mathrm{~mm}$.

Tabela 12 - Variação de pressão, em psi; Comprimento do orifício $=1 \mathrm{~mm}$.

Tabela 13 - Matriz de teste do orifício ํo 6 - Amostras 5 e 6 (Óleo $\mathrm{NH}-10)$.

Tabela 14 - Matriz de teste do orifício oo 9 - Amostra 9 (Óleo NH10).

Tabela 15 - Matriz de teste do orifício no 9 - Amostra 8 (Óleo NH10).

Tabela 16 - Matriz de teste do orifício no 9 - Amostra 10 (Óleo NH10).

Tabela 17 - Matriz de teste do orifício no 12 - Amostras 11 e 12 (Óleo NH-10).

Tabela 18 - Matriz de teste do orifício o 11 - Amostras 13 e 18 (Óleo NH-10), e Amostras 15 e 16 (Óleo 500PS).

Tabela 19 - Matriz de teste do orifício o 9 - Amostras 14 e 17 
(Óleo 500PS).

Tabela 20 - Variação de Pressão obtida com a Emulsão 5 (Gotas Pequenas).

Tabela 21 - Variação de Pressão obtida com a Emulsão 6 (Gotas Grandes).

Tabela 22 - Potência Dissipada, Reynolds e valores medidos para o $d_{50}$ das Amostras 5 e 6.

Tabela 23 - Variação de Pressão obtida com a Emulsão 9 (Gotas Pequenas).

Tabela 24 - Variação de Pressão obtida com a Emulsão 8 (Gotas Grandes).

Tabela 25 - Variação de Pressão obtida com a Emulsão 10 (Gotas Grandes).

Tabela 26 - Potência Dissipada, Reynolds e valores medidos para o d $\mathrm{d}_{50}$ das Amostras 8, 9 e 10.

Tabela 27 - Variação de Pressão obtida com a Emulsão 11 (Gotas Pequenas).

Tabela 28 - Variação de Pressão obtida com a Emulsão 12 (Gotas Grandes).

Tabela 29 - Potência Dissipada, Reynolds e valores medidos para o $d_{50}$ das Amostras 11 e 12.

Tabela 30 - Variação de Pressão obtida com a Emulsão 13 (Gotas Pequenas).

Tabela 31 - Variação de Pressão obtida com a Emulsão 18 (Gotas Grandes).

Tabela 32 - Potência Dissipada, Reynolds e valores medidos para o d $\mathrm{d}_{50}$ das Amostras 13 e 18.

Tabela 33 - Variação de Pressão obtida com a Emulsão 14 (Gotas Grandes).

Tabela 34 - Variação de Pressão obtida com a Emulsão 17 (Gotas Pequenas).

Tabela 35 - Potência Dissipada, Reynolds e valores medidos para o d $d_{50}$ das Amostras 14 e 17. 
Tabela 36 - Variação de Pressão obtida com a Emulsão 15 (Gotas Pequenas).

Tabela 37 - Variação de Pressão obtida com a Emulsão 16 (Gotas Grandes).

Tabela 38 - Potência Dissipada, Reynolds e valores medidos para o $\mathrm{d}_{50}$ das Amostras 15 e 16. 


\section{Nomenclatura}

A Área da seção transversal do duto

ANM Árvore de Natal Molhada

$\mathrm{C}_{\mathrm{o}} \quad$ Coeficiente do Orifício

$\mathrm{d}_{0} \quad$ Diâmetro calculado quando não há quebra de gotas após passagem no orifício

$\mathrm{d}_{10} \quad$ Diâmetro máximo de gota de $10 \%$ do volume da fase dispersa

$\mathrm{d}_{32} \quad$ Diâmetro da gota que possui a mesma relação volume sobre área superficial que uma partícula de interesse

$\mathrm{d}_{43} \quad$ Diâmetro da gota que possui volume igual à média ponderada dos volumes das partículas da mistura

$\mathrm{d}_{50} \quad$ Diâmetro máximo de gota de $50 \%$ do volume da fase dispersa

$\mathrm{d}_{90} \quad$ Diâmetro máximo de gota de $90 \%$ do volume da fase dispersa

$\mathrm{d}_{95} \quad$ Diâmetro máximo de gota de $95 \%$ do volume da fase dispersa.

Maior valor medido nos experimentos apresentados

$\mathrm{d}_{100} \quad$ Diâmetro calculado quando há $100 \%$ quebra de gotas após passagem no orifício

$\mathrm{d}(0,1) \quad$ Representação do Mastersizer 2000 para $0 \mathrm{~d}_{10}$

$\mathrm{d}(0,5) \quad$ Representação do Mastersizer 2000 para o $d_{50}$

$\mathrm{d}(0,9) \quad$ Representação do Mastersizer 2000 para o $\mathrm{d}_{90}$

$\mathrm{d}_{\mathrm{o}} \quad$ Diâmetro do orifício

$\mathrm{d}_{\mathrm{p}} \quad$ Diâmetro do duto

$\mathrm{d}_{\mathrm{g}} \quad$ Diâmetro da gota

$\mathrm{d}_{\max } \quad$ Máximo diâmetro estável de gota

G Gradiente de velocidade

$\mathrm{P} \quad$ Energia adicionada à emulsão

r Raio da gota

RAO Razão Água-Óleo

Re Número de Reynolds

$\mathrm{T} \quad$ Temperatura do fluido

$\mathrm{U}_{\mathrm{ws}} \quad$ Velocidade superficial da água 


\begin{tabular}{|c|c|}
\hline $\mathrm{U}_{\mathrm{m}}$ & Velocidade da mistura \\
\hline $\mathrm{U}_{\mathrm{p}}$ & Velocidade média no duto \\
\hline $\mathrm{U}_{\mathrm{o}}$ & Velocidade média no orifício \\
\hline We & Número de Weber \\
\hline$\Delta \mathrm{p}_{v c}$ & Máxima queda de pressão \\
\hline$\Delta \mathrm{p}_{\text {perm }}$ & Queda de pressão permanente \\
\hline$\Delta \mathrm{x}_{\text {perm }}$ & Comprimento da zona de orifício \\
\hline$\Delta \mathrm{x}$ & Distância em que ocorre a máxima queda de pressão \\
\hline$\Delta \mathrm{u}$ & $\begin{array}{l}\text { Diferencial de velocidade devido ao movimento caótico e } \\
\text { aleatório do fluido }\end{array}$ \\
\hline$\beta$ & Razão entre o diâmetro orifício e o do duto $\left(d_{o} / d_{p}\right)$ \\
\hline$\epsilon_{o}$ & Fração volumétrica do óleo \\
\hline$\epsilon_{o}^{I}$ & $\begin{array}{l}\text { Fração volumétrica crítica do óleo, onde ocorre a inversão da } \\
\text { fase }\end{array}$ \\
\hline$\epsilon_{w}$ & Fração volumétrica da água \\
\hline$\epsilon_{w}^{I}$ & $\begin{array}{l}\text { Fração volumétrica crítica da água, onde ocorre a inversão da } \\
\text { fase }\end{array}$ \\
\hline$\varepsilon$ & Potência dissipada por unidade de massa \\
\hline$\Phi$ & Fração volumétrica da fase dispersa \\
\hline$\mu_{\mathrm{c}}$ & Viscosidade dinâmica da fase contínua \\
\hline$\mu_{\mathrm{d}}$ & Viscosidade dinâmica da fase dispersa \\
\hline$\mu_{\mathrm{o}}$ & Viscosidade dinâmica do óleo \\
\hline$\mu_{\mathrm{w}}$ & Viscosidade dinâmica da água \\
\hline$\mu_{\mathrm{m}}$ & Viscosidade dinâmica da mistura emulsionada \\
\hline$\rho_{\mathrm{o}}$ & Massa específica do óleo \\
\hline$\rho_{\mathrm{w}}$ & Massa específica da água \\
\hline$\rho_{\mathrm{c}}$ & Massa específica da fase contínua \\
\hline$\rho_{\mathrm{m}}$ & Massa específica da mistura emulsionada \\
\hline$v_{o}$ & Viscosidade cinemática do óleo \\
\hline$v_{w}$ & Viscosidade cinemática da água \\
\hline$\sigma$ & Tensão interfacial \\
\hline$\tau$ & Tensão cisalhante \\
\hline
\end{tabular}


"Como é feliz o homem que acha a sabedoria, o homem que obtém entendimento."

Livro de Provérbios do Rei Salomão 


\section{1 \\ Introdução}

As acumulações de petróleo possuem, na época de sua descoberta, certa quantidade de energia denominada energia primária. No processo de produção há uma dissipação desta energia, causada em parte pela descompressão dos fluidos do reservatório. O consumo da energia primária reflete-se principalmente no decréscimo da pressão do reservatório durante a sua vida produtiva, e consequente redução da produtividade dos poços.

Uma das linhas de ação para minorar os efeitos nocivos da dissipação da energia primária dos reservatórios de petróleo é a suplementação desta com energia secundária através da injeção de um fluido em poços selecionados.

A quantidade adicional de óleo que pode ser retirada através da suplementação da energia primária transferida para a acumulação é chamada de recuperação secundária. Esta mesma nomenclatura também se aplica às operações que conduzem à obtenção deste aumento da produção acumulada de óleo.

O uso dos métodos de recuperação secundária visa aumentar a eficiência de recuperação e acelerar a produção. São normalmente utilizados para a recuperação secundária a injeção de água e a injeção imiscível de gás. O método mais comumente utilizado é a injeção de água.

Ao se injetar água em um reservatório, eleva-se a saturação de água nas imediações do poço injetor formando-se um banco de óleo a frente da água injetada. Entre a zona de água e a de óleo há uma região onde a saturação de água cai bruscamente, que é denominada de frente de avanço. É possível observar esta frente na Figura 1.

Quando esta frente de avanço alcança o poço produtor, há um aumento rápido da razão água/óleo (RAO), ocorrendo então a erupção da água ou breakthrough. Após esta erupção, a fração de água continua a crescer até atingir níveis que vão inviabilizar economicamente a produção do poço [1]. Normalmente, em poços offshore, o teor limite de água é $95 \%$. 


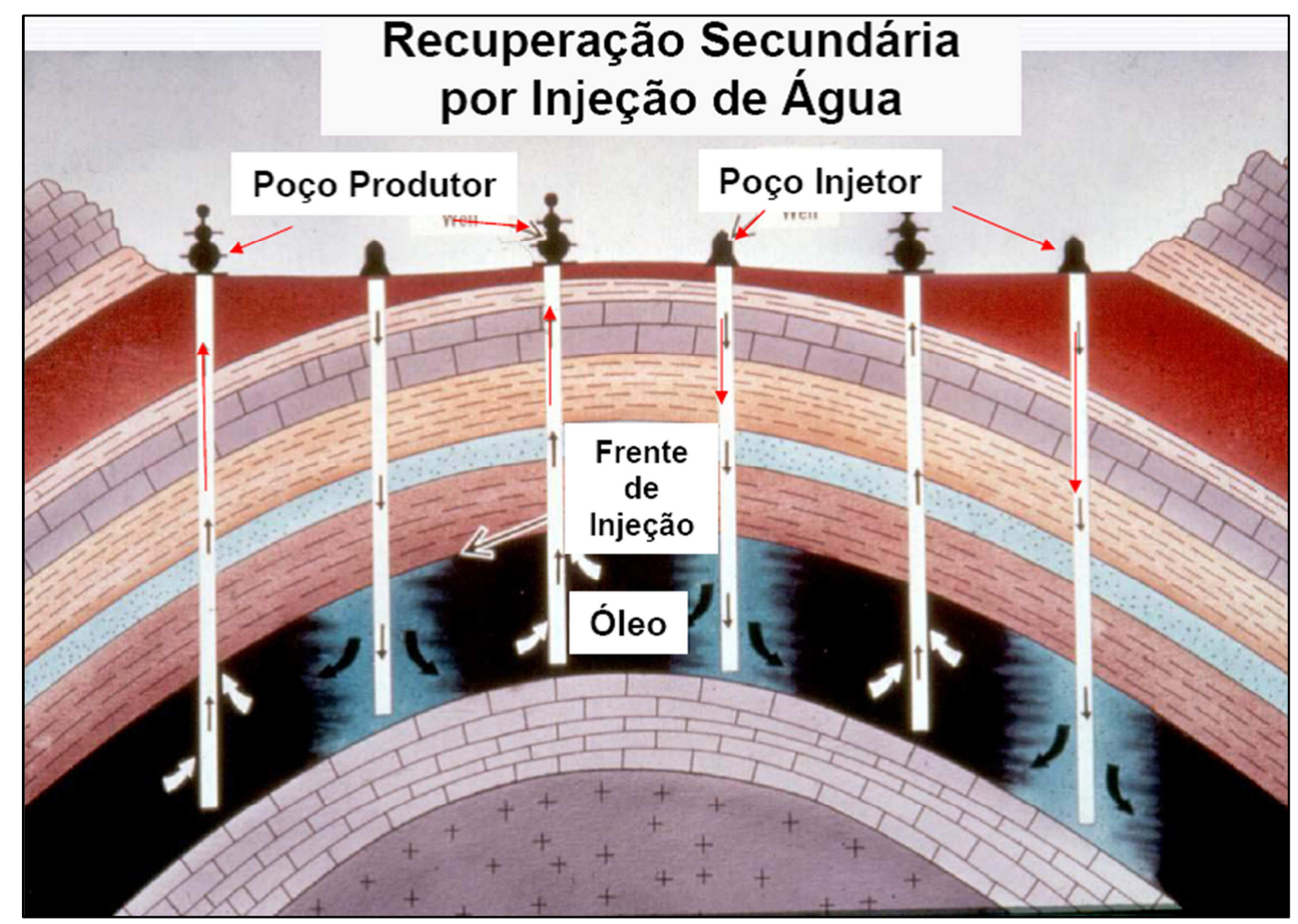

Figura 1 - Esquemático do sistema de injeção de água em um campo de petróleo [2]

Apesar do aspecto positivo da injeção de água, a produção associada de óleo e água tem um impacto negativo nos custos totais de produção, pois o óleo e a água devem ser separados e a água já tratada deve ser descartada, no caso da produção offshore, no mar.

Como a produção de um poço pode ser econômica com altos teores de água, pode ocorrer que a água torne-se, sob estas condições, o meio contínuo da mistura e o óleo está presente sob a forma de gotas. A partir de experimentos laboratoriais desenvolvidos por Janssen et al. [3] observou-se que estas gotas de óleo, nas condições do fundo do poço, possuem tamanhos que vão desde dezenas de micrômetros a poucos milímetros. Contudo, na superfície, no ponto a montante do separador, as gotas estão com diâmetros muito menores que os verificados na condição de fundo de poço. Esta quebra de gotas de óleo desde o poço até a superfície traz efeitos negativos aos custos de produção do projeto [4].

Segundo Van der Zande e Van den Broek [5], o processo de quebra não é intenso na coluna, pois observa-se que a quebra das gotas de óleo ocorre principalmente em regiões de alta intensidade de turbulência. A existência de 
restrições ao longo da coluna e das linhas de produção, como as válvulas de uma Árvore de Natal (ANM) e um choke na chegada a plataforma, indica que estes locais são os pontos no sistema de produção onde a turbulência é mais intensa e consequentemente, onde a maior parte da energia é dissipada. Estas restrições aumentam o processo de dispersão através do incremento da taxa de fragmentação da interface líquido-líquido. Este processo combinado com a presença de compostos tensoativos na mistura, pode levar à formação de emulsões indesejadas que irão dificultar a separação da água e do óleo [6]. Um estudo de visualização deste fenômeno, em andamento, tem indicado que a quebra de gotas ocorre apenas na zona de jato, a jusante do orifício, local onde a turbulência é maior.

Já no processamento do óleo, o tamanho das gotas afeta diretamente a eficiência dos equipamentos de separação. No caso de uma separação baseada na diferença de densidade da água e do óleo, sua eficiência diminui rapidamente quando as gotas que entram no separador possuem diâmetro menor que o valor crítico especificado para o equipamento. A ineficiência na separação óleo/água pode comprometer o enquadramento da água nas especificações ambientais exigidas para descarte no mar e, do óleo para uso no refino. Com isso, outros equipamentos mais caros e sofisticados precisam ser utilizados para que a água que será descartada atenda a parâmetros solicitados [7].

No caso de projetos offshore, em que a planta de processo está instalada sobre navios, a otimização dos equipamentos necessários para a separação águaóleo é mandatória. Um aumento do número de equipamentos na plataforma para separação pode reduzir a capacidade total de processamento ao óleo. Por isso, atualmente, há linhas de pesquisa para instalação de equipamentos de separação água-óleo no fundo do mar a fim de aumentar a capacidade de processamento de óleo de uma plataforma sem que haja a necessidade de aumentar suas dimensões.

Portanto, entender e modelar o processo de quebra de gotas causado por uma restrição numa dispersão líquido-liquido é um item importante quando está se buscando uma melhor predição da distribuição do tamanho de gotas e um aprimoramento no dimensionamento e no projeto dos separadores óleo-água [6].

Este trabalho tem como objetivo avaliar a quebra de gotas de emulsões óleo em água através de orifícios de diferentes dimensões a fim de correlacionar as condições do escoamento, e geometria da constrição com o tamanho final da gota. Para este fim, foi projetado um experimento que permitisse o controle do teor de 
óleo na emulsão, a distribuição inicial do diâmetro das gotas da fase dispersa e a vazão total. O experimento também teria que possibilitar a coleta de amostras sem impactar a distribuição do tamanho de gotas resultante do escoamento a que a emulsão foi submetida.

Nos capítulos a seguir serão apresentadas a revisão bibliográfica realizada tratando sobre a formação de emulsões, tamanho de gotas, mecanismos de quebra de gotas mais significativos e alguns experimentos conduzidos para avaliar este fenômeno, seguida da metodologia experimental empregada com as características dos equipamentos e fluidos utilizados, os resultados obtidos e, finalmente, a conclusão do presente trabalho. 


\section{2 \\ Revisão Bibliográfica}

Neste capítulo será apresentada uma revisão dos principais tópicos relacionados ao desenvolvimento deste trabalho. O mesmo está dividido em duas partes principais: a emulsão e suas características, e os mecanismos de quebra de gotas. A segunda parte servirá de base para avaliação dos resultados obtidos nos experimentos desenvolvidos neste trabalho.

\section{1.}

\section{Emulsões}

\subsection{1.}

\section{Conceitos Básicos}

Uma emulsão é definida como uma mistura de dois líquidos imiscíveis, um dos quais está disperso no outro sob a forma de gotículas estabilizadas pela ação dos agentes emulsificantes. São instáveis termodinamicamente e, portanto não se formam espontaneamente, sendo necessário fornecer energia para formá-las. As forças cisalhantes geradas pelo escoamento do sistema bifásico água-óleo são uma maneira de formação da emulsão. A estabilidade da emulsão formada depende das características do óleo, tais como densidade, viscosidade e a presença de tensoativos naturais (asfaltenos, resinas). Na indústria de petróleo, uma emulsão pode ser do tipo água em óleo (A/O), onde a fase contínua é o óleo, ou do tipo óleo em água (O/A), onde a fase contínua é a água [8], conforme mostrado na Figura 2. Há, contudo outros tipos de emulsões, chamadas emulsões múltiplas, são estas a água em óleo em água (A/O/A) e a óleo em água em óleo $(\mathrm{O} / \mathrm{A} / \mathrm{O})$. $\mathrm{Na}$ análise experimental deste trabalho foi utilizada uma emulsão O/A. 


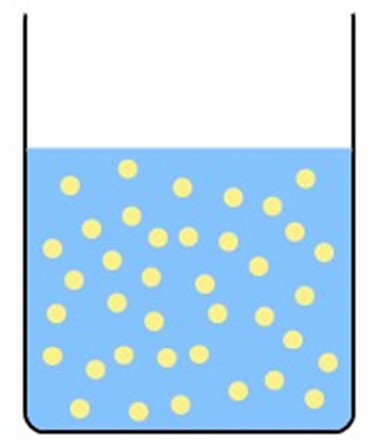

$\mathbf{O} / \mathbf{W}$

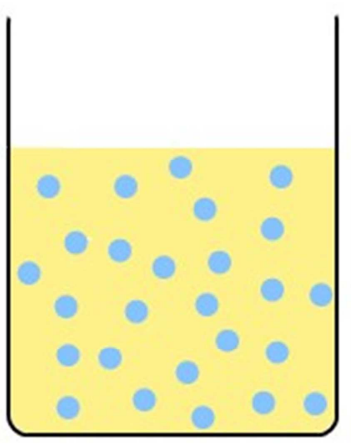

$\mathbf{W} / \mathbf{O}$

\section{Figura 2 - Representação das emulsões O/A e A/O, respectivamente [9]}

A viscosidade de uma emulsão tipo $\mathrm{A} / \mathrm{O}$, geralmente está associada a diversos fatores, dentre eles destacam-se:

- Fração volumétrica da fase interna, $\phi$;

- Viscosidade da água e do óleo;

- Temperatura;

- Distribuição e o tamanho médio das gotas.

\subsection{2.}

\section{Formação da Emulsão}

Para a formação da emulsão além das fases aquosas e oleosas, é necessária a presença do surfactante e de energia. A energia é necessária para que a fase dispersa seja quebrada e haja a formação da emulsão. Para que uma gota sofra deformação, uma tensão externa significativa deve ser aplicada sobre a superfície da gota. Esta tensão pode ser devido a um gradiente de velocidade que é a tensão cisalhante.

Para alcançar elevadas tensões de cisalhamento, muita energia deve ser dissipada no líquido. Durante a formação da emulsão grande parte desta energia é transformada em calor.

Essa energia necessária para deformar e quebrar as gotas da fase dispersa é reduzida se a tensão superficial diminuir. Isto pode ser alcançado através da adição de quantidades suficientes de surfactante [10]. 


\subsubsection{1.}

\section{Quebra de gotas}

A quebra de gotas pode ocorrer no regime laminar devido às tensões cisalhantes ou no regime turbulento, onde os efeitos inerciais também podem ser importantes. A seguir, será tratado cada um dos modos de quebra de gotas.

\subsubsection{1.}

\section{Escoamento Laminar}

A tensão exercida sobre uma gota em um campo com escoamento laminar é função do gradiente de velocidade e da viscosidade da fase contínua. Para que a gota quebre esta tensão deve ser maior que a força da tensão interfacial que age contra a deformação. A relação entre estas duas forças é chamada de número de Weber, We, e é representado pela seguinte fórmula:

$$
W e=\mu_{c} G r / \sigma
$$

Eq. 1

Onde $\mu_{\mathrm{c}}$ é a viscosidade da fase contínua, $\mathrm{G}$ é o gradiente de velocidade, $\mathrm{r}$ é o raio da gota e $\sigma$ é a tensão interfacial.

Se o valor de We exceder um valor crítico, $\mathrm{We}_{\mathrm{cr}}$, a gota quebra. $\mathrm{O}$ valor crítico depende do tipo de escoamento e da razão entre as viscosidades da gota e da fase contínua, $\mu_{\mathrm{d}} / \mu_{\mathrm{c}}$. Esta última dependência é ilustrada na Figura 3.

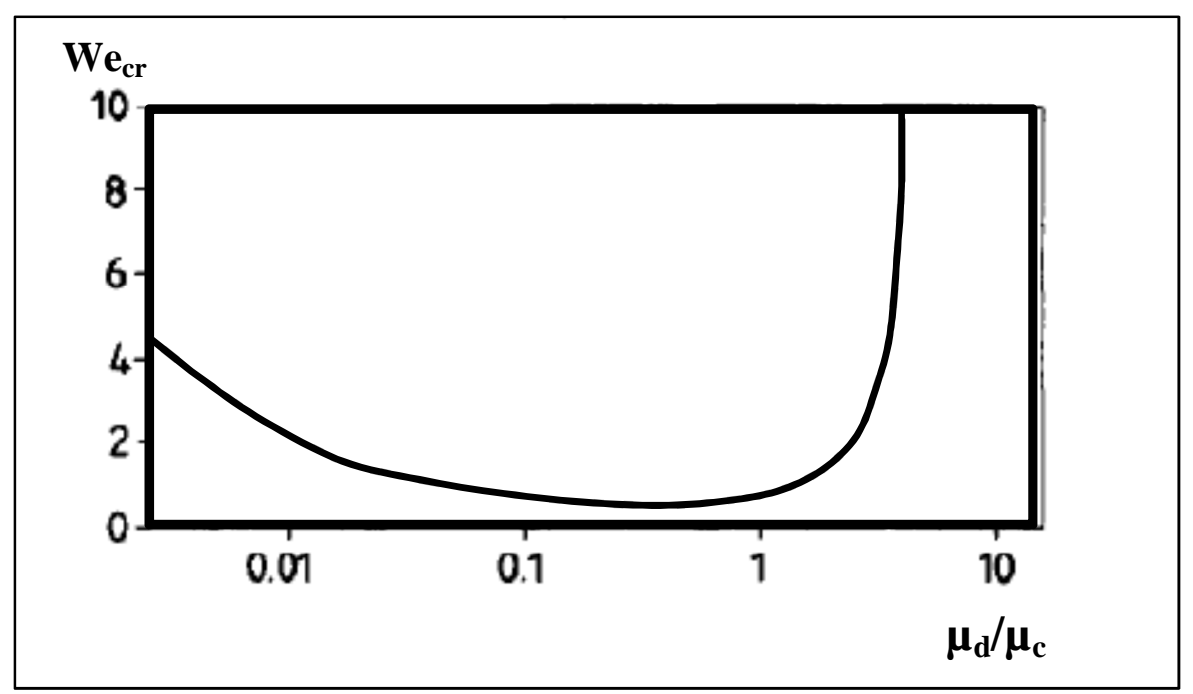

Figura 3 - Número de We crítico para quebra de gotas em um escoamento apenas sob a ação do cisalhamento em função da razão entre as viscosidade das fases dispersa e contínua [10]. 
Pela Eq. 1 verifica-se que para fases contínuas com baixa viscosidade, a deformação de gotas pequenas exige elevados gradientes de velocidade. Quando a razão entre as viscosidades $\mu_{\mathrm{d}} / \mu_{\mathrm{c}}$ é maior que 4 não há ocorrência de quebra de gotas. Isto porque a gota não deforma tão rápido quanto o escoamento puramente cisalhante induz a deformação.

Na prática, o que ocorre é as gotas quebram várias vezes até chegar ao tamanho crítico. Logo uma dispersão no tamanho das gotas será o resultado final deste processo de quebra. Nos experimentos conduzidos por Walstra [10] foi observada a quebra de gotas em condições em que a relação entre as viscosidades $\mu_{\mathrm{d}} / \mu_{\mathrm{c}}$ era igual a 10 . Isto foi possível graças à presença do surfactante, que permitiu o desenvolvimento de um gradiente de tensão interfacial na superfície da gota sob efeito do cisalhamento.

\subsubsection{2. \\ Escoamento Turbulento}

Do item anterior é possível observar que o escoamento laminar não é o mais adequado para quebra de gotas suspensas na água ou em outro líquido de baixa viscosidade. Escoamentos em regime turbulento apresentam taxas de deformação muito altas, o que facilita a deformação e consequentemente a quebra de gotas da fase dispersa.

Se a turbulência é isotrópica, que é mais comum nos caso com elevados números de Reynolds, Re, e os comprimentos característicos pequenos, o fluxo pode ser caracterizado conforme a teoria de Kolmogorov. Nesta, o tamanho dos vórtices é inversamente proporcional ao gradiente de velocidade. Os vórtices maiores são chamados de vórtices geradores de energia e são os principais responsáveis pela quebra das gotas [11].

A intensidade da turbulência em um escoamento geralmente não é muito homogênea e as gotas resultantes possuirão uma grande variação de tamanho. Mesmo que em muitos casos a distribuição do tamanho de gotas resultante tenha uma forma constante para uma dada potência fornecida ao sistema, é muito comum utilizar um tamanho de gotas médio para representar a condição final da emulsão [10]. 
Na Figura 4 é apresentado um comparativo do tamanho de gotas obtido utilizando um misturador, um transdutor ultrassônico e um homogeneizador de alta pressão. No misturador, um agitador mecânico ou uma haste são usados para a mistura do fluido. No transdutor, a mistura da amostra se dá através da perturbação gerada por ondas sonoras. E no homogeneizador de alta pressão a mistura se dá através da rápida despressurização com posterior aceleração da amostra fazendo-a chocar contra as paredes de uma câmara que recebe este fluido.

A Figura 4 representa o tamanho de gotas gerado variando a adição de energia à emulsão. Observa-se que o homogeneizador é mais eficiente que o misturador, pois pelo seu princípio de funcionamento, uma mesma energia é dissipada num tempo muito menor. A inclinação da reta do homogeneizador no gráfico (slope $=-0,6$ ) indica que este equipamento é o mais adequado dos três avaliados para a geração de gotas muito pequenas.

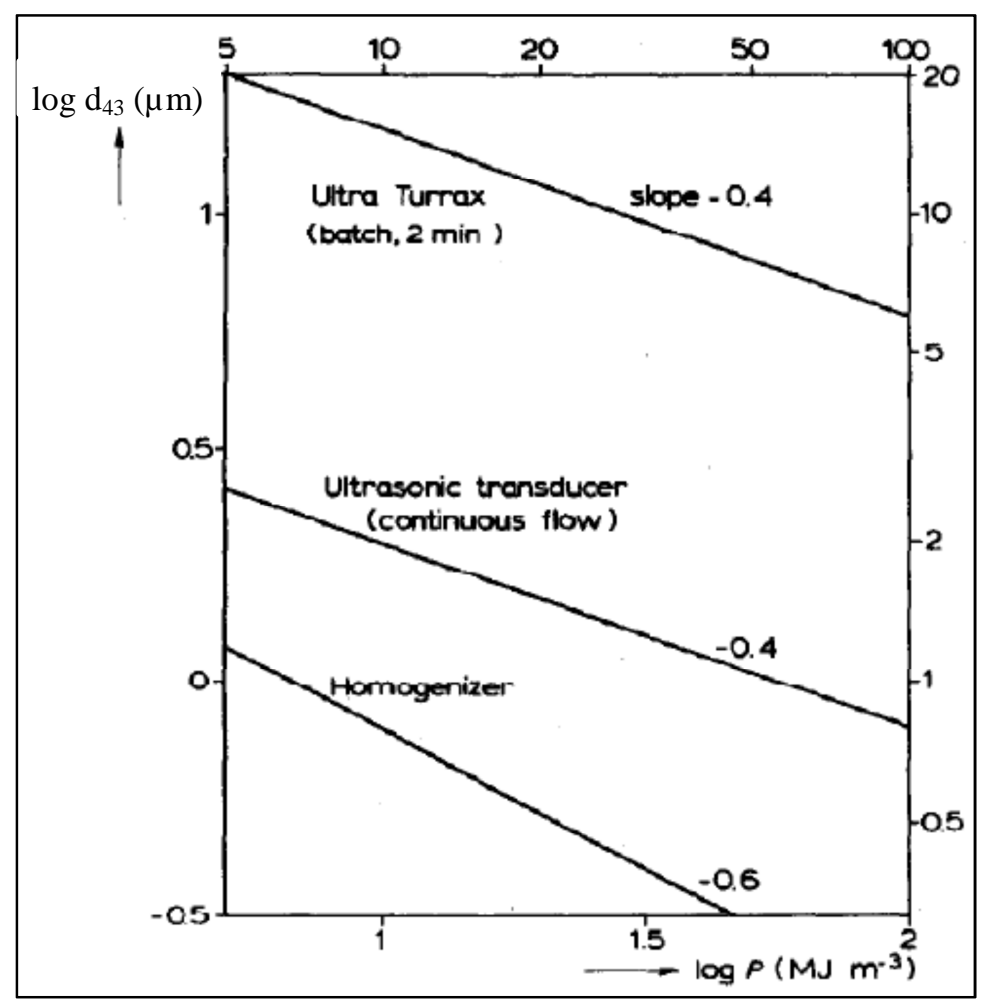

Figura 4 - Diâmetro médio da gota, $d_{43}$, como função da energia adicionada (P), para uma emulsão óleo-água produzido por vários equipamentos [12].

A teoria de Kolmogorov, contudo, não leva em consideração a influência da viscosidade do meio contínuo no tamanho máximo de gotas. A equação abaixo mostra que o cálculo do diâmetro máximo das gotas, está em função da potência 
dissipada por unidade de massa, $\varepsilon$, da tensão interfacial, da massa específica do meio contínuo, $\rho_{\mathrm{c}}$, além de uma constante $\mathrm{C}$ adimensional [10].

$$
d_{\text {max }}=C \cdot \varepsilon^{-0,4} \cdot \sigma^{0,6} \cdot \rho_{c}^{-0,6}
$$

A grosso modo, essa consideração pode ser válida em muito dos casos, mas já foi observado por Walstra que, em algumas exceções, há uma pequena dependência entre o tamanho de gotas e a viscosidade da fase contínua. Nestes casos, o aumento da viscosidade do meio contínuo reduz o tamanho médio das gotas. Aparentemente, flutuações da pressão podem não ser em todos os casos a única causa para a quebra de gotas. Uma gota presa entre vórtices que têm tamanho muito superior ao tamanho desta gota, a tensão cisalhante agirá e isto poderá ser suficiente para que ocorra a quebra. Com a consideração da viscosidade da fase contínua, o tamanho de gota máximo passa a ser calculado da seguinte forma [10]:

$$
d_{\max }=C \cdot \varepsilon^{-0,5} \cdot \sigma \cdot \mu_{c}^{-0,5}
$$

Eq. 3

$\mathrm{Na}$ transição entre a predominância das forças inerciais para as forças viscosas, a viscosidade pode ter algum efeito no processo de quebra. Aumentando a viscosidade do meio contínuo, há a redução do o número de Reynolds, Re, e consequentemente menos turbulência. Neste cenário, os vórtices, em média, são maiores, assim como o cisalhamento exercido nas gotas. $\mathrm{O}$ aumento das variações de escoamento e, consequentemente, do espalhamento do tamanho de gotas fica mais significativo com o aumento da viscosidade do meio contínuo [13].

Experimentos conduzidos por Vankova et al. [14] mostraram que ao reduzir a viscosidade do meio contínuo, não era mais possível ajustar os diâmetros de gota obtidos utilizando a Eq. 3, que representa o regime de emulsificação viscoso. Neste ponto o regime de emulsificação passava do viscoso para o inercial, que é mais bem representado pela Eq. 2. A Figura 5 mostra a comparação entre o tamanho máximo de gotas medido nestes experimentos, $\mathrm{d}_{95}$, com os modelos teóricos representados pelas equações 2 e 3 . 


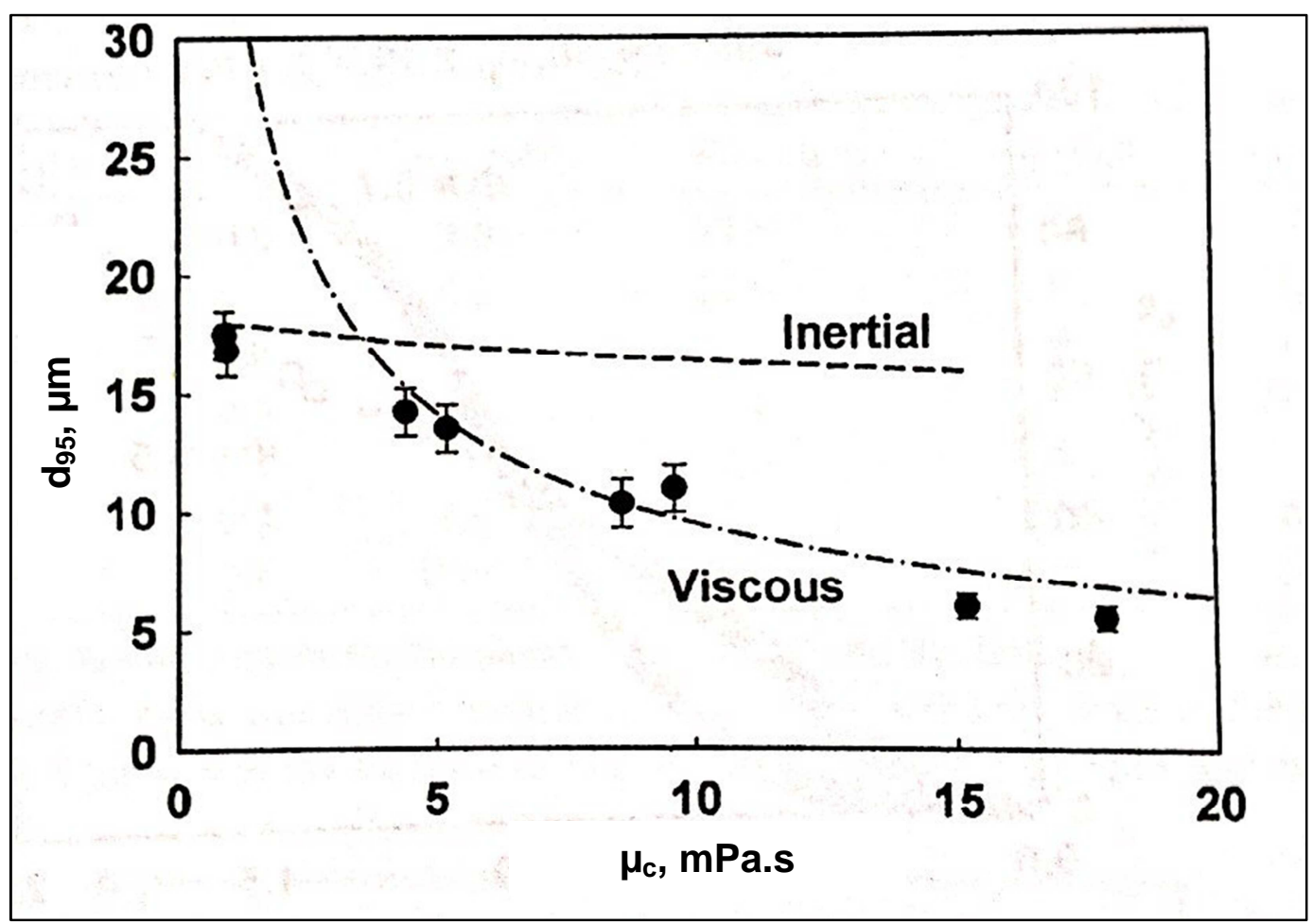

Figura 5 - Tamanho máximo da gota, d ${ }_{95}$, em função da viscosidade da fase conínua. As curvas mostram as previsões teóricas para o tamanho máximo da gota [14].

A Figura 5 mostra a tendência de queda do máximo tamanho de gota quando a viscosidade da fase contínua aumenta e, que o ponto de transição entre os regimes de turbulência inercial e viscoso é quando a viscosidade do meio aquoso é igual a $3 \mathrm{mPa} . \mathrm{s}$ [14].

A Figura 6 mostra que para potências dissipadas constantes, $\varepsilon$, a relação entre o tamanho de gotas característico, $\mathrm{d}_{43}$, e a viscosidade da fase dispersa pode ser representada através de retas em um gráfico $\log$ x log. Nesta mesma figura, é possível verificar que o equipamento usado para a formação da emulsão impacta no resultado final do tamanho de gotas. A influência do equipamento já foi mostrada também, na Figura 4. 


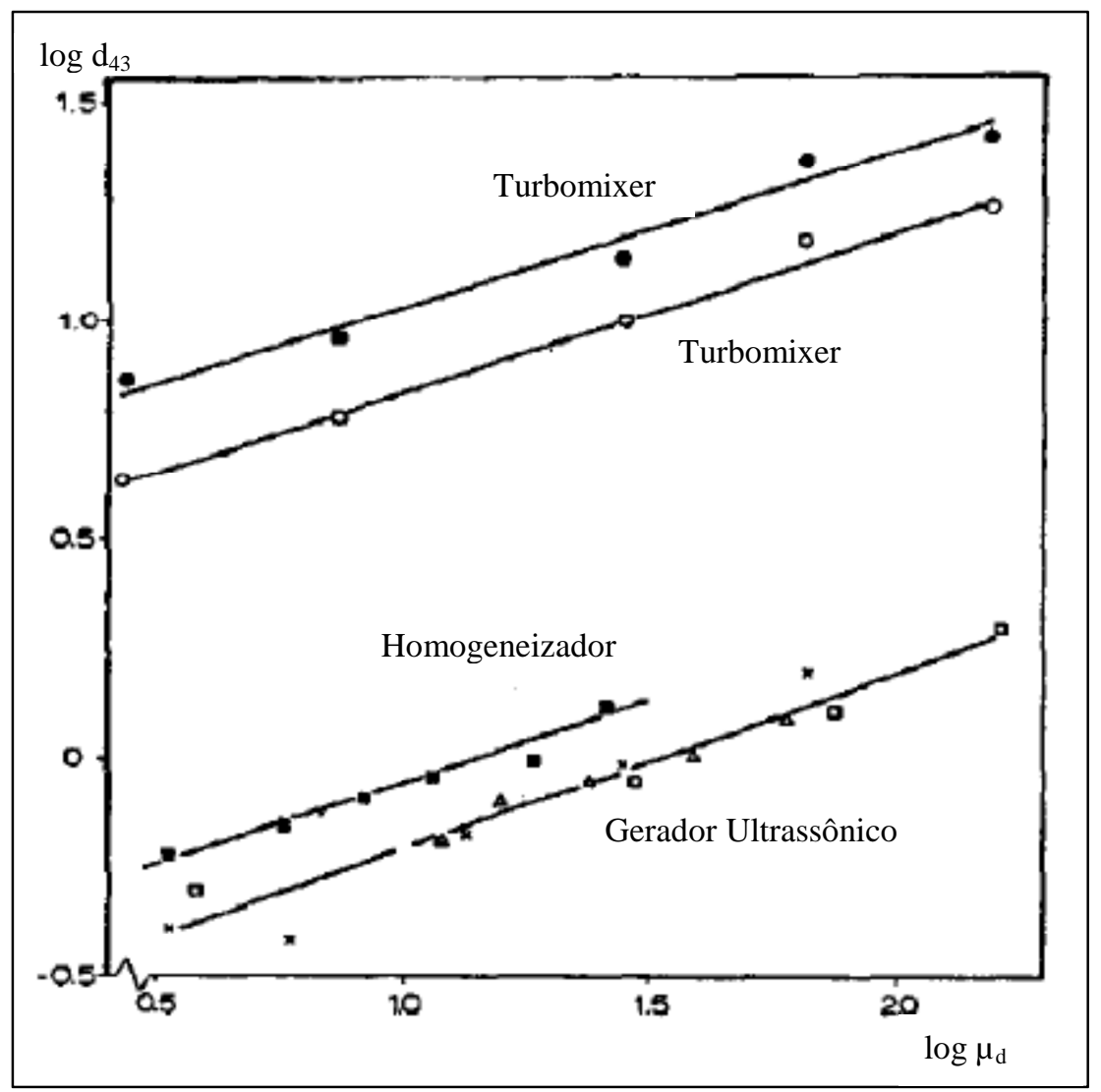

Figura 6 - Efeito da viscosidade da fase dispersa, $\mu_{d}$ em mPa.s, no tamanho de gotas característico, $d_{43}$, para várias máquinas [13]. De cima para baixo, as duas primeiras linhas representam o uso de turbomixer, a terceira um homogeneizador e a última, um gerador ultrassônico.

Algumas tentativas foram feitas por Davies [15] para incorporar o efeito da viscosidade da fase dispersa no modelo que determina o diâmetro máximo da gota, apresentada na Eq. 2. A abordagem utilizada não apresentou a mesma tendência dos valores medidos experimentalmente, mostrados na Figura 6. Esta inconsistência ocorria nas situações onde $\mu_{\mathrm{d}}>\mu_{\mathrm{c}}$. Segundo Walstra [10], para que a Eq. 2 pudesse ser aplicada sob estas condições bastaria a utilização de um valor diferente para a constante, C, dependente da viscosidade. Ensaios posteriores realizados por van der Zande et al. [7], que serão detalhados mais a frente, confirmaram que óleos com diferentes viscosidades apresentam valores diferentes para a constante $\mathrm{C}$.

Em análises experimentais realizadas posteriormente por Vankova et al. [14], verificou-se que as emulsões que eram geradas com os óleos mais viscosos apresentavam maior dispersão do que aquelas obtidas com óleos de baixa 
viscosidade. Observou-se também que a distribuição do tamanho de gotas seguia uma tendência mestra quando as emulsões eram preparadas com óleos de viscosidade similar. Ou seja, neste caso, as dispersões nas emulsões tiveram apenas uma leve variação devido às mudanças na tensão interfacial e a taxa de energia dissipada durante a emulsificação. Este comportamento está representado na Figura 7.

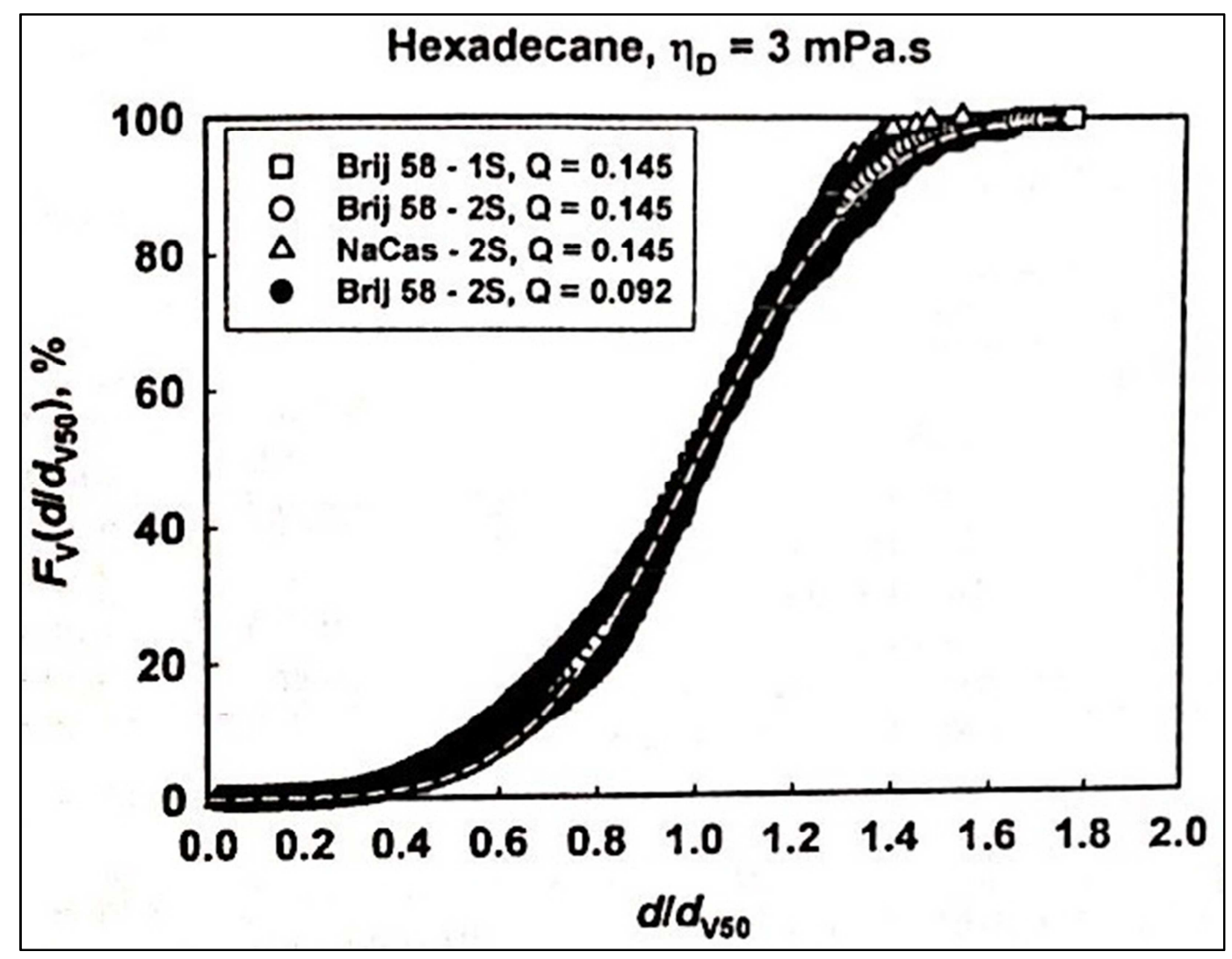

Figura 7 - Distribuição de volume cumulativa versus o diâmetro de gota característico, $\mathrm{d} / \mathrm{d}_{50}$. A fase dispersa é o hexadecano e a variação é no modo de preparo da emulsão [14].

Já as curvas de distribuição do tamanho de gotas geradas a partir de óleos com diferentes viscosidades apresentaram grandes diferenças entre si. Esta dispersão é causada pela influência das gotas satélites, que se formam durante o processo de emulsificação e possuem diâmetro muito reduzido em relação ao valor máximo [14]. Na Figura 8, observam-se as diferentes curvas de tamanho de gotas para óleos com diferentes viscosidades. 


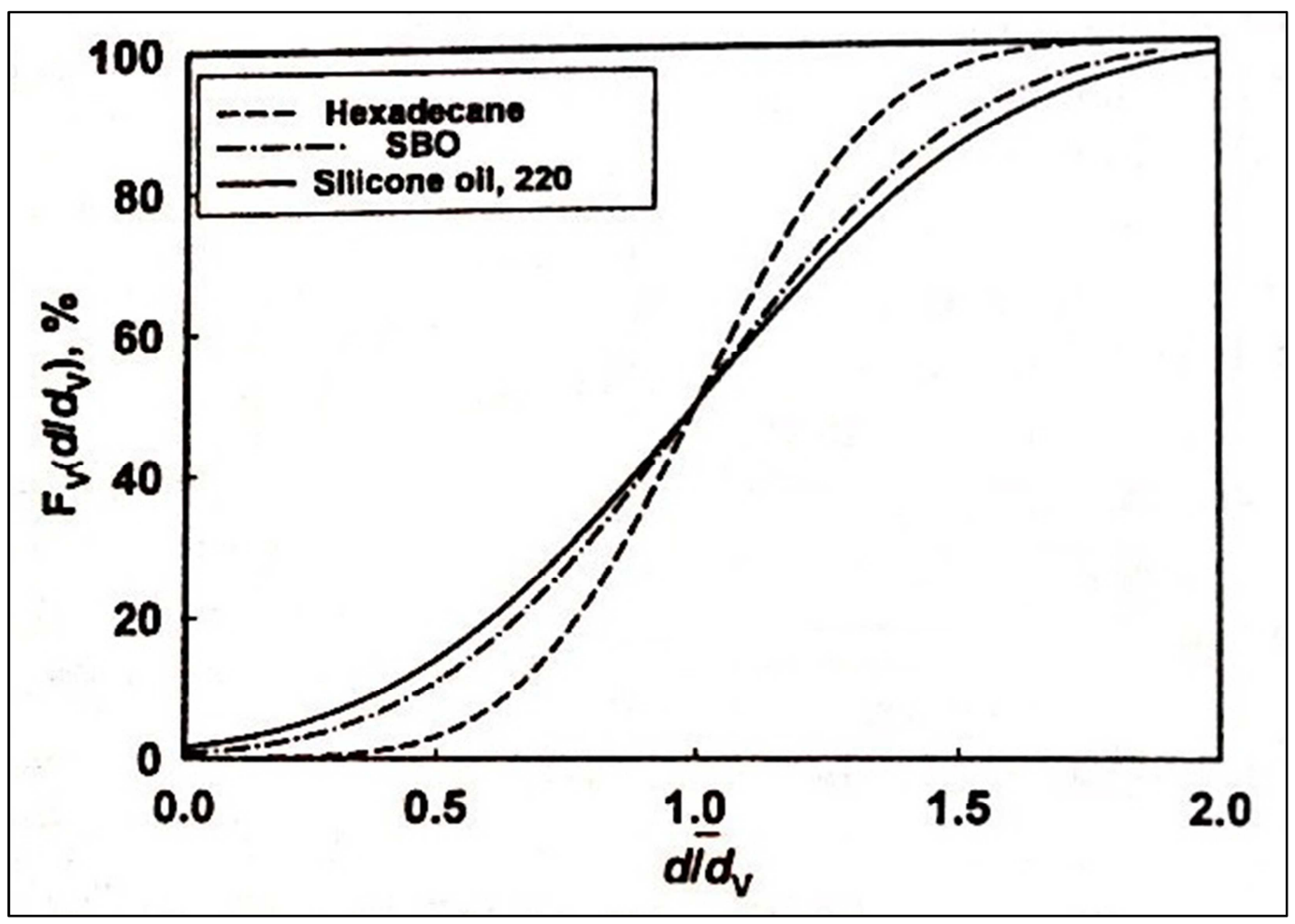

Figura 8 - Comparação dos melhores ajustes entre as funções de volume cumulativo para óleos de diferentes viscosidades versus o diâmetro de gota característico, $d / d_{50}$. Os óleos utilizados foram o Hexadecano ( $\left.\mu_{d}=3 \mathrm{mPa} . \mathrm{s}\right), 0$ SBO $\left(\mu_{d}=27\right.$ mPa.s $)$ e o óleo siliconado $\left(\mu_{d}=95\right.$ mPa.s $)$ [14].

\subsubsection{2.}

Surfactantes

Durante a emulsificação três processos principais ocorrem:

1. As gotas são deformadas e possivelmente se quebram;

2. O surfactante é transportado para a interface entre as fases;

3. As gotas encontram uma às outras e podem coalescer.

Estes processos ocorrem simultaneamente e cada um desses ocorre várias vezes durante a formação da emulsão, o que implica que o regime permanente não é alcançado. As condições mudam durante a formação da emulsão, quanto maior a área superficial das gotas menor a concentração do surfactante na solução.

O surfactante desempenha dois papéis fundamentais durante a emulsificação: reduz a tensão interfacial, facilitando assim a quebra das gotas; e previne, em diferentes graus, a coalescência. 
Diferentes surfactantes reduzem a tensão interfacial e isto afetará o tamanho final da gota de acordo com a Eq. 2. Com uma menor tensão interfacial, menos energia é necessária para obter certo tamanho de gota. Como pode ser visto na Figura 9 cada surfactante gera uma curva diferente relacionando o tamanho de gota obtido com a concentração do surfactante.

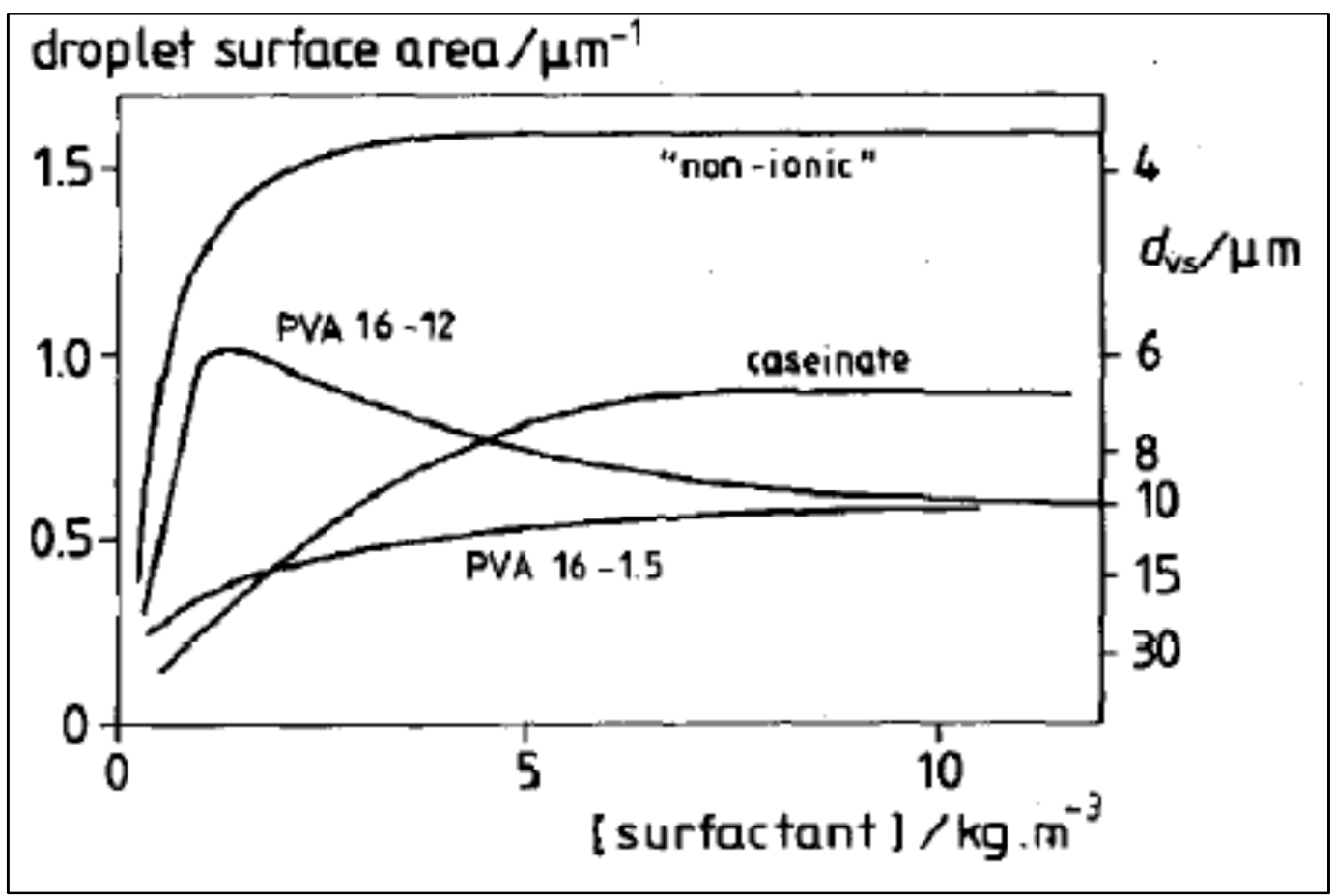

Figura 9 - Efeito da concentração total de surfactante no tamanho de gotas médio resultante. Quatro surfactantes usados neste experimento [10].

A coalescência ocorre quando duas ou mais gotas se encontram e se juntam, formando uma única gota. A coalescência é dificultada pela presença de surfactantes, que podem agir de duas formas. A presença de surfactantes na interface forma uma camada protetora que evita a aproximação das interfaces dificultando assim a coalescência. A presença de surfactante também dificulta a coalescência pelo efeito de Gibbs-Marangoni. Conforme esquematizado na Figura 10, à medida que as gotas se aproximam, a concentração de surfactante ao longo da interface torna-se não uniforme. A região da interface mais próxima da gota vizinha possui uma concentração de surfactante menor do que a região adjacente. Este gradiente de tensão interfacial causa um escoamento que leva a fase contínua para o filme entre as gotas, dificultando a junção das interfaces. 


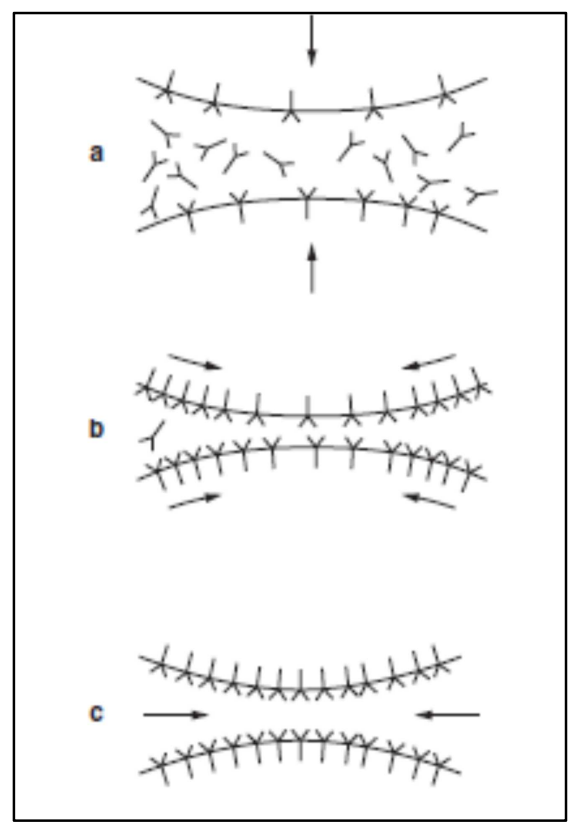

Figura 10 - Diagrama do efeito Gibbs-Marangoni agindo em duas gotas que se aproximam durante a emulsificação. As moléculas do surfactante estão representadas pela letra $\mathrm{Y}[10]$.

Muito da coalescência ocorre com gotas recém-formadas, que foram originadas de uma gota principal, e estão muito próximas uma da outra. Ou seja, estas gotas se encontram num tempo muito pequeno. Qualitativamente, o tamanho médio da gota aumenta com o crescimento da fração volumétrica da fase interna. Isto se deve, à menor concentração de surfactante disponível por unidade de área criada, à maior frequência de encontro destas gotas e à redução da turbulência, causando assim uma quebra de gotas menos eficiente [10].

O efeito da concentração da fase dispersa, $\phi$, foi avaliada por Vankova [14] com óleos que possuíam viscosidade de 95, 1000 e 10000 mPa.s. Na Figura 11 e na Figura 12, observa-se que os valores de diâmetro de gota característicos $\mathrm{d}_{95} \mathrm{e}$ $\mathrm{d}_{32}$ tiveram um pequeno aumento em relação ao valor inicial quando a fração da fase interna, $\phi$, está abaixo de 0,5. Um crescimento do valor de $\phi$ acima de 0,5 causa uma redução acentuada para os valores de $d_{95}$ e $d_{32}$. Além do mais, foi observado no microscópio que teores de $\phi$ acima de 0,6 levaram à redução da dispersão da emulsão. Este efeito foi mais pronunciado para as emulsões com óleo mais viscoso, que possuíam uma dispersão muito grande com baixo $\phi$. 


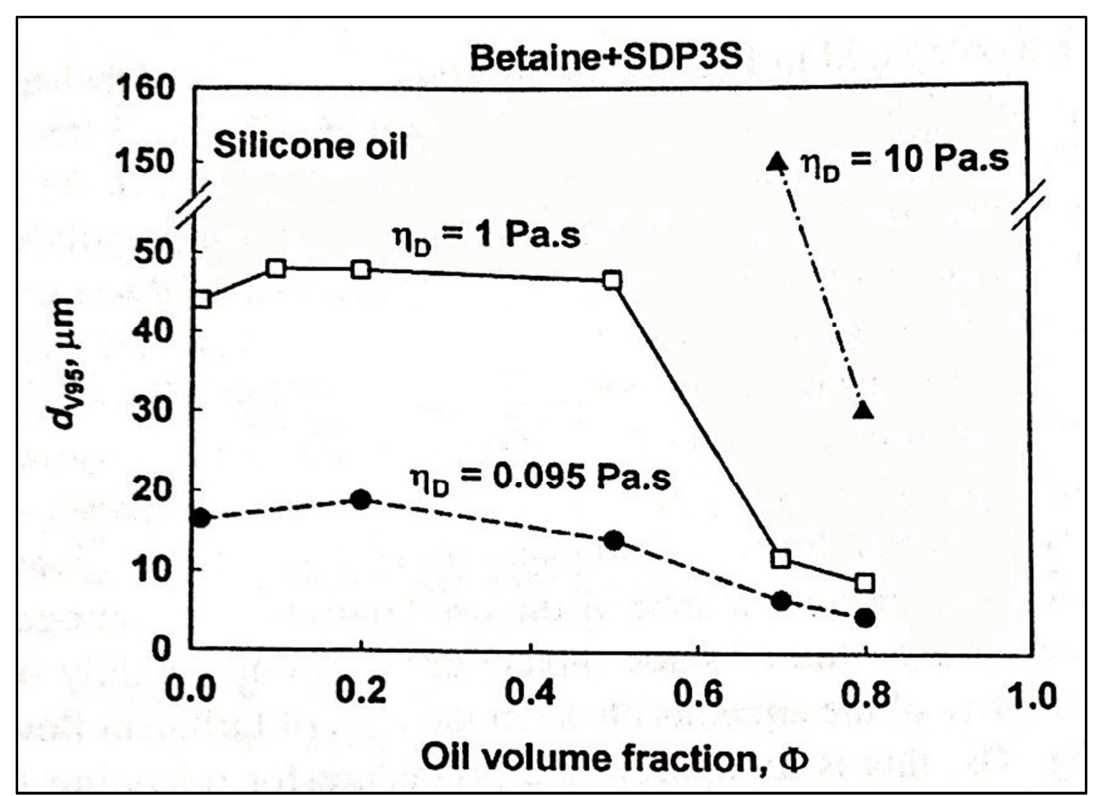

Figura 11 - Diâmetro de gota característico d 95 para os três óleos avaliados em função do teor da fração interna [14].

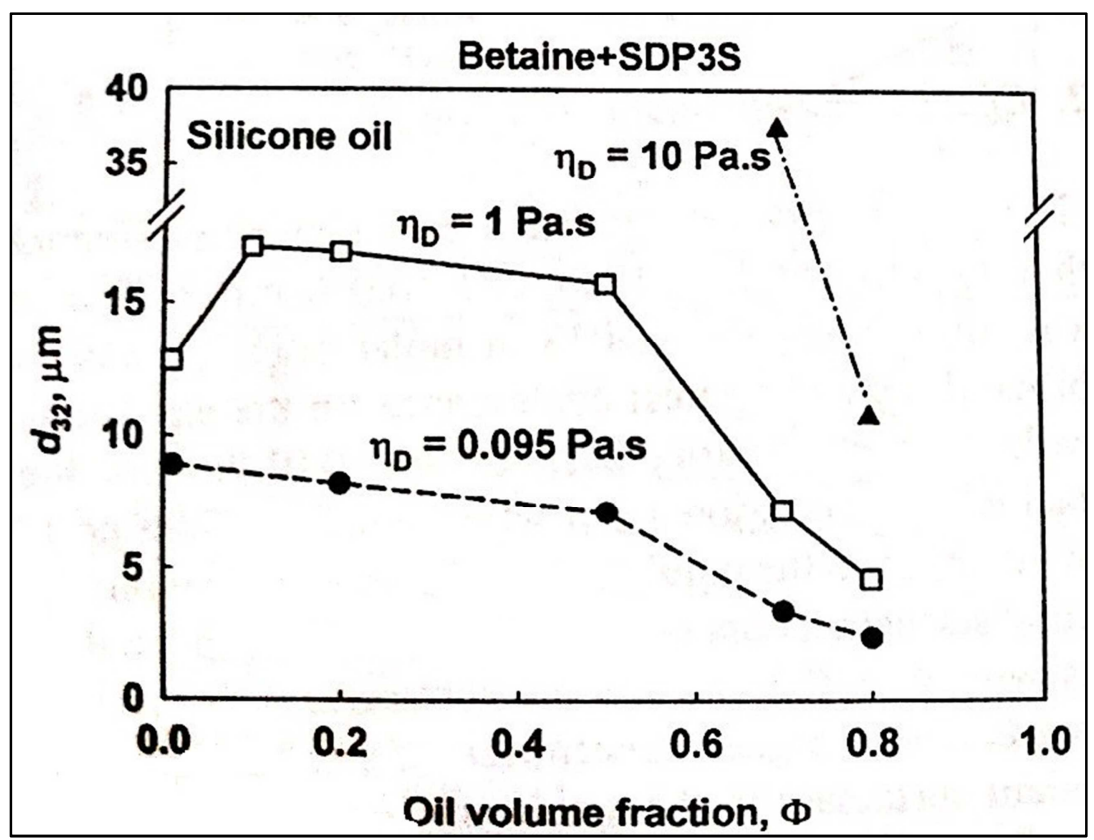

Figura 12 - Diâmetro de gota característico $d_{32}$ para os três óleos avaliados em função do teor da fração interna [14].

O decréscimo do tamanho de gotas nestas condições $(\phi>0,6)$ está relacionado ao aumento da viscosidade da emulsão concentrada, o que induz uma mudança na emulsificação do regime inercial para o viscoso. Esta hipótese foi validada através de ensaios reológicos que observaram a presença de uma tensão 
necessária para iniciar o escoamento da emulsão, que é a tensão limite de escoamento. O valor desta tensão aumentou com o crescimento da fração interna e diminuição do tamanho médio de gotas [16].

\subsection{3.}

\section{Viscosidade da Emulsão}

Como visto anteriormente, as emulsões são dispersões com gotas de líquido deformáveis numa fase contínua líquida. Contudo, se estas gotas são muito pequenas, elas se comportam como dispersões com partículas de tamanho pequeno, pois estas gotas dificilmente se deformam. Como resultado estas emulsões seguem as mesmas regras das dispersões sólidas.

A viscosidade da emulsão é antes de tudo controlada pela fase contínua líquida que pode ser Newtoniana ou Não-Newtoniana. Depois, é influenciada pela fase dispersa adicionada, onde o tamanho, forma, quantidade e deformação das partículas podem variar consideravelmente, assim como a interação entre cada uma delas [17].

\subsubsection{1. Efeito da fase contínua}

A viscosidade da fase contínua é muito utilizada para o cálculo da viscosidade da emulsão. Quando esta viscosidade é alterada, a viscosidade da suspensão cresce na mesma proporção, desde que todos os outros parâmetros tenham sido mantidos. Essa proporcionalidade é importante quando é considerado o efeito da temperatura.

O efeito da temperatura na viscosidade da emulsão é controlado pela variação da viscosidade e da temperatura da fase contínua, desde que todos os outros parâmetros sejam mantidos. A variação da viscosidade com a temperatura é de $3 \%$ a cada grau, no caso de um sistema em que a água é a fase contínua. Em emulsões base óleo, o aumento pode ser muito maior, como pode ser visto na Figura 13. 


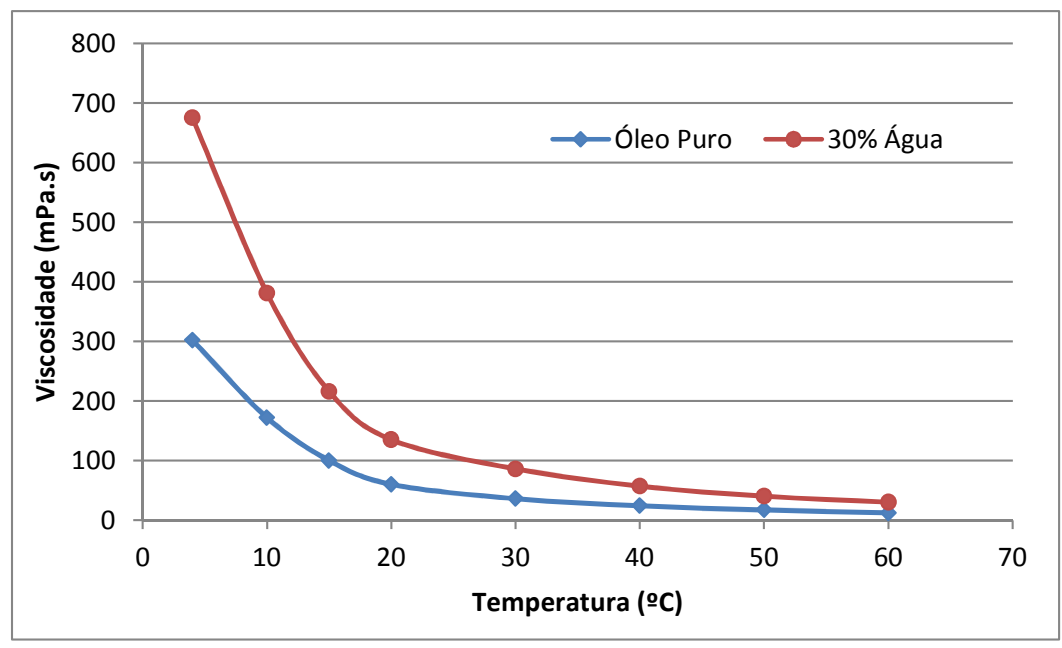

Figura 13 - Viscosidade do óleo puro e de uma emulsão água/óleo com 30\% de água, em função da temperatura [8].

\subsubsection{2. Efeito da fase dispersa}

As primeiras avaliações do efeito da fase dispersa na viscosidade de uma dispersão consideravam uma pequena quantidade de partículas em suspensão. Estas partículas estariam tão distantes uma da outra que não haveria influência entre elas. Logo, o efeito do tamanho da partícula não poderia ser avaliado [17].

Posteriormente diversos autores desenvolveram metodologias para calcular o aumento da viscosidade da emulsão considerando a fração da fase dispersa e, em alguns modelos, a viscosidade desta fase. Na Figura 13 pode-se observar o aumento da viscosidade da emulsão água/óleo, numa mesma temperatura, devido à adição de 30\% de água como fase dispersa. Logo, a fração da fase interna afeta diretamente as propriedades reológicas da emulsão devido às interações entre as gotas [19].

Observou-se também que há uma fração limite para a fase dispersa, onde a partir deste valor, não é possível incorporar à emulsão estabilizada volume adicional da fase dispersa. Esta fração é chamada de ponto de inversão de fase. Próximo a este ponto há um aumento significativo de viscosidade quando há um pequeno acréscimo da fase dispersa. Na Figura 14 verifica-se o aumento acentuado da viscosidade da emulsão quando a fração da fase dispersa se aproxima do ponto de inversão de fase. 


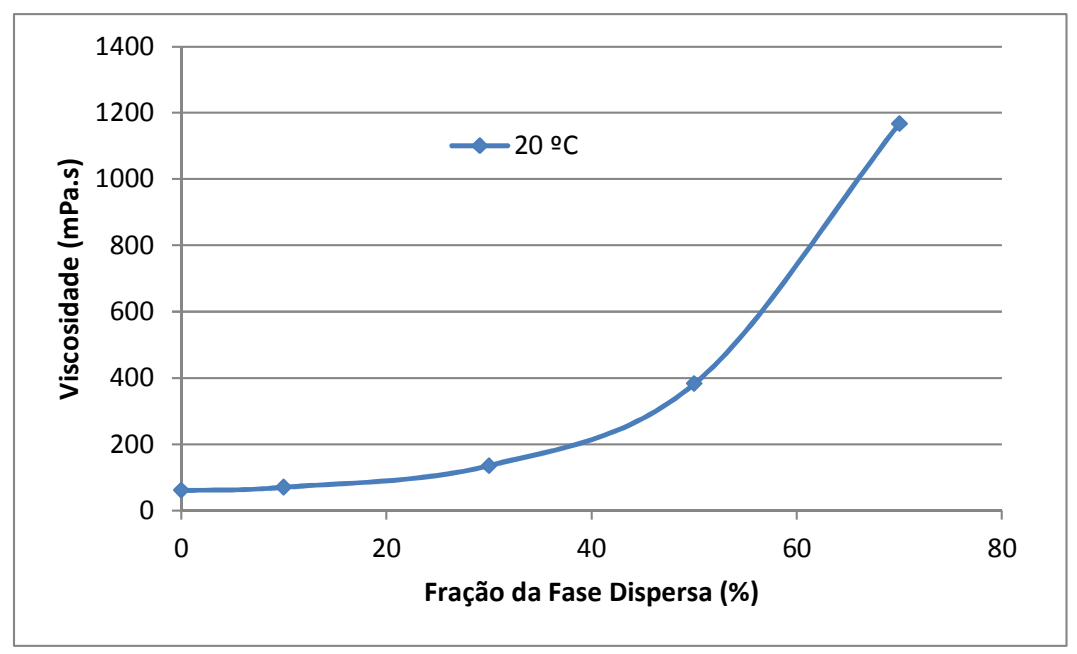

Figura 14 - Viscosidade da Emulsão a $20^{\circ} \mathrm{C}$ versus fração da fase dispersa. Neste caso, o ponto de inversão de fase é $70 \%$ [8].

As metodologias para o cálculo da viscosidade e para a previsão do ponto de inversão de fase da emulsão serão detalhadas mais a frente neste trabalho.

Outra característica que impacta na viscosidade da emulsão é a tensão de cisalhamento. Esta tem relação direta com o arranjo espacial das partículas. Quando a dispersão está em repouso, as partículas estão dispersas aleatoriamente ao longo da fase contínua devido à ação do movimento Browniano. Ao serem cisalhadas com uma baixa taxa de cisalhamento, as partículas mantêm esta distribuição aleatória durante o movimento o que faz com que a viscosidade fique mais alta. Já quando a taxa de cisalhamento é mais alta, as partículas são levadas a um arranjo espacial de camadas, como observado na Figura 15 [17]. Na Figura 16 é possível observar este efeito, já que o aumento da taxa de cisalhamento causou uma diminuição significativa no valor da viscosidade da emulsão.

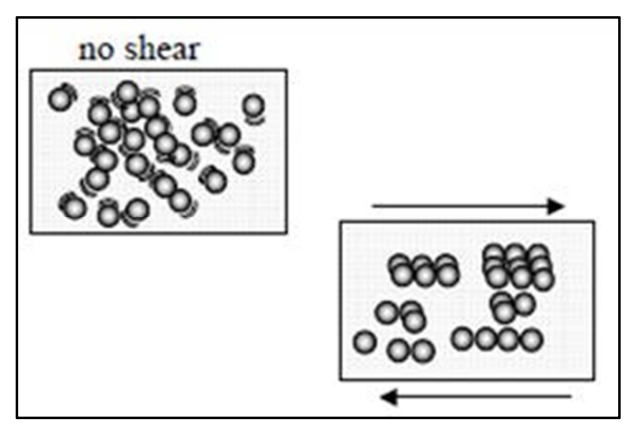

Figura 15 - Formação das camadas quando as partículas são sujeitas a tensão cisalhante [17]. 


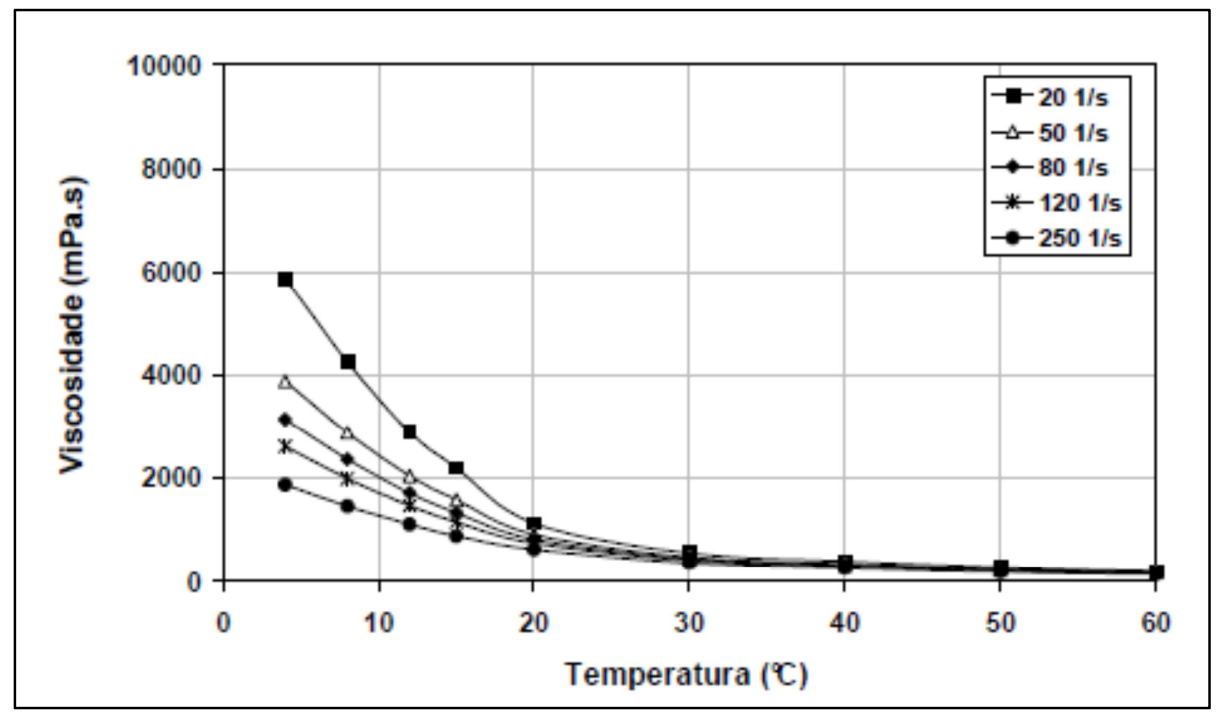

Figura 16 - Efeito da Temperatura e da taxa de cisalhamento na viscosidade da emulsão. A influência do cisalhamento é mais significativa quando a temperatura do fluido está abaixo de $20^{\circ} \mathrm{C}[20]$.

\subsubsection{3. \\ Ponto de Inversão de Fase}

Como dito anteriormente, o ponto de inversão de fases é a fração máxima da fase dispersa que pode estar presente na fase contínua. Acima deste valor ocorre a inversão da emulsão, ou seja, a fase contínua vira a dispersa e vice versa [21]. Neste ponto ou próximo dele, há uma mudança brusca nas características reológicas da emulsão e a perda de carga induzida por esta muda abruptamente e significativamente. É muito importante o conhecimento deste ponto, pois ele afeta diretamente o dimensionamento de dutos de transporte de óleo e água, largamente usados na indústria do petróleo [22].

Contudo, no que se refere à inversão de fases no escoamento em dutos, o conhecimento é muito escasso, a determinação deste fenômeno se dá caso a caso através de análise laboratorial do óleo a ser produzido. Oglesby observou que há uma drástica mudança na queda de pressão no ponto de inversão de fase de uma emulsão $\mathrm{A} / \mathrm{O}$, e a magnitude desta mudança aumentava com o aumento da velocidade da mistura e da viscosidade do óleo [23].

Segundo Arirachakarn et al. esta queda acentuada da queda de pressão na emulsão A/O ocorre porque as gotas de água ficam mais concentradas e começam a coalescer. Após passar o ponto de inversão de fase, onde a viscosidade é 
máxima, a água passa a ser a fase contínua [22]. O comportamento da emulsão se dá conforme o esquema apresentado na Figura 17, abaixo.

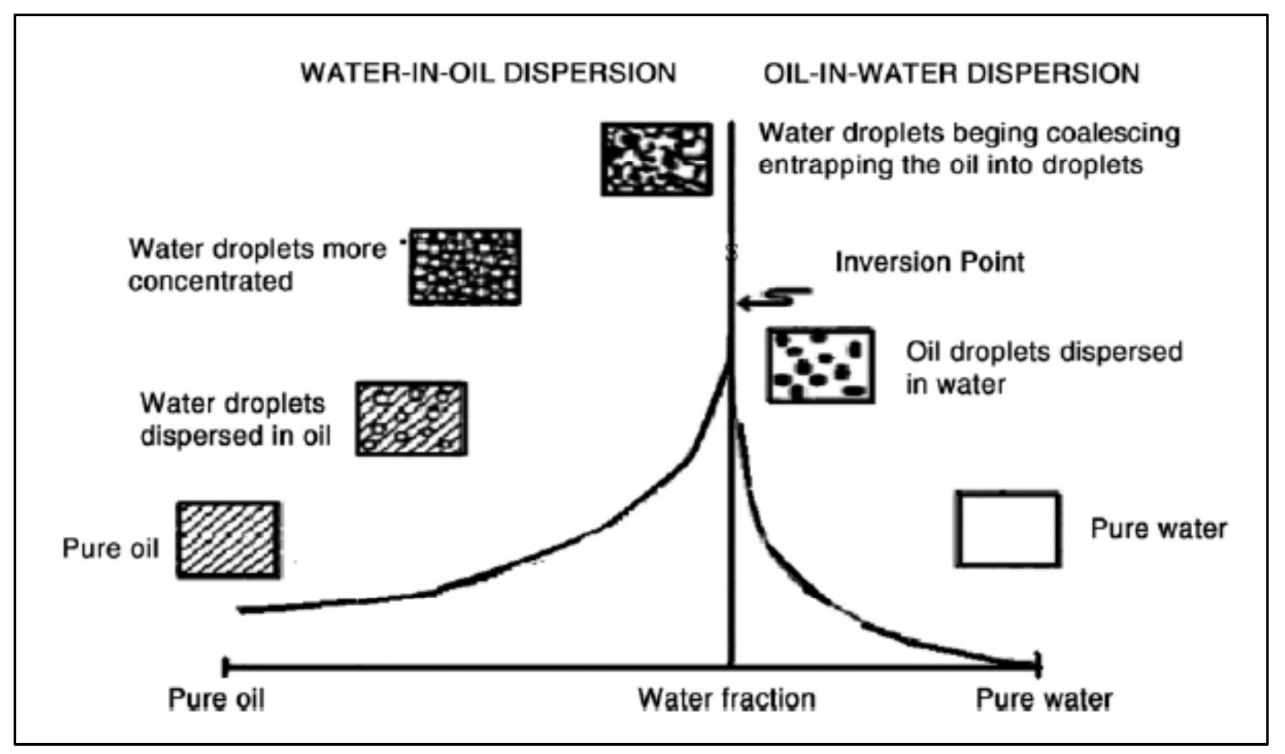

\section{Figura 17 - Representação esquemática da inversão de fases [22].}

Experimentos conduzidos por Angeli e Hewitt observaram a inversão de fase em dutos horizontais de aço e acrílico. Um pico acentuado no gradiente de pressão apareceu no ponto de inversão de fase, conforme pode ser observado na Figura 18. Vale ressaltar que a fração de água adicionada, a viscosidade do óleo, a velocidade da mistura, a tensão interfacial entre óleo e água, o material do duto, o tamanho médio das gotas e o padrão de fluxo devem ser considerados na previsão do ponto de inversão de fases [24].

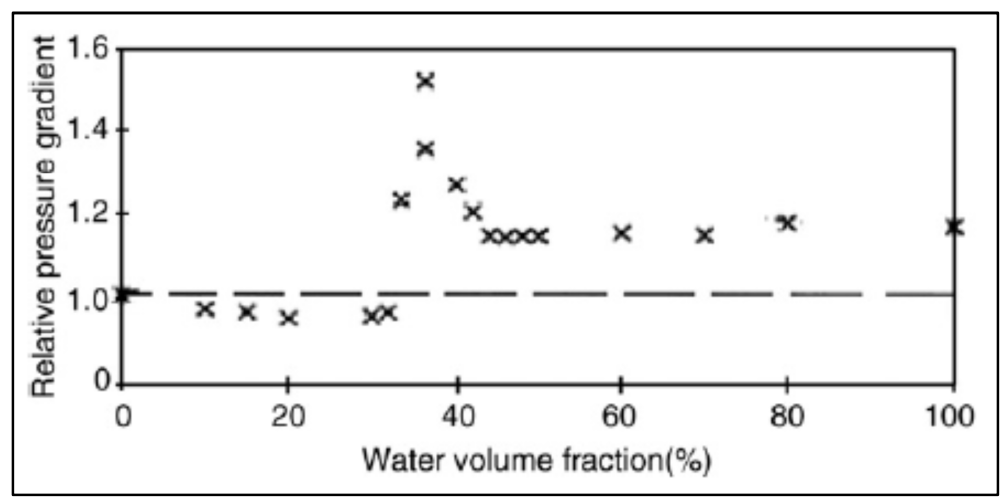

Figura 18 - Gradiente de pressão relativo ao caso sem água, no duto de aço na velocidade de mistura de $2,1 \mathrm{~m} / \mathrm{s}$ [24]. 


\subsubsection{1. \\ Determinação do Ponto de Inversão}

O primeiro modelo disponível para a modelagem da inversão de fase foi desenvolvido por Ostwald. Ele assumiu que a fração volumétrica da fase dispersa não poderia exceder o volume relativo ocupado por uma configuração de esferas num pacote fechado, que é aproximadamente $74 \%$ para esferas rígidas monodispersas. Acima deste valor, a inversão de fases ocorreria [25].

Nesta abordagem, contudo, não foi levado em consideração nenhum efeito do surfactante, que conhecidamente tem importância considerável em muitos casos. Outros modelos que são usados comumente, também não consideram a função do surfactante na modelagem da inversão de fases.

Um dos modelos existentes para a previsão da inversão de fases é o de Arirachakarn et al., que surgiu a partir de variados resultados experimentais [22]. A correlação proposta para determinar a fração crítica de água $\left(\boldsymbol{\epsilon}_{\boldsymbol{w}}^{\boldsymbol{I}}\right)$, ou seja, a concentração de água no instante que ocorre inversão de fase, está representada na equação abaixo, onde $\mu_{\mathrm{o}}$ é a viscosidade do óleo, $\mu_{\mathrm{m}}$ é a viscosidade da mistura, $\mathrm{U}_{\mathrm{ws}}$ é a velocidade superficial da água e $\mathrm{U}_{\mathrm{m}}$ é a velocidade da mistura. As duas velocidades são tomadas na condição de inversão de fase.

$$
\epsilon_{w}^{I}=\left(\frac{U_{w s}}{U_{m}}\right)_{I}=0,5-0,1108 \log \left(\mu_{o} / \mu_{m}\right)
$$

Eq. 4

Para óleos muito viscosos, acima de $200 \mathrm{mPa} . \mathrm{s}$, foi reportado que o valor para a fração crítica tendia a uma constante.

Outro modelo para previsão da fração crítica é o de Brauner e Ullmann [26] que considera que a inversão de fase em um sistema de escoamento óleo-água corresponde à fronteira de transição entre a dispersão óleo em água para a dispersão água em óleo. Para o modelo, os autores propuseram as seguintes condições: a composição da fase óleo e da fase água, e a temperatura do sistema, não mudam com a inversão de fase; os efeitos da molhabilidade da parede ao líquido podem ser negligenciados; a energia livre das duas fases permanece a mesma e apenas as energias livres das interfaces deveriam ser consideradas.

Baseada nas considerações acima foi proposta a seguinte correlação para previsão da fração crítica da fase dispersa $\left(\boldsymbol{\epsilon}_{\boldsymbol{o}}^{I}\right)$, no caso o óleo, onde $\tilde{\rho}$ é a relação 
entre as massas específicas $\tilde{\rho}=\rho_{o} / \rho_{w}$ e $\tilde{v}$ é a relação entre as viscosidades cinemáticas $\tilde{v}=v_{o} / v_{w}$ :

$$
\epsilon_{o}^{I}=\frac{\widetilde{\rho} \tilde{v}^{0,4}}{1+\widetilde{\rho} \tilde{v}^{0,4}}
$$

Este modelo apresentou bom ajuste com os dados disponíveis sobre o holdup crítico para a inversão de fase e trouxe explicações das características do fenômeno de inversão de fases no escoamento óleo-água em dutos [26].

Apesar dos dois modelos acima citados, na indústria do petróleo, a determinação do ponto de inversão de fases se dá no laboratório através da constante adição de água sob agitação, que é a fase dispersa, à amostra de óleo em análise. No instante em que não é mais possível incorporar água a esta amostra, sendo visível a presença de água livre após um período de repouso préestabelecido, é determinado o ponto de inversão de fase.

\subsubsection{4.}

\section{Cálculo da Viscosidade da Emulsão}

Para escoamento de sistemas emulsionados óleo-água, a consideração que a mistura entre os dois fluidos poderia ser tratada como um pseudo-fluido com propriedades adequadamente ponderadas, seria adequada para as previsões dos gradientes de pressão se a viscosidade não apresentasse comportamento anômalo durante o escoamento.

Como visto anteriormente, a viscosidade da emulsão é governada por diversos fatores: viscosidade da fase contínua; viscosidade da fase dispersa; fração volumétrica da fase dispersa; tensão cisalhante no caso de fluidos não newtonianos; temperatura; tamanho de gotas médio e distribuição do tamanho de gotas; além da tensão interfacial. Logo, como a viscosidade da emulsão é um parâmetro que pode apresentar grande variação é fundamental conhecer os modelos existentes para a determinação deste valor.

Uma das equações utilizadas nas previsões de modelos de viscosidade é a de Dukler et al. [27] que propõe uma média ponderada das propriedades em função da fração volumétrica das fases. Foi desenvolvida inicialmente para sistemas gáslíquido, e apresenta bons resultados quando o meio contínuo é a agua. Abaixo está 
representado o modelo para o cálculo da viscosidade da mistura ou emulsão, $\mu_{\mathrm{m}}$, em um escoamento óleo-água.

$$
\mu_{m}=\mu_{o} \epsilon_{o}+\mu_{w} \epsilon_{w}
$$

Onde $\mu_{\mathrm{o}}$ e $\mu_{\mathrm{w}}$ são as viscosidades do óleo e da água respectivamente e, $\epsilon_{o}$ e $\epsilon_{w}$ são as frações volumétricas de óleo e água.

Outro modelo usado para determinação da viscosidade da emulsão é o de Ronningsen [28]. Este foi desenvolvido para a modelagem de emulsões água em óleo (A/O) de óleos produzidos no Mar do Norte. Este modelo é uma evolução da equação de Broughton e Squires [29], Eq. 7, e expressa os termos $a$ e $k$ desta equação como uma função linear da temperatura e insere quatro coeficientes $\left(\mathrm{k}_{1} \mathrm{a}\right.$ $\mathrm{k}_{4}$ ) que são dependentes da taxa de cisalhamento, conforme Eq. 8. Vale observar que Ronningsen utilizou o $\epsilon_{w}$ para representar a fração volumétrica da fase dispersa ao invés do $\Phi$, porém ambos têm o mesmo significado.

$$
\begin{aligned}
& \ln \mu_{m}=a+k \cdot \Phi \\
& \ln \mu_{m}=k_{1}+k_{2} \cdot T+k_{3} \cdot \epsilon_{w}+k_{4} \cdot T \cdot \epsilon_{w}
\end{aligned}
$$

Há ainda outras correlações para o cálculo da viscosidade da emulsão em um escoamento água-óleo, porém não há até o momento um consenso sobre qual destas é a melhor para a predição da viscosidade da dispersão. Na indústria de petróleo, quando não há um ensaio laboratorial que represente o comportamento da viscosidade da emulsão, utiliza-se o modelo de cálculo que melhor se ajustou a um óleo similar ao que se pretende produzir.

Até o momento, não há um modelo generalizado para a realização desta predição. Observa-se que as diferentes correlações têm bons ajustes para óleos de características particulares, e que a implementação de todos os fatores no cálculo da viscosidade da mistura é complexa.

\section{2. \\ Quebra de Gotas no Escoamento}

A teoria de quebra de gotas pode ser descrita usando apenas duas forças; a força externa que age na gota tentando deformá-la e a força interna que é restauradora. Hinze utilizou esta abordagem e outros trabalhos seguiram sua linha [30]. A relação entre a força deformadora, $\tau$, que pode ser viscosa ou inercial 
dependendo da natureza do escoamento ao redor da gota, e a tensão restauradora, б/d, é o número de Weber, We, conforme já abordado anteriormente.

$$
W e=\tau \cdot d / \sigma
$$

Eq. 9

Como visto também, para que ocorra a quebra de uma gota é necessário que o seu valor de We seja maior que um valor crítico $\mathrm{We}_{\mathrm{cr}}$. Quando há a quebra de gota, há a redução do valor de We. Com isso, a quebra ocorre até que para todas as gotas $\mathrm{We}<\mathrm{We}_{\mathrm{cr}}$. Para que seja possível o cálculo das forças deformadoras que agem na gota, é importante conhecer o escoamento ao redor desta [4].

\subsection{1.}

\section{Mecanismos de quebra de gotas}

$\mathrm{Na}$ sequência serão apresentados os mecanismos de quebra de gotas. Primeiramente, discorre-se sobre o mecanismo durante o escoamento em um duto. Posteriormente, sobre a quebra influenciada pela passagem em um choke.

\subsubsection{1. Escoamento Turbulento em dutos}

Até o momento pouco foi estudado a respeito da quebra de gotas causada pela turbulência do escoamento. O que já foi observado é que as gotas tendem a quebrar na região próxima a parede, onde há maior cisalhamento, e que a taxa de dissipação média da energia cinética está relacionada com o fator de fricção dado pela equação de Blasius, válida apenas para dutos lisos.

Deve ser pontuado o fato de que, provavelmente, a quebra de gotas é resultado da combinação de duas contribuições distintas: uma devida ao gradiente de velocidade médio nas proximidades da parede, que é responsável pela deformação da gota; e outra devida à turbulência, que é responsável pelas oscilações das gotas antes da ocorrência da quebra [6].

O efeito do material do duto no tamanho de gotas já foi reportado por Angeli e Hewitt, mostrando que o aumento do fator de fricção da parede tende a gerar gotas menores [31].

Vale ressaltar que mesmo com o tempo de residência dos fluidos produzidos sendo maior na coluna e linha de produção do que nas restrições do sistema, a 
quebra de gotas se dará predominantemente nos chokes, pois a queda de pressão nestes elementos é maior e mais acentuada que na coluna e na linha.

Durante a realização dos experimentos que compõem este trabalho, foi verificada a ocorrência de redução do tamanho de gotas apenas por conta do escoamento no duto. A quebra foi mais significativa nas maiores vazões, ou seja, no cenário com maior Reynolds. Os gráficos mostrando a quebra de gotas ocorrida no escoamento durante o experimento serão apresentados no Capítulo 4, que trata sobre os resultados obtidos.

\subsubsection{2.}

\section{Escoamento através de uma restrição}

Uma grande variedade de ckokes é usada nos sistemas de produção de óleo atualmente instalados. Eles são utilizados para criar uma queda de pressão localizada e assim poder controlar a vazão produzida. Nestes elementos do sistema de produção, o escoamento é forçado através de uma restrição onde há dissipação da energia e queda de pressão.

A montante do orifício há um escoamento turbulento plenamente desenvolvido, e ao chegar à restrição há uma aceleração do escoamento e a formação de um jato. Neste ponto a zona de recirculação é pequena, ao contrário do que ocorre a jusante do choke onde esta zona é maior. Devido à aceleração, a pressão diminui e alcança o valor mínimo no ponto em que o diâmetro do jato é mínimo. Esta posição é chamada de Vena Contracta, VC, e nesta região a velocidade é alta e a energia é dissipada numa taxa elevada. A jusante da VC o fluido desacelera e parte da pressão é recuperada até o ponto onde o escoamento volta a ser plenamente desenvolvido [4].

Na Figura 19 segue uma representação esquemática que mostra os campos de escoamento e pressão dentro de um orifício circular instalado em um duto circular. 


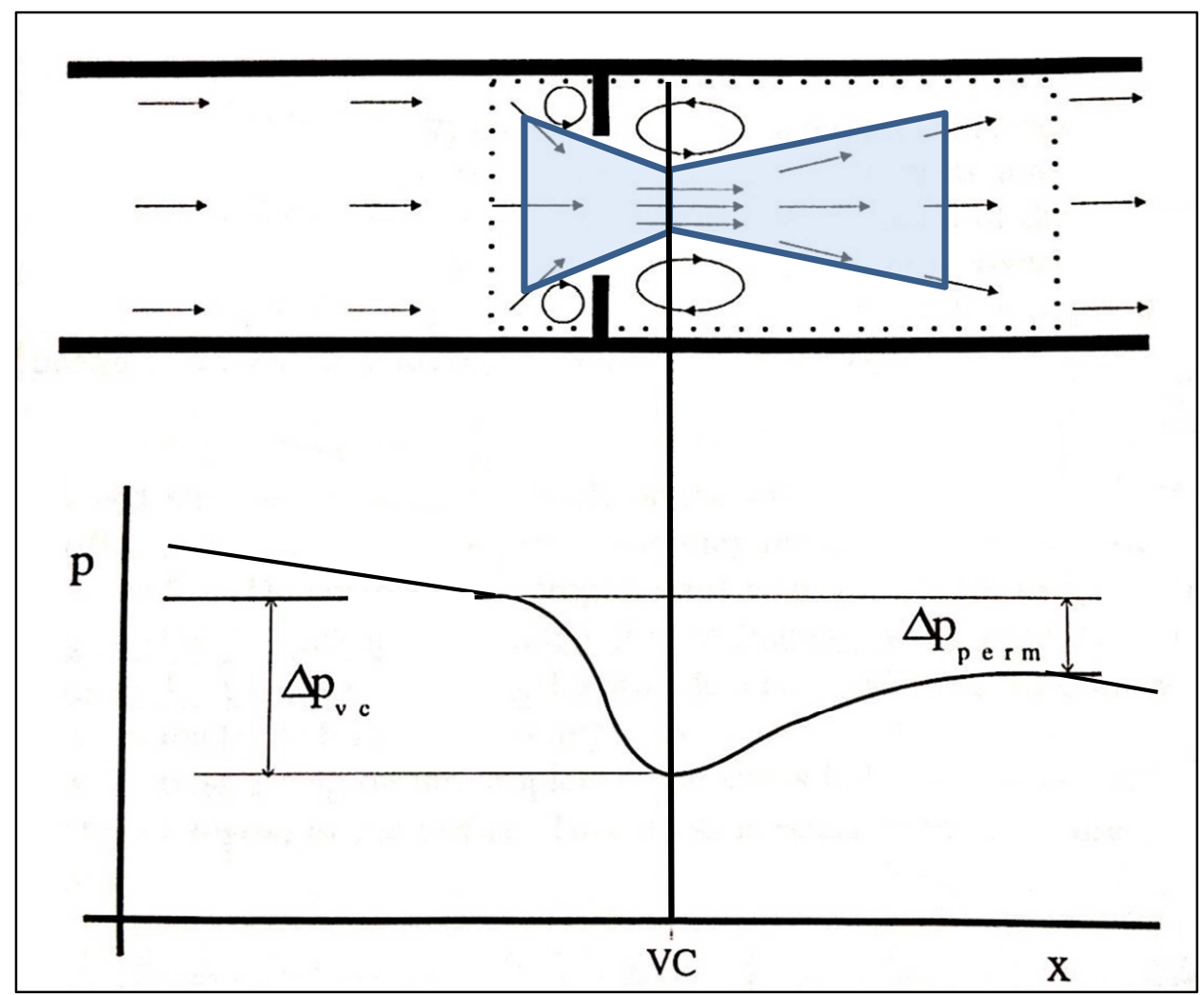

Figura 19 - Esquemático dos campos de pressão e escoamento através de um orifício. A linha preta, que corta a região azul no ponto mais estreito, indica o ponto de ocorrência da Vena Contracta [4].

A máxima queda de pressão, $\Delta \mathrm{p}_{v c}$, pode ser calculada usando a equação do orifício:

$$
\Delta p_{v c}=\frac{1}{C_{o}^{2}} \cdot \frac{1}{2} \cdot \rho_{c} \cdot U_{p}^{2} \cdot\left(\beta^{-4}-1\right)
$$

Onde $\mathrm{C}_{\mathrm{o}}$ é o coeficiente do orifício, $\rho_{\mathrm{c}}$ a massa específica da fase contínua, $\mathrm{U}_{\mathrm{p}}$ a velocidade média no duto e $\beta$ a razão entre o diâmetro orifício, $\mathrm{d}_{\mathrm{o}}$, e o do duto, $d_{p}$. $O$ valor de $C_{o}$ depende de $U_{p}$ e $\beta$, mas para valores de Reynolds muito altos ( $\operatorname{Re}>10000)$, este termo fica constante com valor aproximado de 0,62 [32].

Galinat et al. [6] verificou que através do parâmetro geométrico $\beta$ e do $\operatorname{Re}$ do escoamento era possível prever se ocorreria ou não a quebra de gotas. Com estes dois termos era possível determinar uma fronteira de ocorrência deste fenômeno. Na Figura 20 é mostrado o mapa de quebra gerado através da relação entre os termos $\beta$ e Re para uma solução de n-heptano em água, com o teor da fase dispersa entre 1,7 e $3 \%$. Nesta figura observa-se que para valores de $\beta$ menores que 0,4 , há a quebra de gotas mesmo com o escoamento no regime laminar. 


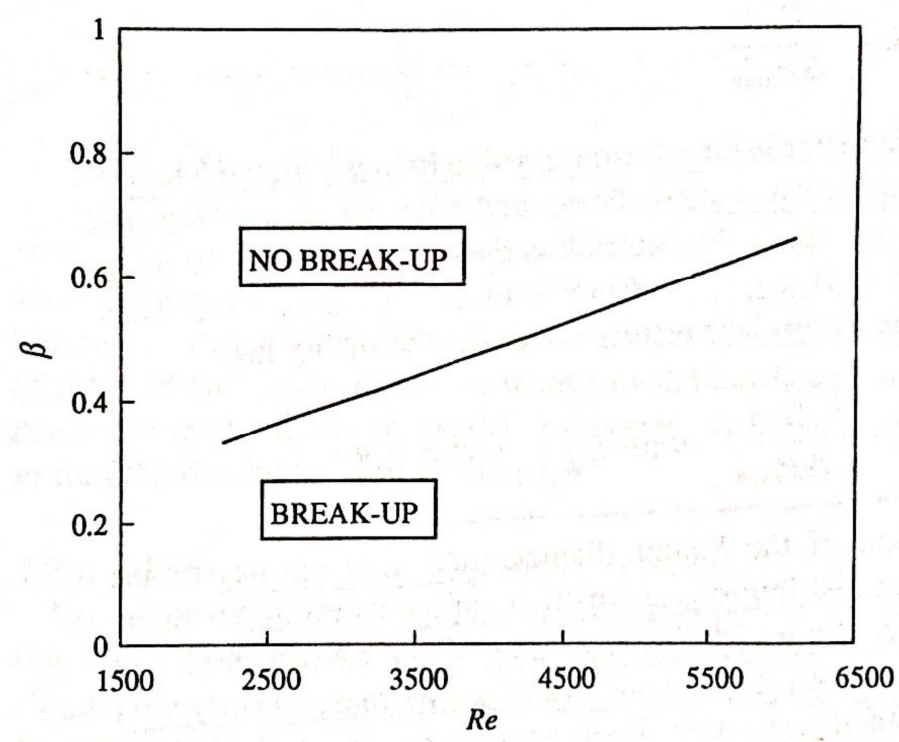

Figura 20 - Mapa de quebra de gota de uma solução n-heptano/água em função do $\operatorname{Re}$ e da razão de restrição, $\beta$. Acima da reta inclinada não foi verificada quebra de gotas [6].

O fator de recuperação, que é a relação entre a queda de pressão permanente, $\Delta \mathrm{p}_{\text {perm }}$, e a $\Delta \mathrm{p}_{v c}$ é dado pela seguinte fórmula:

$$
\frac{\Delta p_{\text {perm }}}{\Delta p_{v c}}=1-\beta^{2}
$$

Baseado em análises experimentais [33, 34], foram determinadas as distâncias características onde ocorrem as mudanças no escoamento e na pressão citadas acima. A aceleração do fluido inicia-se a $0,6 . \mathrm{d}_{\mathrm{p}}$ antes do início do orifício, a Vena Contracta está a jusante do orifício a uma distância de 1,65. $\left(\mathrm{d}_{\mathrm{p}}-\mathrm{d}_{\mathrm{o}}\right)$, e a pressão é totalmente recuperada entre $4,5 . d_{p}$ [33] e 8,5.d $d_{p}$ [34] a jusante do orifício.

\subsubsection{3.}

\section{Quebra devida à aceleração}

A tensão deformadora que age nas gotas é a tensão induzida pela aceleração do fluido na região de entrada do orifício. Esta tensão é igual à queda de pressão através do diâmetro da gota:

$$
\tau=\frac{\partial p}{\partial x} \cdot d \approx \frac{\Delta p_{v c}}{\Delta x} \cdot d
$$


Onde $\Delta \mathrm{x}$ é a distância em que a máxima queda de pressão ocorre. Percy e Sleicher assumiram que este termo é da ordem do diâmetro do orifício, $\mathrm{d}_{\mathrm{o}}$, com isso a expressão para o número de Weber pode ser escrito na seguinte forma:

$$
W e=\frac{\tau . d}{\sigma}=\frac{\Delta p_{v c} d^{2}}{\sigma d_{o}}
$$

Considerando que a gota só quebra se o $\mathrm{We}>\mathrm{We}_{\mathrm{cr}}$, pode-se a partir da Eq. 13 chegar à correlação a seguir para o diâmetro da gota:

$$
d=K\left(\frac{d_{o} \sigma}{\Delta p_{v c}}\right)^{0,5}
$$

Onde $\mathrm{K}$ é um termo que varia dependendo do percentual de quebra de gotas que se pretende considerar, e pode ser calculado através da expressão $K=0,32+$ 2,8 . $f$, onde $f$ varia entre 0 e 1 . Quando há $100 \%$ de quebra das gotas após o orifício, o d $\mathrm{d}_{100}$ é calculado e o valor de $f$ é igual a 1 , logo $\mathrm{K}$ será igual a 3,1. Se não há quebra de gotas, o diâmetro calculado é o próprio $\mathrm{d}_{0}$ e o valor de $\mathrm{K}$ será de 0,32 [35].

Galinat et al. [6] realizou uma análise experimental para verificar a quebra de gotas em orifícios com $\beta=0,5$, inseriu os resultados de $d_{32}$ e $d_{95}$ obtidos no experimento num gráfico em função de um comprimento característico $\mathrm{L}_{0}$, onde $\mathrm{L}_{0}$ é igual a $\left(d_{o} \sigma / \Delta p_{v c}\right)^{0,5}$, e comparou o comportamento destes termos com o $\mathrm{d}_{0}$ e $\mathrm{d}_{100}$ calculados a partir da Eq. 14. Desta forma, seriam obtidos graficamente os valores para $\mathrm{K}$, pois estes representariam o coeficiente angular das retas traçadas.

Como nos ensaios os coeficientes angulares de $d_{32}$ e $d_{95}$ apresentaram valores entre o $d_{0}$ e $d_{100}$, acredita-se que a expressão desenvolvida para prever a quebra de gotas devido à aceleração desenvolvida por Percy e Sleicher é consistente com o verificado na prática. Outro ponto que pode ser observado na Figura 21 é que o valor de $\mathrm{d}_{95}$ determinado não pode ser usado como representativo para o $d_{100}$. 


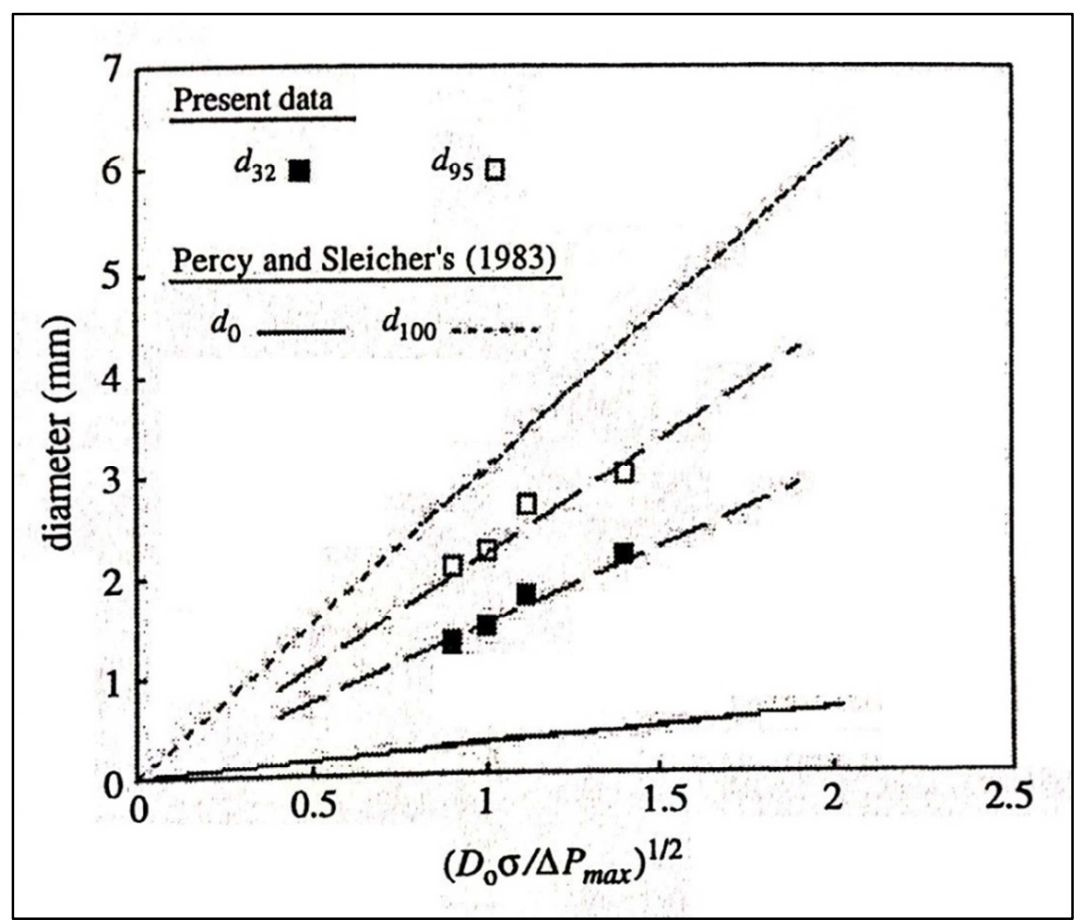

Figura 21 - Comparação entre os diâmetros $\mathrm{d}_{32}$ e $\mathrm{d}_{95}$ a jusante do choke, com os dados experimentais de Percy e Sleicher, em função do comprimento característico $\mathrm{L}_{0}$. $O \Delta \mathbf{P}_{\text {máx }}$ é igual ao $\Delta \mathbf{P}_{v c}$ das equações anteriores [6].

O experimento conduzido por van der Zande e van den Broek [4] avaliou a quebra de gotas de duas emulsões formadas a partir de óleos minerais, fabricados pela Shell, com viscosidade de 18 e $140 \mathrm{mPa} . \mathrm{s}$ a $22^{\circ} \mathrm{C}$, em orifícios com diâmetros entre 1,0 e 3,0 mm. A concentração volumétrica da fase dispersa era de 0,5\% nos dois casos.

Em uma primeira abordagem considerou-se que a quebra de gota seguia ao conceito proposto na Eq. 14. Por isso, um gráfico foi gerado com a relação entre o tamanho específico de gotas $\mathrm{d}_{95}$ verificado no experimento após a quebra, em função do comprimento característico $\mathrm{L}_{0}$, igual a $\left(d_{o} \sigma / \Delta p_{v c}\right)^{0,5}$. Pela Figura 22, observa-se que há bom ajuste entre os termos $\mathrm{d}_{95}$ e $\mathrm{L}_{0}$. Esta condição pode ser verificada através da linearidade existente entre os dois termos até a condição de $\mathrm{L}_{0}<60 \mu \mathrm{m}$. Acima deste valor de $\mathrm{L}_{0}$, há um desvio dos valores em relação à linha reta. 


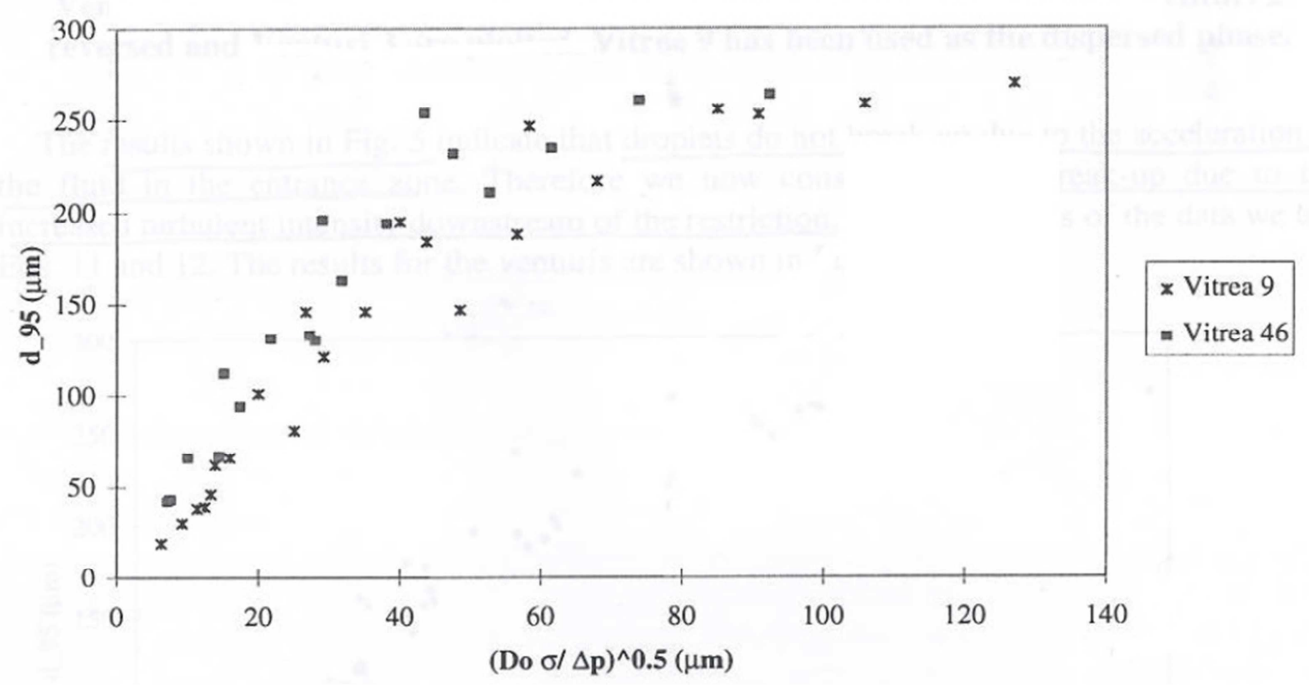

Figura 22 - Relação entre o d 95 e o parâmetro $L_{0}$, para quebra de gotas em orifícios entre 1,0 e 3,0 mm. Os dois óleos usados são o Vitrea 9 e Vitrea 46, com viscosidade de 18 e $140 \mathrm{mPa} . \mathrm{s}$ a $22^{\circ} \mathrm{C}$, respectivamente [4].

Este resultado indicaria que a consideração feita por Percy e Sleicher para o processo de quebra de gotas está correta, e significaria que as gotas quebram devido ao processo de aceleração do fluido na zona de entrada do orifício. Como consequência, restrições com escoamento e campo de pressão similares na zona de entrada, resultariam em tamanho de gotas similares.

Contudo, neste mesmo experimento, foi observado que orifícios com zonas de entrada iguais, mas com formatos diferentes a jusante da restrição, apresentaram diâmetros de gotas diferentes após serem submetidos às mesmas condições de vazão. Segundo a Eq. 14, estes valores deveriam ser iguais, já que não houve alteração em nenhum dos termos da equação. As geometrias dos orifícios testados estão representadas na Figura 23.

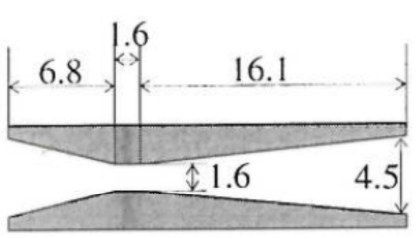

Venturi 1

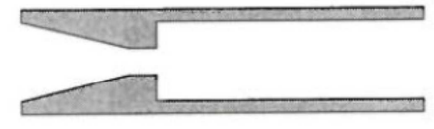

Venturi 2

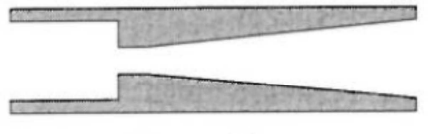

Venturi 3

Figura 23 - Características geométricas dos Orifícios testados. Medidas apresentadas estão em mm [4].

A discrepância observada nos diferentes orifícios indicou que as gotas não quebram por conta da aceleração do fluido na zona de entrada. Por esta razão, foi 
necessário considerar a quebra da gota devido ao aumento da turbulência a jusante da restrição.

$\mathrm{Na}$ seção a seguir será apresentado como o diâmetro de gota pode ser previsto em função das forças que atuam no movimento turbulento e quais parâmetros são importantes para a sua determinação.

\subsubsection{4.}

\section{Quebra devido ao movimento turbulento}

Outra abordagem possível para quebra de gotas é a consideração das forças turbulentas presente na zona de jato do orifício. Como a velocidade do fluido nesta região é muito maior que a velocidade média do duto, a turbulência é mais intensa. Desta forma, as gotas que não se quebraram na turbulência do duto podem quebrar nesta região a jusante do orifício. Na Figura 24 é apresentado um esquemático com a região do jato a jusante do orifício, neste caso a velocidade do fluido na região do jato, $U_{j}$, é maior que a velocidade média no duto, $U_{p}$.

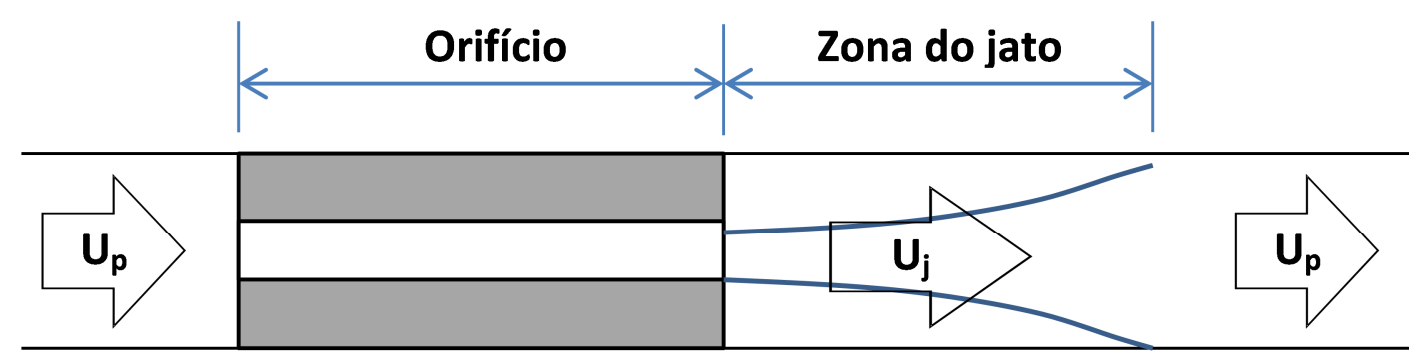

Figura 24 - Visão Esquemática da Zona do jato a jusante do Orifício, neste ponto a velocidade do fluido é superior à verificada no duto.

No escoamento turbulento, estará presente em uma gota de diâmetro $d$ um diferencial de velocidade, $\Delta \mathrm{u}$, devido ao movimento caótico e aleatório do fluido. A tensão inercial induzida por este diferencial de velocidade é igual a $\rho_{\mathrm{c}} \cdot(\Delta \mathrm{u})^{2}$, e a tensão viscosa igual a $\mu_{\mathrm{c}} \cdot \Delta \mathrm{u} / \mathrm{d}$, onde $\mu_{\mathrm{c}}$ é a viscosidade da fase contínua.

Para escoamentos altamente turbulentos as força inercial é a dominante no processo de quebra de gota. Neste caso o número de Weber pode ser escrito da forma abaixo:

$$
W e=\frac{\tau . d}{\sigma}=\frac{\rho_{c}(\Delta u)^{2} . d}{\sigma}
$$


Para o caso de turbulência homogênea isotrópica a relação entre o $\Delta$ u e a potência dissipada por unidade de massa, $\varepsilon$, é dada por:

$\Delta u \propto(\varepsilon d)^{1 / 3}$

Eq. 16

A consideração de turbulência homogênea isotrópica não é válida para todo o campo de escoamento no orifício, mas apenas na escala das gotas. Como visto anteriormente, só os vórtices com tamanho similar ou menor que as gotas fazem com que estas oscilem e eventualmente quebre.

Considerando uma escala de ordem do tamanho das gotas, a distribuição de energia é independente da geometria dos limites do escoamento, o que basicamente faz com que a turbulência seja isotrópica nesta escala pequena. Além do mais, se for considerada uma zona de turbulência onde $\varepsilon$ é aproximadamente constante, os requisitos para a turbulência homogênea isotrópica são atendidos.

Substituindo a Eq. 16 na Eq. 15, e considerando que as gotas quebrarão na condição de $\mathrm{We} \gg \mathrm{We}_{\mathrm{cr}}$, o máximo diâmetro estável de gota, $\mathrm{d}_{\max }$, numa zona turbulenta com potência dissipada por unidade de massa, $\varepsilon$, pode ser escrito como:

$$
d_{\max }=C\left(\frac{\sigma}{\rho_{c}}\right)^{0,6} \varepsilon^{-0,4}
$$

Eq. 17

Vale destacar que os parâmetros $\sigma$ e $\rho_{\mathrm{c}}$ são propriedades do fluido, apenas o termo $\varepsilon$ representa a ação do escoamento para deformar a gota. O termo $\mathrm{C}$ é obtido experimentalmente, e segundo Hinze [29] este valor é igual a 0,725 quando a viscosidade da fase dispersa não é considerada.

Como é difícil experimentalmente medir a potência dissipada localmente, utiliza-se para o cálculo do $\mathrm{d}_{\max }$ a potência dissipada média por unidade de massa, $\bar{\varepsilon}$, em toda a zona do orifício. Para determinar este parâmetro, é necessário considerar uma zona de orifício que contém um elemento de fluido, esta zona está marcada na Figura 19 pela linha pontilhada. Depois, faz-se a relação entre a energia necessária para que o elemento de fluido passe pelo orifício e a massa deste elemento multiplicado pelo tempo de residência média do fluido na zona do orifício.

A energia necessária para que haja a passagem do elemento de fluido pelo orifício pode ser calculada pela seguinte expressão, $\Delta p_{\mathrm{perm}} \cdot A \cdot \Delta x_{\mathrm{perm}}$, onde A é a área da seção transversal do duto e $\Delta \mathrm{x}_{\text {perm }}$ é o comprimento da zona de orifício, 
que é a distância a partir de onde a pressão começa a cair até o ponto onde há a recuperação da pressão.

A massa do elemento de fluido é dada pela fórmula $\rho_{\mathrm{c}} \cdot A \cdot \Delta x_{\text {perm }}$ e o tempo de residência médio é igual a $\Delta x_{\text {perm }} / U_{p}$. Com estas três expressões combinadas determina-se a fórmula para calcular a potência dissipada média por unidade de massa na zona do orifício. Esta está representada abaixo:

$$
\bar{\varepsilon} \propto \frac{\Delta p_{\text {perm }} U_{p}}{\rho_{c} \Delta x_{\text {perm }}}
$$

Eq. 18

A partir dos conceitos acima foi avaliado no experimento de van der Zande e van den Broek [4], citado no item anterior, se os diâmetros característicos d95 teriam bom ajuste com os valores calculados a partir da Eq. 17. Para isto, os mesmos valores obtidos para $\mathrm{d}_{95}$, mostrados na Figura 22 , foram postos no gráfico em função do termo $(\sigma / \rho)^{0,6} \varepsilon^{-0,4}$. Observou-se que houve um ajuste linear entre os dois termos do gráfico e que apenas nos valores mais altos, onde $(\sigma / \rho)^{0,6} \varepsilon^{-0,4}$ é maior que $150 \mu \mathrm{m}$, há um desvio dos dados desta linha reta. O coeficiente angular das retas que podem ser traçadas para cada óleo é igual ao termo C da Eq. 17.

A Figura 25 mostra a relação entre os diâmetros medidos no experimento e a expressão para cálculo do diâmetro máximo na quebra devido ao regime turbulento.

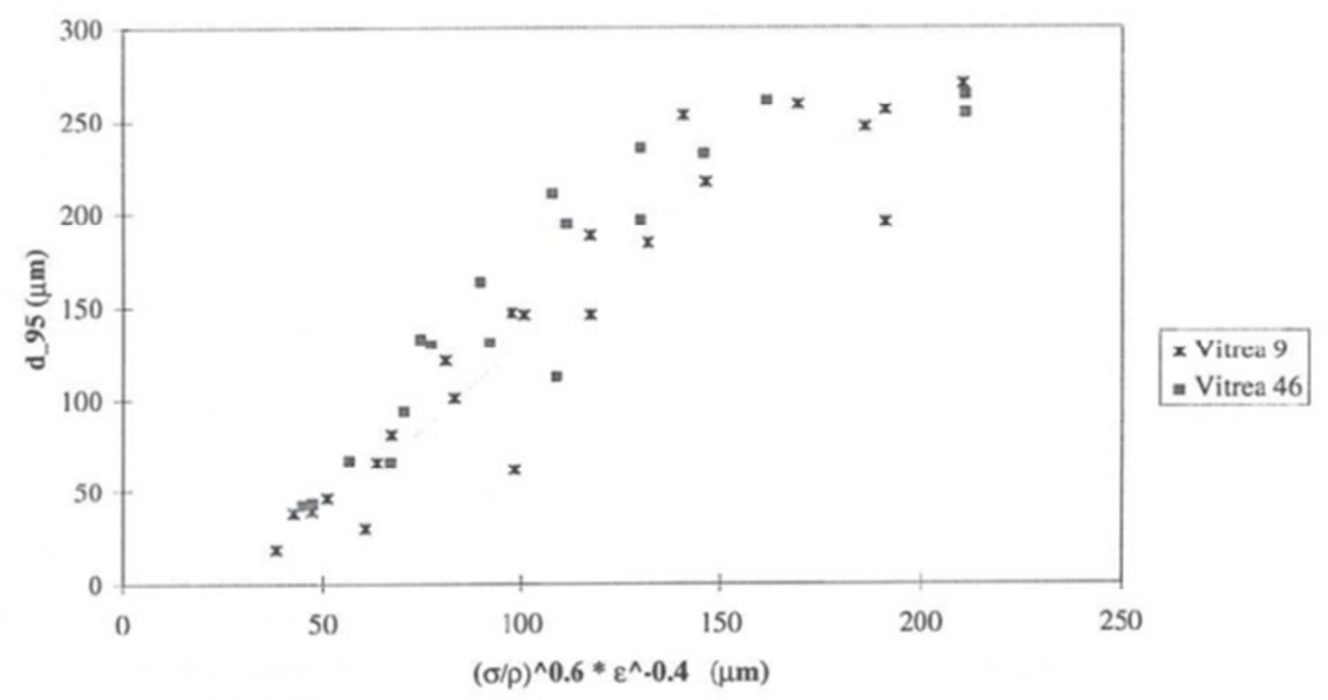

Figura 25 - Relação entre o $d_{95}$ e o parâmetro de quebra devido ao movimento turbulento, em orifícios entre 1,0 e 3,0 mm. Os dois óleos usados são o Vitrea 9 e Vitrea 46 [4]. 
Este experimento indica que a energia dissipada, o que leva à queda de pressão permanente, e não o gradiente de pressão é responsável pela quebra de gotas. O máximo valor para o diâmetro estável de uma gota pode ser previsto a partir da Eq. 17. A Figura 25 mostra que esta relação é adequada para descrever os dados obtidos com orifícios, independentemente do formato da zona de saída a jusante da restrição.

Outro ponto relevante verificado é que a viscosidade da fase dispersa afeta diretamente o tamanho máximo estável da gota no sentido que, quando há aumento da viscosidade, o termo $d_{95}$ cresce. Esta influência pode ser entendida pelo aumento da resistência da gota contra a deformação. Logo para uma mesma potência dissipada, uma menor quantidade de energia estará disponível para o aumento da área interfacial, o que trará como consequência, gotas maiores. Contudo, o aumento no valor da viscosidade não gera um aumento da mesma ordem no diâmetro da gota.

O termo $\mathrm{C}$ que pode ser obtido através do gráfico tem papel importante na previsão do tamanho de gotas que será gerado no experimento, pois ele incorpora o efeito da viscosidade da fase dispersa no modelo apresentado. Nos óleos mais viscosos, em que o valor de C é maior que o valor proposto por Hinze [29] de 0,725, a equação prevê gotas menores do que as que são medidas em laboratório. Apesar da diferença nos tamanhos, a tendência da curva é bem representada através do modelo.

No caso do experimento, mesmo com a grande diferença entre as viscosidades dos óleos utilizados, 18 e $140 \mathrm{mPa} . \mathrm{s}$, a diferença nos valores do $\mathrm{d}_{95}$ ficou menor que $10 \%$.

Observa-se na Figura 25 que os dados obtidos não partem da origem, isto se deve às aproximações feitas durante a modelagem do processo de quebra. A expressão que calcula o $\bar{\varepsilon}$ pode ser melhorada se a zona de recirculação, que não contribui para a dissipação de energia, for considerada, reduzindo assim o volume efetivo do orifício e o tempo de residência do fluido em escoamento. Esta nova consideração traria aumento do termo $\bar{\varepsilon}$. Segundo van der Zande e van den Broek [4], o impacto deste ajuste foi a redução da dispersão observada na Figura 25, não tendo eliminando o desvio observado.

Outra forma de melhorar a descrição do processo de quebra é considerar que a potência dissipada não é distribuída homogeneamente através da região orifício. 
Não é improvável que uma pequena região, imediatamente a jusante da restrição, tenha uma turbulência muito elevada. Nem todas as gotas passariam por esta região ou ficariam tempo suficiente para quebrarem.

Graças a esta heterogeneidade, observou-se que a distribuição do tamanho de gotas após a quebra no orifício dependia da distribuição das gotas injetadas a montante do orifício [4]. A redução do tamanho de gota na injeção, $\mathrm{d}_{\mathrm{inj}}$, causa o decréscimo do tamanho de gota após a quebra, $\mathrm{d}_{\mathrm{down}}$. Isto ocorre até um valor mínimo, que é o diâmetro estável, $\mathrm{d}_{\text {stable, }}$ onde o não ocorrerá a quebra da gota.

Na Figura 26 é possível observar o efeito do tamanho de gota na entrada no diâmetro da gota após o orifício, e que não ocorre mais a quebra na gota quando o $\mathrm{d}_{\mathrm{inj}}$ for menor que $65 \mu \mathrm{m}$. Esta sensibilidade ao $\mathrm{d}_{\mathrm{inj}}$ foi feita sob uma mesma condição de escoamento, com a vazão de 0,73 1/min através de um orifício de 1,5 $\mathrm{mm}$ [7].

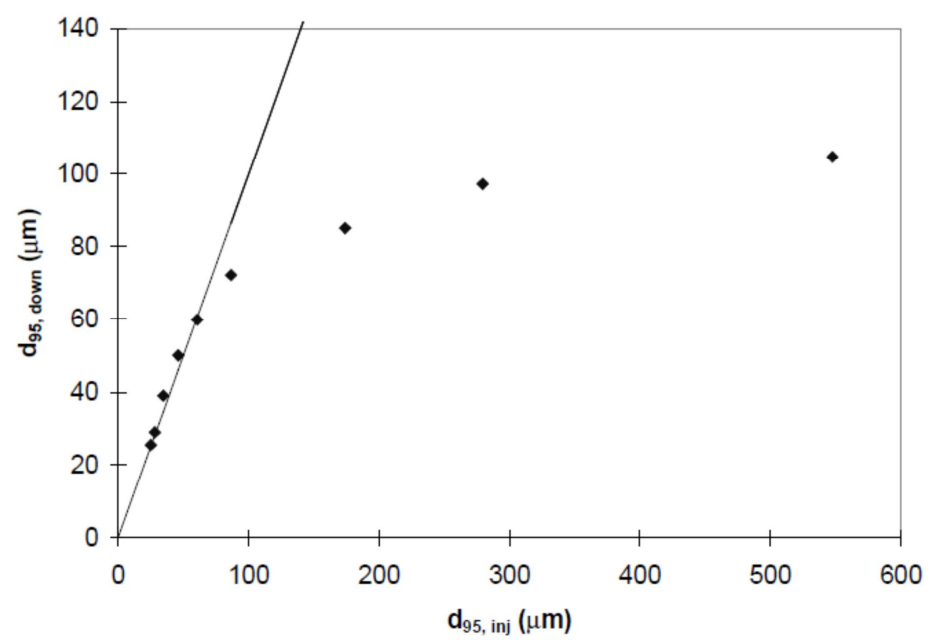

\section{Figura 26 - Efeito da distribuição do tamanho de gota injetado na distribuição a jusante do orifício. Usado o óleo Vitrea 9 [7].}

Neste mesmo teste laboratorial, a análise representada na Figura 26 foi repetida para o n-heptano e para o Vitrea 46, além de ter sido testada outras condições de escoamento para os três óleos. Como resultado determinou-se o máximo tamanho de gota estável, $\mathrm{d}_{\max }$, para as três amostras sob várias condições de escoamento. Na Figura 27 segue o ajuste dos três óleos analisados. Como dito anteriormente, com o coeficiente angular das retas traçadas para cada óleo, obtémse o termo C da Eq. 17. 


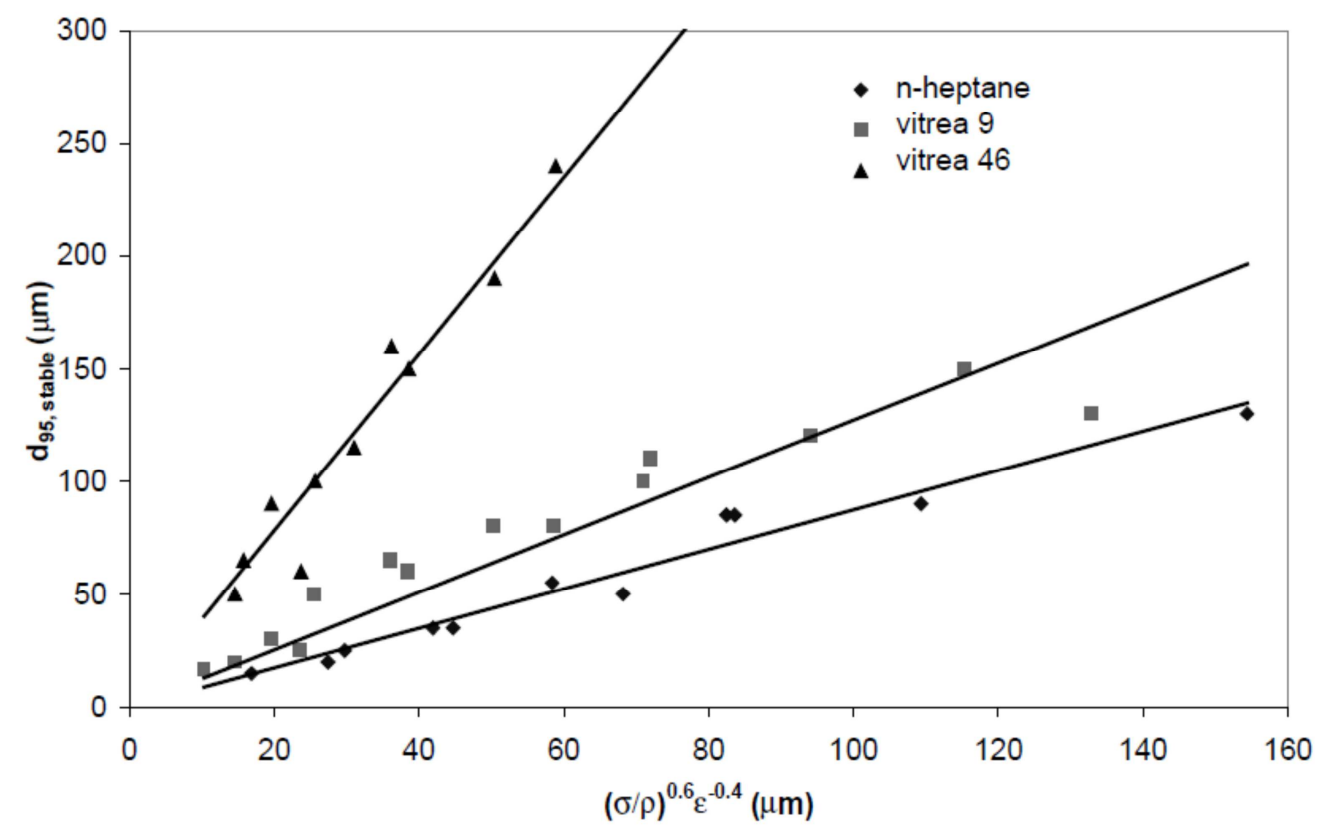

Figura 27 - Relação entre o $d_{\max }$ e o parâmetro de quebra devido ao movimento turbulento, em orifícios entre 1,0 e $3,0 \mathrm{~mm}$, com o ajuste linear dos três óleos analisados (n-heptano, Vitrea 9 e Vitrea 46) [7].

Vale ressaltar, que é possível que sejam encontradas a jusante do orifício gotas com diâmetro maior que o máximo estável, $\mathrm{d}_{\max }$, isto se deve ao fato de que nem todas as gotas ficaram tempo suficiente na zona turbulenta para alcançar a condição de quebra máxima.

Um ponto tratado no item anterior e que também foi relevante nos experimentos conduzidos por van der Zande et al. [7] foi a influência da geometria da restrição no tamanho de gotas final. Como visto, a geometria de saída da restrição invalidou a abordagem que a quebra de gota se dava por conta da aceleração do fluido na entrada da restrição. Isto porque, restrições com zonas de entrada similares, mas de saída diferentes, apresentaram diferenças significativas no tamanho das gotas após a restrição, mesmo com condições de escoamento similares.

Nesta análise [7], a quebra foi avaliada comparando duas configurações de restrição: a primeira, com um orifício e a segunda, com dois orifícios em série. A premissa era que a perda de carga nas duas configurações deveria ser igual. Para atendê-la, o diâmetro dos orifícios que eram postos em série era maior que o do orifício que seria instalado sozinho. Desta forma, para uma mesma vazão, a queda 
de pressão em cada um dos orifícios em série seria a metade da observada no orifício individual.

Neste experimento comparou-se o orifício de 1,0 $\mathrm{mm}$ com dois orifícios em série de 1,18 mm, e o orifício de 2,0 $\mathrm{mm}$ com dois de 2,31 $\mathrm{mm}$ em série. Estas combinações foram escolhidas em função da perda de carga permanente gerada. Esta pode ser calculada a partir da combinação da equação de orifício, Eq. 10, com a relação entre a perda de carga permanente e a máxima perda de carga, Eq. 11. A equação resultante desta combinação é:

$$
\Delta p_{\text {perm }}=\frac{1}{c_{o}^{2}} \cdot \frac{1}{2} \cdot \rho_{c} \cdot U_{p}^{2} \cdot\left(\beta^{-4}-1\right) \cdot\left(1-\beta^{2}\right)
$$

Nesta análise específica foi usado o óleo Vitrea 9 como fase dispersa, a vazão para os dois primeiros orifícios foi $0,48 \mathrm{l} / \mathrm{min}$ e para os outros dois foi de 1,45 1/min. Os resultados obtidos no processo de quebra de gotas nas duas combinações citadas acima são mostrados na Figura 28.

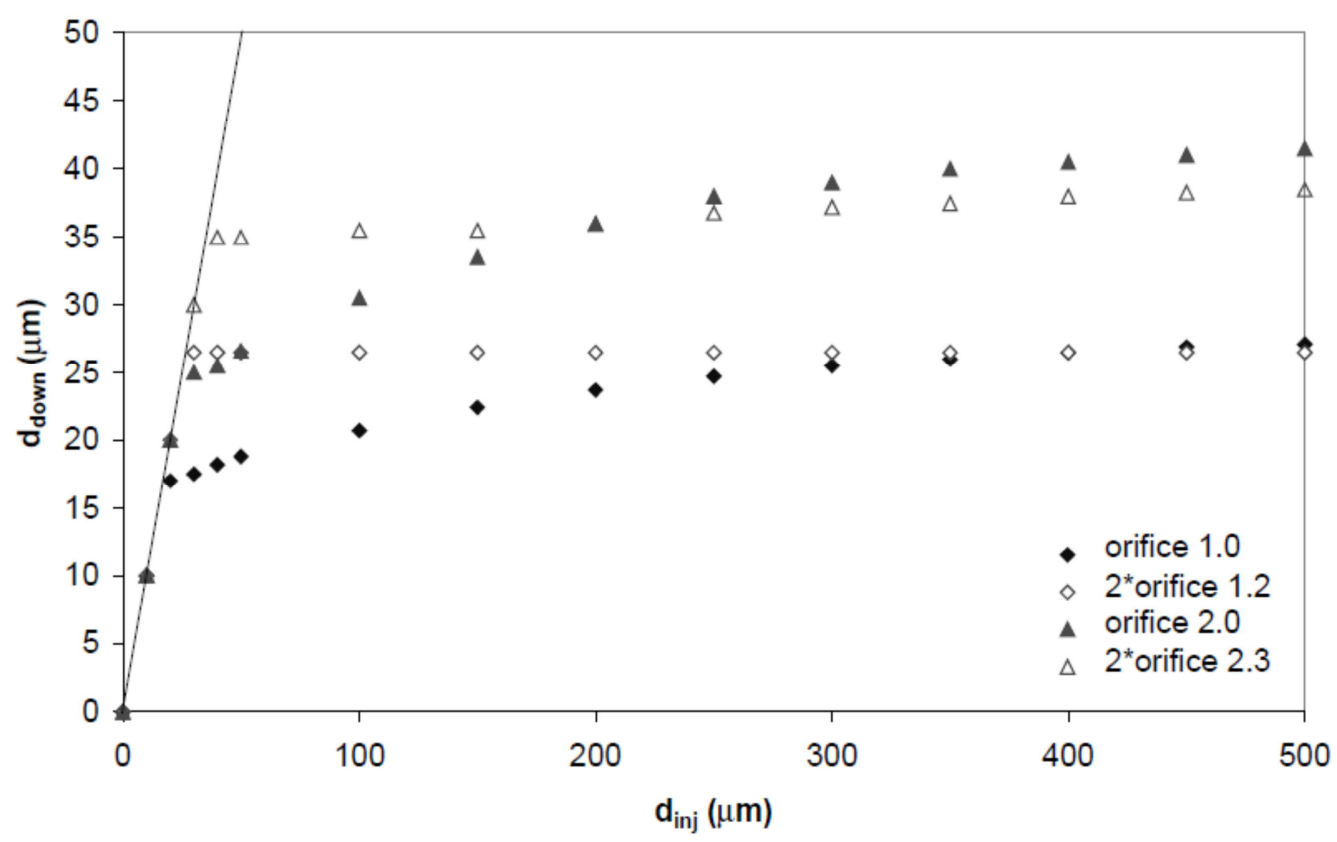

Figura 28 - Tamanho de gotas a jusante da restrição em função do diâmetro de entrada. A quebra ocorre em um orifício e em dois orifícios postos em série [7].

Pelo gráfico, observa-se que, para gotas pequenas, a configuração com dois orifícios em série causa menos quebra de gotas que o orifício simples. Isto é causado pela diminuição da potência dissipada média por unidade de massa. Este efeito benéfico é contra-atacado pelo aumento do tempo de residência destas gotas 
na zona turbulenta. Este último efeito fica mais pronunciado para gotas grandes, pois estas gotas precisam quebrar mais vezes para atingir o diâmetro estável. É comum que gotas grandes não fiquem tempo suficiente na turbulência para alcançar este valor. $\mathrm{O}$ uso de dois orifícios ao invés de um, aumenta o tempo de residência, o que leva a mais quebra.

A observação deste fenômeno é importante na indústria do petróleo para a escolha do separador mais adequado para a separação água-óleo, já que o tamanho de gotas a jusante do choke é sensível à geometria deste. A mudança do choke pode trazer uma diminuição da quebra de gotas e consequentemente um aumento na eficiência de separação. 


\section{3 \\ Experimentos}

Baseado nos conceitos apresentados no capítulo anterior e nos experimentos já realizados verifica-se que a potência dissipada tem impacto fundamental no mecanismo de quebra de gotas em orifícios, e que o tamanho de gotas a montante da restrição influencia o tamanho a jusante. Contudo, as análises estão restritas a uma faixa limitada de vazão e de queda de pressão. Além disto, não são claros quais os mecanismos responsáveis pela quebra de gotas. Este quadro motivou o presente trabalho que se propôs a contribuir para o tema com um estudo experimental sobre a quebra de gotas variando de forma mais ampla as vazões do sistema, as quedas de pressão localizadas e as características do orifício a fim de corroborar as conclusões apresentadas anteriormente ou propor novos parâmetros para previsão do tamanho de gotas.

Este capítulo é dedicado à descrição dos experimentos conduzidos.

\section{1. \\ Objetivos do Experimento}

No projeto da bancada experimental, buscou-se reproduzir o mais próximo possível o sistema utilizado na literatura para avaliação do tamanho de gotas. Por isso, pensou-se em um experimento com dois circuitos de injeção independentes com controle individual da vazão, um alojador para os orifícios, um medidor de pressão diferencial e dois pontos de tomada de amostra do fluido para medição do tamanho de gotas, um antes e outro após o alojador de orifícios. Desta forma seria possível controlar todas as variáveis que impactam o tamanho de gotas, verificar as condições de entrada e saída do fluido e, caso necessário, reproduzir o experimento. Outra característica importante da bancada, é que esta deveria ter flexibilidade para avaliar uma faixa de valores de pressão e vazão maior do que a apresentada na literatura. Isto de certa forma foi alcançado neste trabalho já que as condições de pressão avaliadas estão acima das verificadas na bibliografia e que os orifícios utilizados possuíam diferentes diâmetros e comprimentos. 


\section{2.}

\section{Descrição geral do experimento}

Como mostrado no item anterior, o experimento foi montado com dois circuitos de injeção independentes, um para a água e outro para a emulsão concentrada. A emulsão concentrada é a emulsão formada a partir dos óleos escolhidos que, depois da separação gravitacional, tem a água livre drenada. A utilização da emulsão concentrada no experimento teve por objetivo manter o controle do tamanho das gotas que seriam injetados no circuito principal. A emulsão concentrada é do tipo O/A para que durante a injeção não ocorresse mudança nas suas propriedades. Na Figura 29, segue um esquemático da bancada utilizada neste estudo, com os dois circuitos e os equipamentos utilizados.

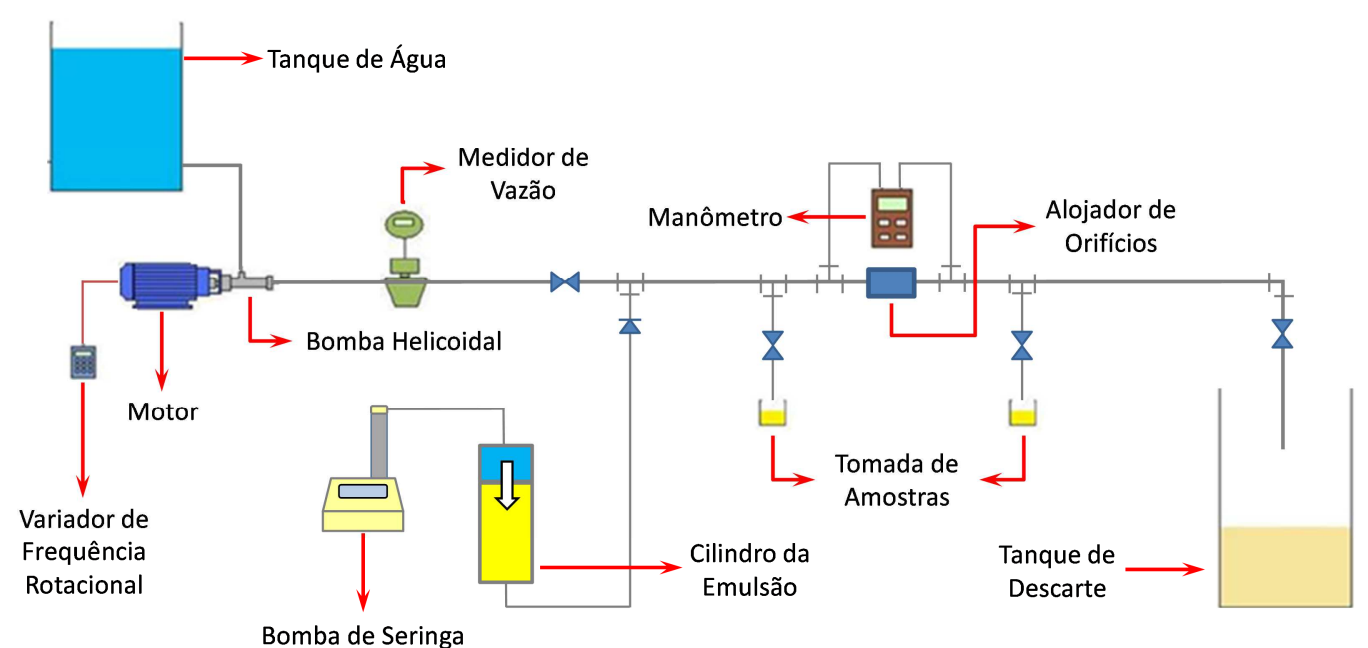

Figura 29 - Visão Esquemática da bancada experimental utilizada.

A água foi armazenada em um tanque ALPINA de 601 , e era o fluido principal do sistema. Para escoamento da água foi utilizada uma bomba helicoidal de deslocamento positivo da marca AMBORETTO modelo DRX-15M de 0,5 hp e vazão nominal de 2,0 1/min. O controle da vazão era possível graças à utilização de um variador de rotação WEG CFW 08. O sistema de injeção de água possuía um sensor medidor de vazão e transmissor MICRO MOTION Modelo 1700 instalado a jusante da bomba helicoidal.

Antes do início dos experimentos, foi conduzida uma análise para verificar se o medidor de vazão estava calibrado. Para esta avaliação foi medido o tempo de enchimento total ou parcial de uma proveta de 2 litros para diferentes vazões ajustadas pelo medidor; esta medição do tempo era feita três vezes por vazão. 
Após a medição do tempo, era calculada a vazão observada e então, este valor era comparado com o lido no medidor. Durante o enchimento da proveta, a vazão era lida cinco vezes. Tanto para o tempo medido quanto para a vazão lida, eram obtidos a média, o desvio padrão e a incerteza das leituras. A seguir estão as tabelas que mostram os tempos medidos para cada volume considerado, as vazões calculadas, as vazões lidas e a diferença observada entre a leitura e a medição.

Tabela 1 - Tempos medidos para diferentes volumes amostrados.

\begin{tabular}{|c|c|c|c|c|c|c|c|}
\hline & \multicolumn{4}{|c|}{ Vazão Medida - Cronômetro (1/min) } & \multirow{2}{*}{$\begin{array}{c}\text { t médio } \\
\text { (s) }\end{array}$} & \multirow{2}{*}{$\begin{array}{c}\text { Desvio } \\
\text { Padrão } \\
\text { (s) }\end{array}$} & \multirow{2}{*}{$\begin{array}{l}\text { Incerteza } \\
(\delta), \text { em s }\end{array}$} \\
\hline & $\begin{array}{c}\text { Vol. Amostra } \\
\text { (ml) }\end{array}$ & $\mathrm{t}_{1}(\mathrm{~s})$ & $\mathrm{t}_{2}(\mathrm{~s})$ & $t_{3}(s)$ & & & \\
\hline Caso 1 & 2000 & 58,60 & 58,22 & 58,22 & 58,35 & 0,22 & 0,44 \\
\hline Caso 2 & 1500 & 60,93 & 60,35 & 59,63 & 60,30 & 0,65 & 1,30 \\
\hline Caso 3 & 1000 & 58,25 & 59,22 & 59,09 & 58,85 & 0,53 & 1,05 \\
\hline Caso 4 & 500 & 60,31 & 60,87 & 59,81 & 60,33 & 0,53 & 1,06 \\
\hline Caso 5 & 200 & 58,62 & 60,29 & 59,68 & 59,53 & 0,85 & 1,69 \\
\hline
\end{tabular}

Tabela 2 - Vazões calculadas a partir dos tempos medidos acima.

\begin{tabular}{|c|c|c|c|c|c|c|}
\hline & $\begin{array}{c}\text { Vazão 1 } \\
(1 / \mathrm{min})\end{array}$ & $\begin{array}{c}\text { Vazão 2 } \\
(1 / \mathrm{min})\end{array}$ & $\begin{array}{c}\text { Vazão 3 } \\
(1 / \mathrm{min})\end{array}$ & $\begin{array}{c}\text { Vazão } \\
(1 / \mathrm{min})\end{array}$ & $\begin{array}{c}\text { Desvio } \\
\text { Padrão } \\
(1 / \mathrm{min})\end{array}$ & $\begin{array}{c}\text { Incerteza } \\
(\delta), \text { em } \\
1 / \mathrm{min}\end{array}$ \\
\hline Caso 1 & 2,0478 & 2,0611 & 2,0611 & 2,0567 & 0,0077 & 0,0154 \\
\hline Caso 2 & 1,4771 & 1,4913 & 1,5093 & 1,4925 & 0,0161 & 0,0323 \\
\hline Caso 3 & 1,0300 & 1,0132 & 1,0154 & 1,0195 & 0,0092 & 0,0183 \\
\hline Caso 4 & 0,4974 & 0,4929 & 0,5016 & 0,4973 & 0,0044 & 0,0087 \\
\hline Caso 5 & 0,2047 & 0,1990 & 0,2011 & 0,2016 & 0,0029 & 0,0057 \\
\hline
\end{tabular}


Tabela 3 - Vazões lidas no medidor

\begin{tabular}{|c|c|c|c|c|c|c|c|c|}
\hline & \multicolumn{5}{|c|}{ Vazão Lida - Medidor (1/min) } & \multirow{2}{*}{\begin{tabular}{|c}
$\begin{array}{c}\mathrm{Q} \\
\text { med. } \\
(1 / \mathrm{min})\end{array}$ \\
2,0050
\end{tabular}} & \multirow{2}{*}{$\begin{array}{l}\text { Desv. } \\
\text { Padrão } \\
(1 / \mathrm{min}) \\
0,0029\end{array}$} & \multirow{2}{*}{$\begin{array}{c}\text { Incert. } \\
(\delta), \text { em } \\
1 / \text { min } \\
0,0058\end{array}$} \\
\hline Caso 1 & 2,0012 & 2,0052 & 2,0034 & 2,0066 & 2,0088 & & & \\
\hline Caso 2 & 1,5017 & 1,5005 & 1,5034 & 1,5031 & 1,5016 & 1,5021 & 0,0012 & 0,0024 \\
\hline Caso 3 & 1,0036 & 1,0051 & 1,0003 & 1,0025 & 1,0016 & 1,0026 & 0,0018 & 0,0037 \\
\hline Caso 4 & 0,5036 & 0,5007 & 0,5024 & 0,5021 & 0,5047 & 0,5027 & 0,0015 & 0,0030 \\
\hline Caso 5 & 0,2032 & 0,2005 & 0,2040 & 0,2009 & 0,2070 & 0,2031 & 0,0026 & 0,0053 \\
\hline
\end{tabular}

Tabela 4 - Diferença entre as Vazões médias Lidas e Calculadas

\begin{tabular}{|c|c|c|c|}
\hline \multirow{2}{*}{} & \multicolumn{2}{|c|}{ Vazão (1/min) } & \multirow{2}{*}{ Dif. (\%) } \\
\cline { 2 - 3 } & Lido & Calculada & \\
\hline Caso 1 & 2,0050 & 2,0567 & $-2,5$ \\
\hline Caso 2 & 1,5021 & 1,4925 & 0,6 \\
\hline Caso 3 & 1,0026 & 1,0195 & $-1,7$ \\
\hline Caso 4 & 0,5027 & 0,4973 & 1,1 \\
\hline Caso 5 & 0,2031 & 0,2016 & 0,8 \\
\hline
\end{tabular}

Verifica-se que os erros observados no medidor de vazão estão menores que $3 \%$, logo foi considerado que o valor medido pelo equipamento era confiável e que poderia ser utilizado nos cálculos dos termos que fossem necessários, como o número de Reynolds e a potência dissipada.

Já no circuito da emulsão concentrada, está instalada uma bomba de seringa da marca TELEDYNE ISCO modelo 500 D com vazão máxima igual a 204 $\mathrm{ml} / \mathrm{min}$, e volume do cilindro igual a $507 \mathrm{ml}$. Para enchimento do cilindro, este é conectado a um reservatório de água, posto ao lado da bomba, por uma mangueira e uma válvula. Esta possui um controlador que permite a regulagem de todas as suas funções como vazão de injeção, refil do cilindro, volume de água presente no cilindro, início e parada da bomba. Para as condições do experimento, as vazões de injeção eram ajustadas para que o teor de óleo após a mistura fosse igual a 3\%. No controlador também há um visor onde é possível verificar as condições em que 
a bomba está operando. Esta bomba injeta água na parte superior do cilindro de emulsão e na saída da linha de injeção está instalada uma válvula. Como a bomba de seringa funciona transferindo energia de forma indireta para a amostra em um cilindro, não exigindo a passagem da emulsão através de um rotor, não é verificada uma quebra de gotas durante a injeção da amostra. Por este motivo, a bomba de seringa mostrou-se como a mais adequada para a injeção da emulsão concentrada.

Este cilindro contém a emulsão concentrada que é injetada no circuito de água. O cilindro tem volume de $1000 \mathrm{ml}$ com um pistão interno que o separa em dois compartimentos, e empurra a emulsão para o circuito de água conforme a vazão de água injetada pela bomba de seringa. Neste experimento, a entrada da água no cilindro se dá pela parte superior, e consequentemente a saída da emulsão concentrada ocorre pela parte de baixo. Isto porque verificou-se que nesta configuração não ocorria a presença de óleo livre no sistema, diferentemente do que foi constatado na primeira montagem, quando a entrada da água ocorria pela parte de baixo e a saída da emulsão na parte de cima. Apesar de ter sido verificado através de medições da distribuição do tamanho de gotas que a emulsão era estável durante semanas, a adição de pressão a amostra causou a separação de parte do óleo presente na emulsão. Como os óleos utilizados possuíam massa específica menor que a da emulsão concentrada, este óleo livre formado migrava para a parte superior do compartimento que continha a amostra. Para reduzir o óleo livre no sistema, a montagem do cilindro previa a saída da emulsão concentrada pela parte inferior.

Os detalhes sobre a metodologia para a formação da emulsão e suas características serão tratados no próximo item. Na Figura 30 são apresentadas as fotos com a instalação da bomba de seringa e do cilindro com a emulsão concentrada. 

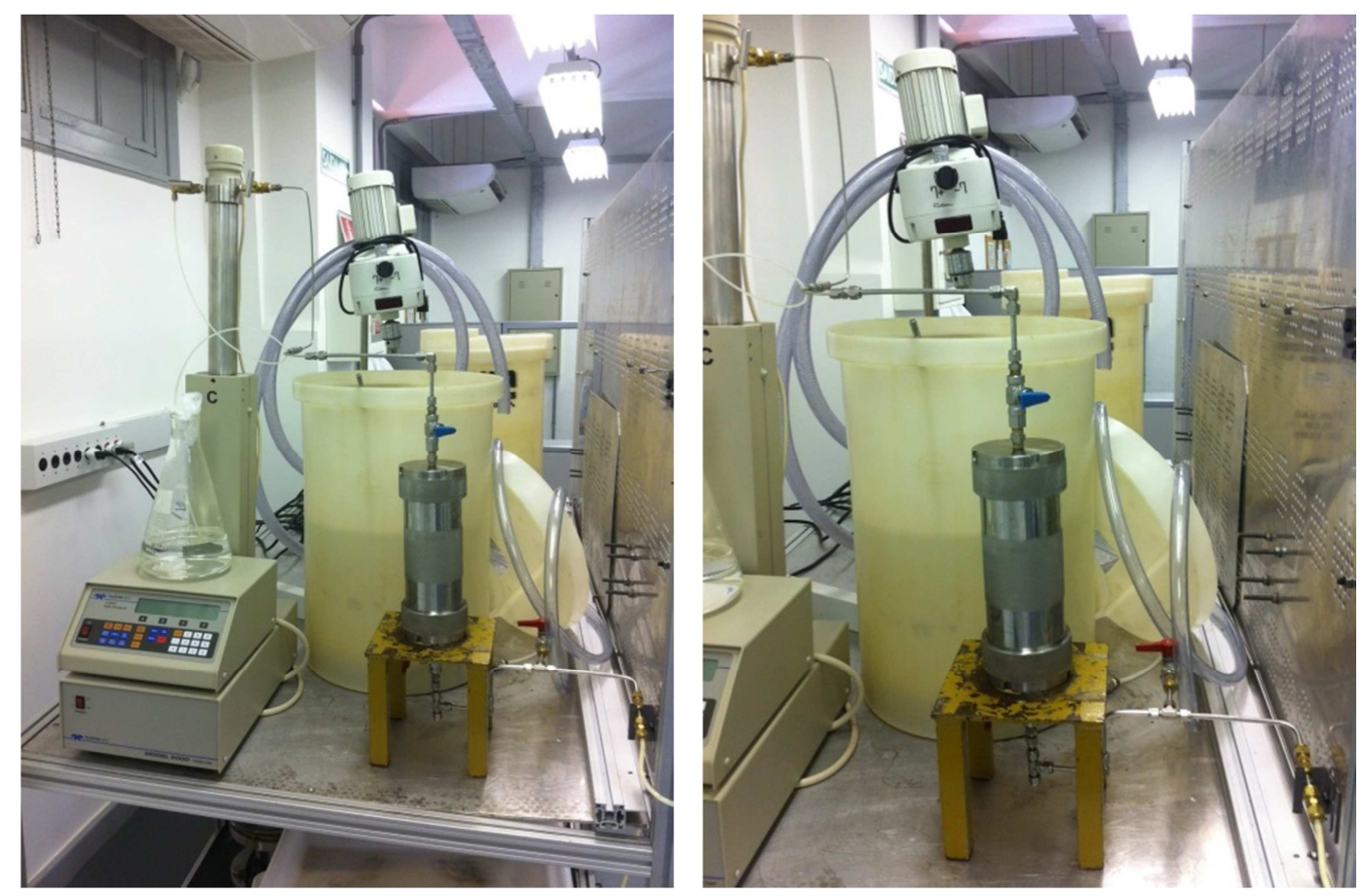

Figura 30 - Imagem da ligação do cilindro com emulsão concentrada a bomba de seringa, à esquerda. Observa-se que a saída da bomba é conectada ao topo do cilindro. Atrás do cilindro, observa-se o tanque de água.

No final do circuito da emulsão foi instalada uma check valve que tinha por objetivo impedir a entrada de água no circuito da emulsão. Imediatamente antes desta válvula foi instalada uma mangueira plástica para visualização da injeção de emulsão. Esta visualização era importante, pois a tomada de amostras só poderia ocorrer após o início da mistura e o volume disponível de emulsão para o número de pontos que se desejava analisar era restrito. Na Figura 31 é mostrada a conexão entre os dois circuitos que ocorre no T localizado no centro da foto. 


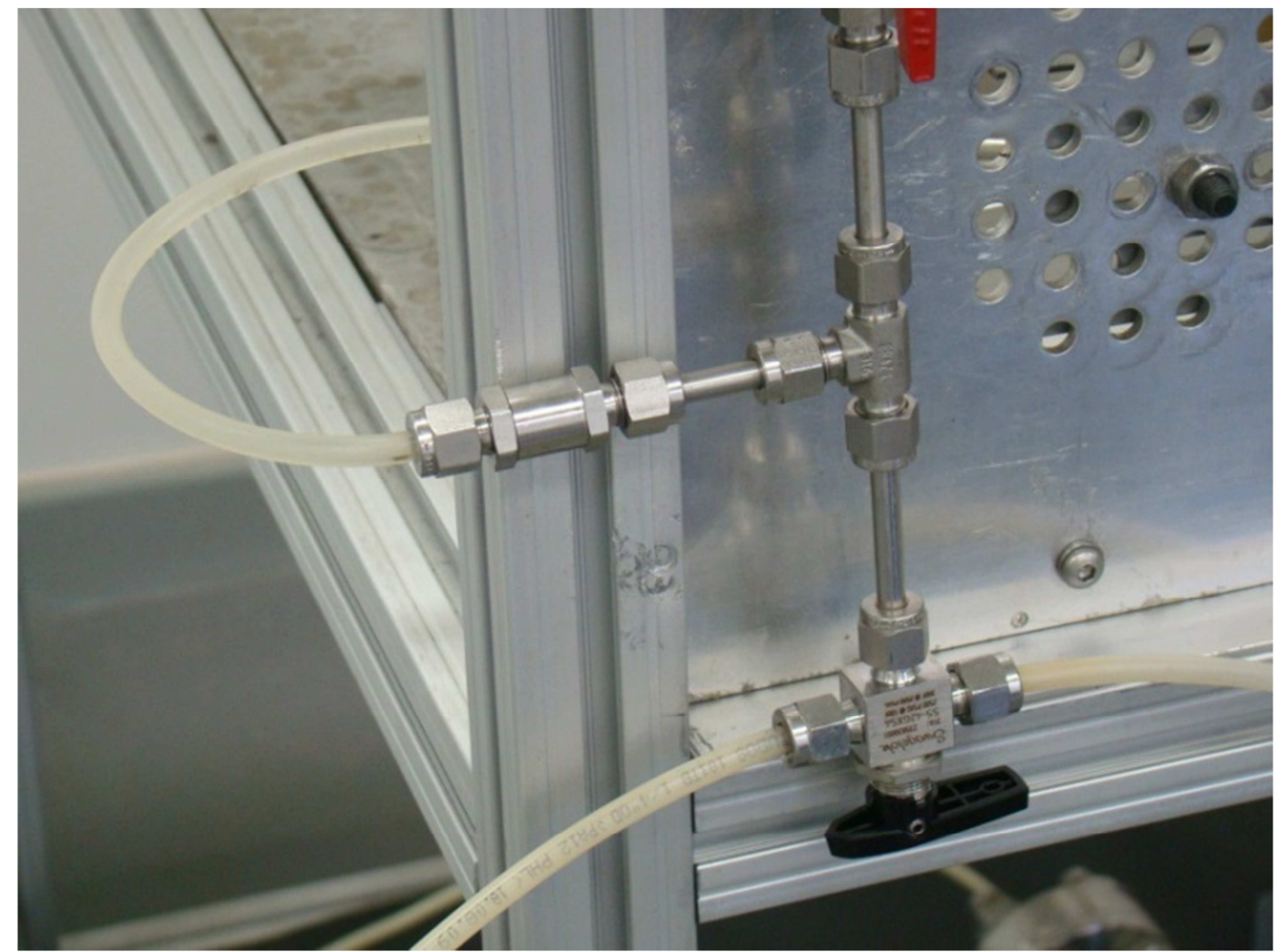

Figura 31 - Conexão entre o circuito de água e o de emulsão concentrada. Na parte superior esquerda observa-se a mangueira plástica para visualização da injeção de emulsão e ao final desta a check valve.

Após mistura da emulsão concentrada com a corrente principal de água, os fluidos seguem por uma tubulação de aço inox com diâmetro nominal de 1/4" $(6,35 \mathrm{~mm})$ e diâmetro interno de 3,175 mm até o alojador de orifícios. Para medir a queda de pressão nos orifícios utilizados, foi instalado o manômetro de pressão diferencial digital DWYER SERIES 490, Modelo 490-4, que possui precisão de 0,1 psi e o máximo diferencial de pressão permitido de 100,0 psi. As pressões são tomadas antes e após o alojador.

Há ainda no circuito dois pontos de tomada de amostras: um antes do orifício e outro após o orifício. Para facilitar a tomada de amostra foi colocada uma válvula SWAGELOCK SS-43GS4 de 1/4" em cada ponto de coleta. Na Figura 32 observa-se os dois pontos de amostragem, o manômetro instalado, os dois pontos de tomada de pressão e o alojador de orifícios no centro. 


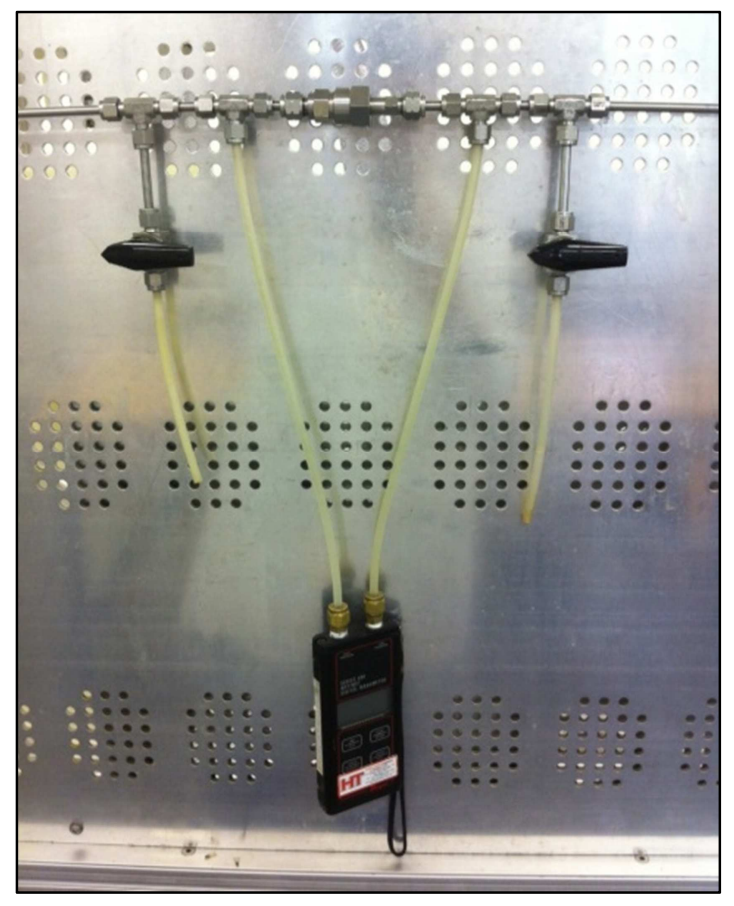

Figura 32 - Pontos de coleta de amostras com as válvulas pretas, manômetro e alojador de orifícios no centro.

As duas amostras coletadas são levadas para o analisador de partículas Mastersizer 2000 (Malvern Instruments) onde é determinada a distribuição do tamanho de gotas da fase dispersa da emulsão através do príncípio de difração da luz. No Mastersizer um feixe de laser é enviado em direção à amostra líquida a ser analisada. Quando o feixe colimado encontra as partículas, parte do laser é difratado e, subsequentemente, focado, por meio de lentes, no detector. Quanto menor o tamanho da partícula, maior será o ângulo de difração.

A recirculação e escoamento da amostra analisada no Mastersizer 2000 são realizados pelo equipamento de dispersão e bombeio Hydro 2000MU que é parte do conjunto de medição de partículas. A apresentação dos resultados obtidos no Mastersizer 2000 é feita por gráficos com a distribuição percentual em volume em função do tamanho da gota e, através de uma tabela onde são informados para cada medição realizada, na configuração padrão, os diâmetros característicos $\mathrm{d}(0,1)$, $\mathrm{d}(0,5)$ e $\mathrm{d}(0,9)$ que representam os diâmetros máximos de gota dos volumes da fase dispersa de 10, 50 e 90\%, respectivamente. Neste trabalho serão apresentados os valores $\mathrm{d}(0,5)$ obtidos na medição e a indicação destes será como $\mathrm{d}_{50}$. Na Figura 33 é mostrada a bancada ótica do Mastersizer 2000, ao fundo, e o Hydro 2000MU. 


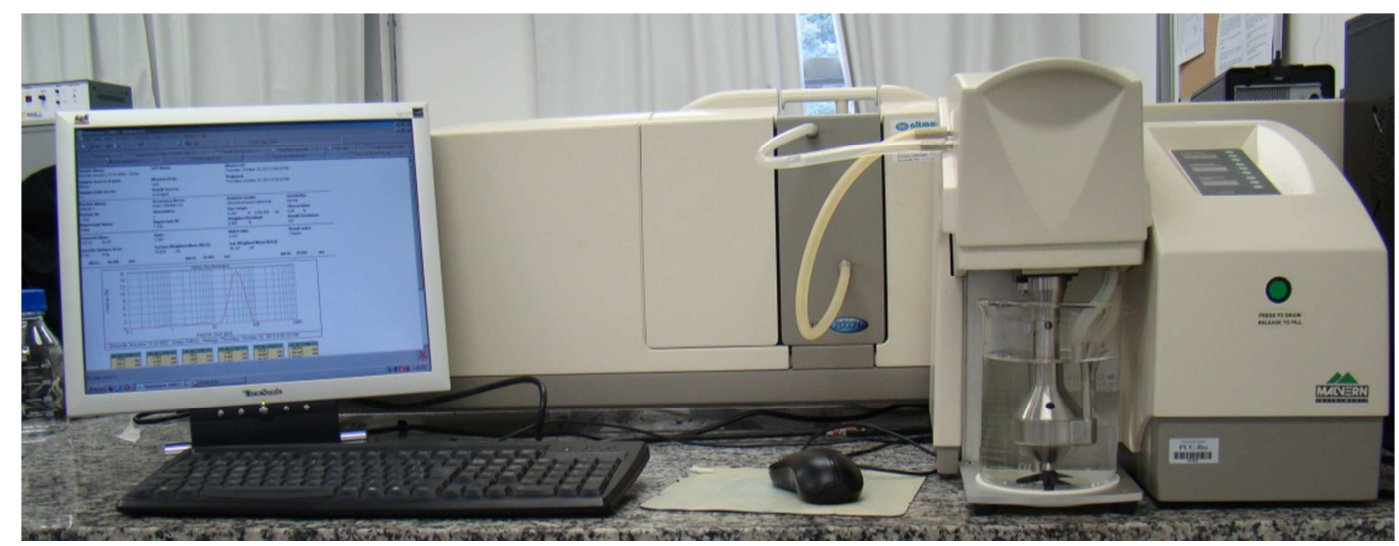

Figura 33 - Vista do Mastersizer 2000 e a direita, o Hydro2000MU.

Entre as duas tomadas de pressão e os pontos para coleta de amostra encontra-se uma peça especialmente projetada e fabricada para alojar os diferentes orifícios que foram utilizados durante os experimentos. Como o objetivo do trabalho era avaliar restrições com diâmetros e comprimentos diferentes, buscouse uma solução que permitisse esta flexibilidade sem a necessidade de grandes intervenções na bancada, e uso de material. A opção construtiva escolhida foi a do alojador com insertos de orifícios, pois este permitia que apenas os orifícios fossem alterados permitindo no futuro, que outras formas também fossem avaliadas utilizando este alojador. O projeto do alojador foi elaborado em conjunto com o Centro de Pesquisa da Petrobras. Na Figura 34 está, em ordem, a sequência das peças que compõem o conjunto alojador/orifício: Porca da união, batente do inserto, inserto de orifício e alojamento do inserto; e na Figura 35, um desenho esquemático com a montagem e o corte do alojador.
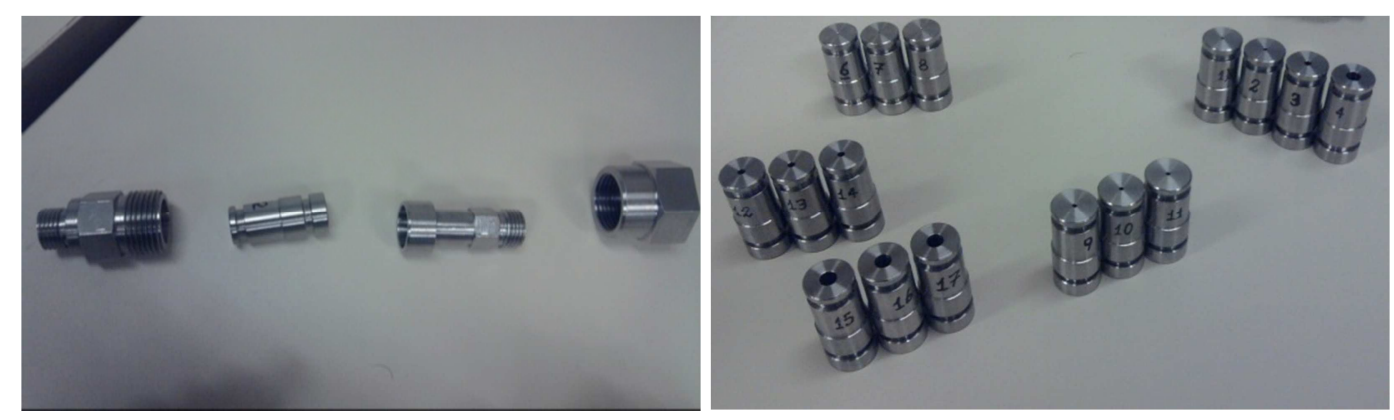

Figura 34 - À esquerda, as peças que compõem o conjunto alojador/orifício, e à direita os orifícios disponíveis para utilização no experimento. 

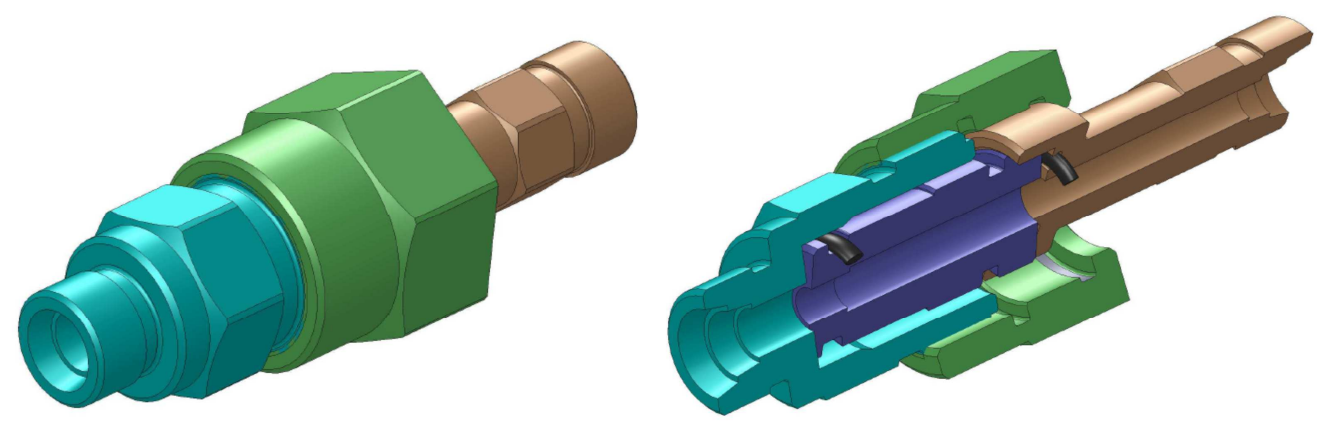

Figura 35 - Montagem do alojador com orifício, com corte representativo. $O$ orifício é a peça azul escura mostrada no corte.

Para a execução dos experimentos foi solicitada a fabricação de dezessete orifícios com características de diâmetro e comprimento conforme a Tabela 5, além da peça no5 que tinha como especificação um diâmetro de $0,1 \mathrm{~mm}$ e comprimento de 1,0 mm. Esta última não pode ser construída por conta das limitações de equipamento para a execução do furo no diâmetro solicitado dentro da margem de erro de 5\%. Logo, dezesseis orifícios estiveram disponíveis para a realização dos experimentos. As características de diâmetro e comprimento destes orifícios são indicadas na Tabela 5.

\section{Tabela 5 - Características dos Orifícios Construídos}

\begin{tabular}{|c|c|c|c|c|}
\hline $\begin{array}{c}\text { Diâmetro } \\
(\mathrm{mm})\end{array}$ & \multicolumn{4}{|c|}{ Comprimento (mm) } \\
\cline { 2 - 5 } & 30 & 10 & 5 & 1 \\
\hline 0,5 & Peça 1 & Peça 6 & Peça 7 & Peça 8 \\
\hline 1 & Peça 2 & Peça 9 & Peça 10 & Peça 11 \\
\hline 2 & Peça 3 & Peça 12 & Peça 13 & Peça 14 \\
\hline 4 & Peça 4 & Peça 15 & Peça 16 & Peça 17 \\
\hline
\end{tabular}

Os desenhos construtivos dos orifícios, com todas as cotas e as características de entrada e saída, são mostrados na Figura 36. Nesta figura, dois tipos de orifício são mostrados, os que têm comprimento de $30 \mathrm{~mm}$, peça da esquerda, e os com comprimento inferior a este valor. Nos desenhos, as cotas A e C referem-se ao diâmetro da restrição, e a cota B ao comprimento do orifício quando este é menor que $30 \mathrm{~mm}$. 

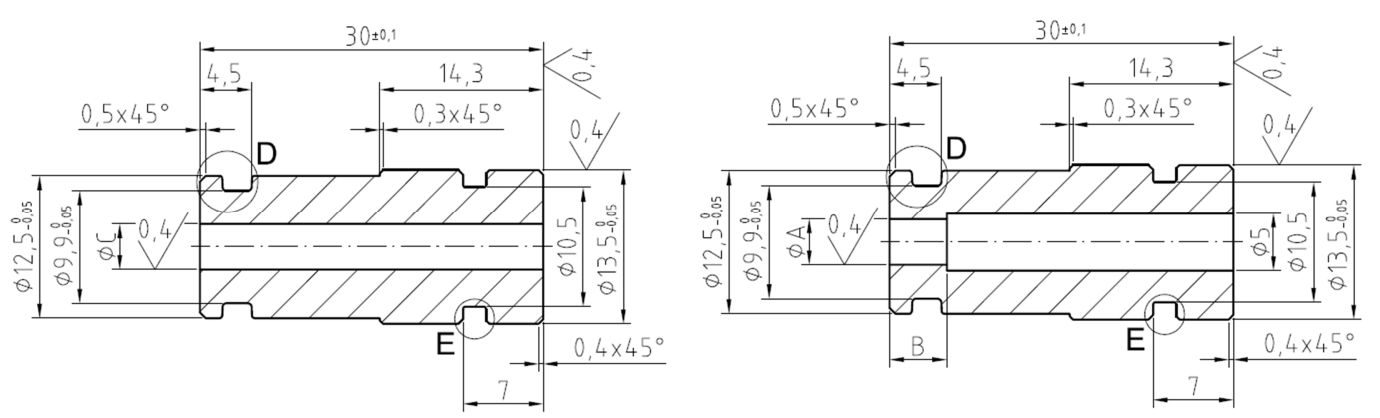

Figura 36 - Projeto dos Orifícios construídos, com as cotas em mm. As cotas A e C referem-se aos diâmetros utilizados e a $\mathrm{B}$ aos comprimentos menores de $30 \mathrm{~mm}$.

Apesar da disponibilidade de utilizar dezesseis orifícios, apenas quatro foram utilizados para obtenção dos dados de tamanho de gotas. Isto ocorreu ou devido às limitações do equipamento, ou por opção do executante com fins de avaliar uma determinada zona de valores de pressão e vazão. O detalhamento dos orifícios escolhidos e os motivos para estas escolhas serão discutidos mais a frente neste trabalho.

Após o alojador, no final da tubulação de aço inox do circuito, foi colocada uma válvula para fechamento do sistema após a parada da injeção. Verificou-se que este procedimento era fundamental para evitar a despressurização de todo o sistema, principalmente do circuito da emulsão concentrada, pois aumentava o tempo necessário para reinício da injeção de emulsão e, principalmente, causava a perda da emulsão para o tanque de descarte. Os procedimentos para a coleta de amostras e operação da bancada serão mostrados mais adiante neste trabalho. $\mathrm{Na}$ Figura 37, é possível observar toda a bancada experimental, desde o ponto de mistura dos dois circuitos, de água e de emulsão, até a saída para o tanque de descarte. 


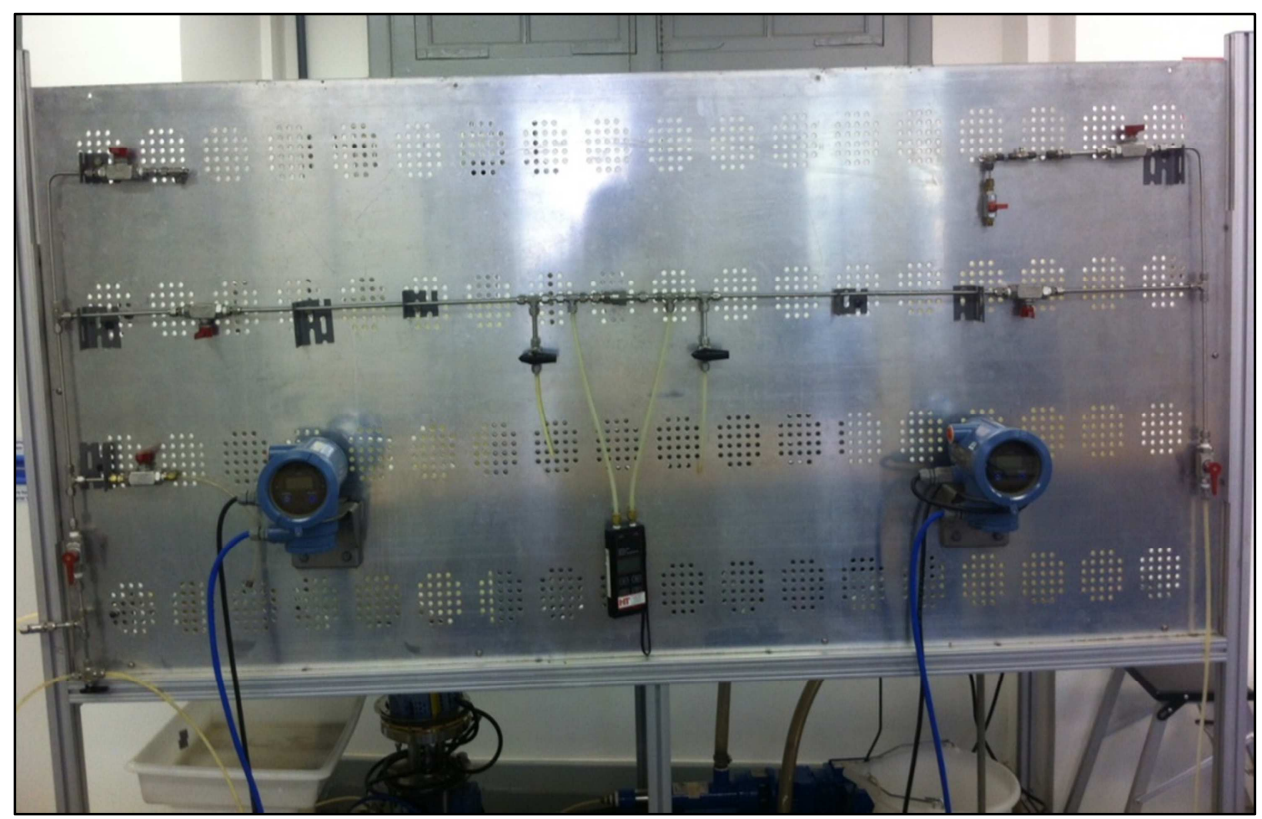

Figura 37 - Visão da bancada desde o ponto de mistura, canto inferior esquerdo, até a válvula de fechamento, canto direito, passando pelos pontos de amostragem, manômetro e alojador de orifícios. $O$ equipamento circular azul é o medidor de vazão.

\section{3. Fluidos}

Para a escolha do fluido que seria utilizado no experimento foi necessário atender à premissa de que o óleo deveria ter boas características para a formação de emulsão estável já que haveria um circuito específico para a injeção de emulsão concentrada. O óleo utilizado seria um óleo mineral já que este possui propriedades mais estáveis que amostras oriundas diretamente do reservatório.

O primeiro óleo escolhido foi o NH-10 da Petrobras que possui boa emulsibilidade e baixo ponto de fluidez. Posteriormente, no decorrer do experimento, decidiu-se avaliar o comportamento da quebra de gota em um óleo mais viscoso como contraponto ao óleo $\mathrm{NH}-10$, de baixa viscosidade. O óleo escolhido neste segundo momento foi o 500PS da Agecom. As características destes dois óleos em função da temperatura foram obtidas através de ensaios laboratoriais e estão representadas na Tabela 6. 
Tabela 6 - Propriedades dos Óleos NH-10 e 500PS.

\begin{tabular}{|c|c|c|c|c|c|c|}
\hline & \multicolumn{2}{|c|}{$\begin{array}{c}\text { Viscosidade } \\
\text { Cinemática }\left(\mathrm{mm}^{2} / \mathrm{s}\right)\end{array}$} & \multicolumn{2}{c|}{$\begin{array}{c}\text { Massa Específica } \\
(\mathrm{g} / \mathrm{ml})\end{array}$} & \multicolumn{2}{c|}{$\begin{array}{c}\text { Tensão Superficial } \\
(\mathrm{mN} / \mathrm{m})\end{array}$} \\
\hline $\mathrm{T}\left({ }^{\circ} \mathrm{C}\right)$ & NH-10 & $500 \mathrm{PS}$ & NH-10 & $500 \mathrm{PS}$ & NH-10 & $500 \mathrm{PS}$ \\
\hline 20 & 24,06 & 302,7 & 0,8925 & 0,8854 & 29,5 & 30,2 \\
\hline 25 & 19,06 & 218,1 & 0,8890 & 0,8822 & 29,6 & 30,3 \\
\hline 30 & 15,57 & 159,0 & 0,8858 & 0,8787 & 29,7 & 30,8 \\
\hline
\end{tabular}

O passo seguinte à escolha do óleo foi desenvolver uma metodologia para a formação de emulsão a partir das amostras disponíveis. Como o procedimento experimental previa que a emulsão concentrada fosse injetada na corrente principal com água, era importante que esta emulsão fosse do tipo óleo em água (O/A) a fim de que não houvesse a inversão da emulsão após a mistura com a corrente de água.

Foram analisadas três relações óleo/água diferentes para verificar qual apresentaria melhor estabilidade e manteria a característica de emulsão O/A. As relações volumétricas óleo/água analisadas foram: 30/70, 50/50 e 70/30. Apenas para o óleo NH-10 foi feita esta sensibilidade. Foi utilizado o surfactante Dodecil sulfato de sódio (SDS) por ser hidrofílico e, consequentemente, tender a gerar emulsões O/A. A primeira concentração proposta para o SDS foi a de 3,2 g/l de água, que é maior que a concentração micelar crítica (CMC) do SDS que é igual a 2,4 g/l, porém durante o preparo foi observada a formação de uma grande quantidade de espuma. A utilização de uma quantidade de surfactante superior à CMC teve como função, garantir que possíveis perdas de surfactante durante o preparo e separação da amostra, não impactassem a estabilidade da amostra. Por conta da grande quantidade de espuma, reduziu-se o teor de SDS para 1,5 g/l, valor menor que a $\mathrm{CMC}$, para verificar se haveria redução de espuma e se a emulsão continuaria estável.

As três emulsões foram preparadas segundo a ordem listada e parte de cada amostra foi posta no microscópio para verificar se a emulsão era O/A ou A/O. Na Figura 38 estão ilustradas as emulsões nos três teores preparados vistas pelo microscópio. 

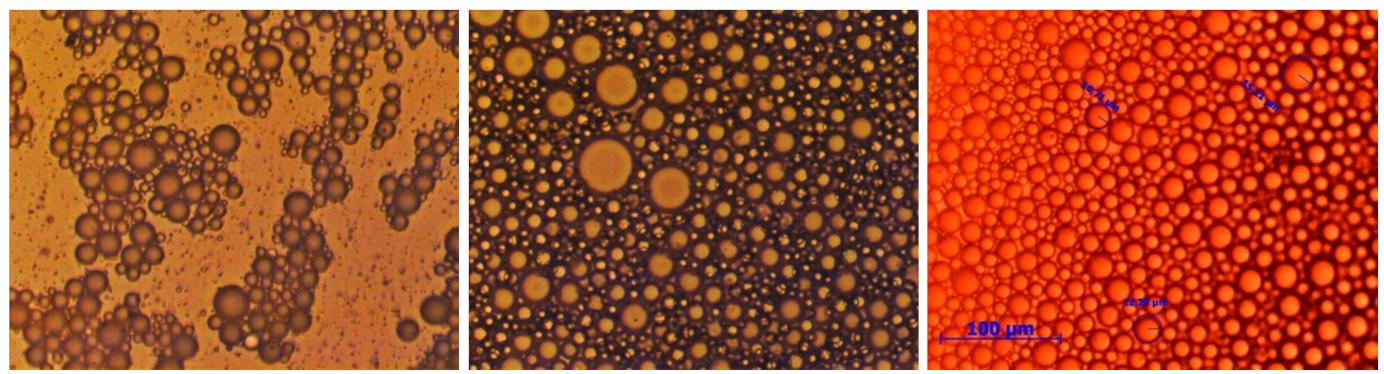

Figura 38 - Emulsões O/A preparadas para avaliação de estabilidade. Os teores volumétricos óleo/água ilustrados são 30/70, 50/50 e 70/30.

As três amostras apresentaram característica de emulsão O/A e depois do preparo foram postas no funil de separação para que, após repouso, fosse retirada a água livre e assim fosse obtida a emulsão concentrada. Foi observada também, boa estabilidade após semanas em repouso, mesmo com a redução do teor de SDS, tendo sido escolhida então, a emulsão com relação óleo/água 50/50 para garantir que não haveria mudança nas propriedades. A Figura 39 mostra a emulsão no funil de separação com água livre no fundo e a emulsão concentrada ainda estável vinte dias após a drenagem da água livre.
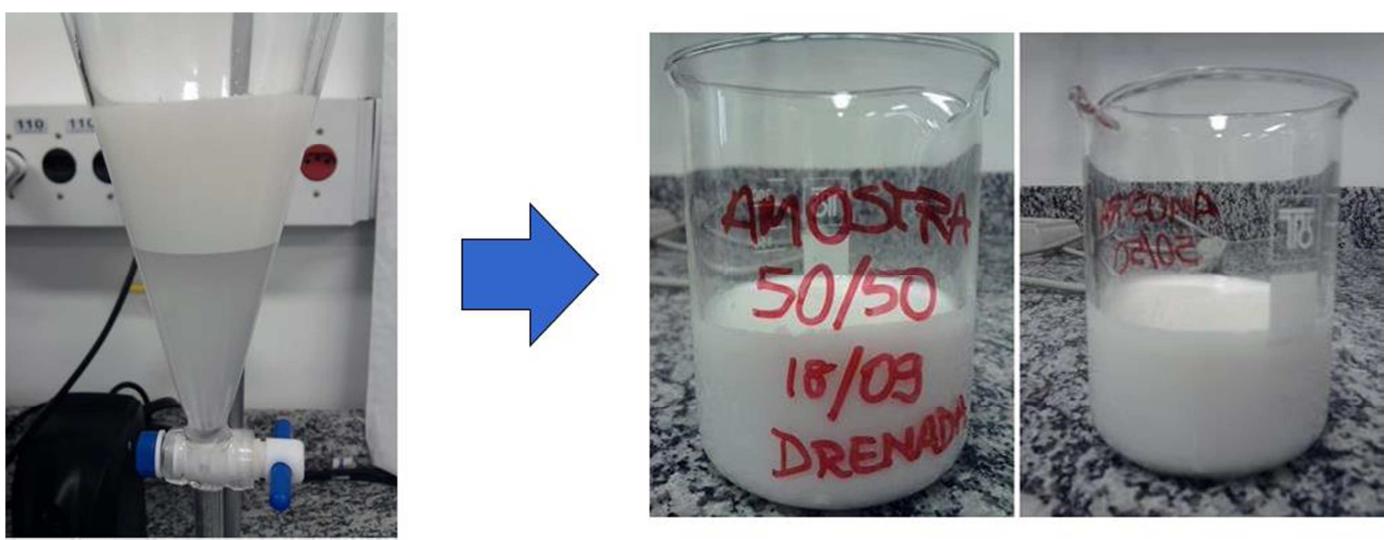

Figura 39 - Emulsão com a água livre totalmente segregada e verificação de estabilidade da amostra 20 dias após a drenagem.

O passo seguinte era estabelecer um tempo e intensidade de agitação para obtenção do tamanho de gotas desejado para a realização do teste. Os tamanhos de gotas d(0,9) desejados na avaliação eram 60 e $100 \mu \mathrm{m}$. As primeiras análises foram feitas em amostras de emulsão com $500 \mathrm{ml}$, porém os tempos obtidos nestas análises mostraram-se inadequados para o preparo de volumes maiores, da ordem de 1,5 1, pois a quantidade de fluido presente no bécher não era misturada adequadamente já que o Ultrarrax, que é o aparelho para misturar o óleo e a água, 
não tem bom alcance de mistura em toda a profundidade da amostra. Para que houvesse uma homogeneização na mistura da amostra era necessário a cada intervalo de tempo determinado alterar a posição vertical do Ultrarrax. Isto foi considerado, um procedimento ruim, pois aumentaria as variáveis no processo de mistura da emulsão podendo assim comprometer a repetibilidade do método.

Para solucionar este problema, a emulsão que seria separada foi dividida em três volumes iguais de $500 \mathrm{ml}$, e cada parte foi submetida separadamente à agitação do Ultrarrax dentro de um bécher de 21 . O uso deste recipiente com volume muito superior ao necessário objetivou utilizar a potencialidade do Ultrarrax que é a mistura no sentido radial, ou seja, do centro para a borda. Como o volume de emulsão era muito menor, a altura de líquido no bécher era a suficiente para que ocorresse a mistura sem a necessidade de alterar a posição do equipamento.

O tempo e intensidade de agitação encontrados para o óleo NH-10 após este procedimento foram: 3 minutos com rotação a $6500 \mathrm{rpm}$ para emulsões com gotas pequenas $\left(d_{90}=60 \mu \mathrm{m}\right)$ e, 20 segundos com a mesma rotação, para emulsões com gotas maiores $\left(\mathrm{d}_{90}=100 \mu \mathrm{m}\right)$. Para o óleo 500PS os valores encontrados foram: 3 minutos com rotação a $13500 \mathrm{rpm}$, para o caso com gotas pequenas e, o mesmo tempo de rotação a $9500 \mathrm{rpm}$ para as emulsões com gotas de $100 \mu \mathrm{m}$. As informações com os tempos e intensidades determinados acima estão consolidadas na Tabela 8 .

As condições de agitação acima geraram, após drenagem da água livre, emulsões concentradas com boa estabilidade, não tendo sido observada a presença de óleo livre, nem alteração na distribuição do tamanho de gotas até o momento da utilização da amostra no circuito experimental.

Após a determinação do tempo e intensidade de rotação foi possível estabelecer um procedimento para o preparo das emulsões consolidando todas as observações e lições aprendidas citadas acima. No item a seguir será apresentado o procedimento consolidado, com todos os equipamentos e valores utilizados para a formação de 1,5 1 de emulsão concentrada e medição do tamanho de gotas.

Para a realização dos ensaios foram geradas, inicialmente, amostras para testar o procedimento de preparo da emulsão, seja a quantidade de surfactante ou o tamanho final da gota. Para o óleo NH-10 cinco amostras foram preparadas para a realização destes testes. Já com o 500PS foram necessárias quatro amostras para 
ajustar o tempo e intensidade de rotação para obter o tamanho de gotas desejado. Após a realização dos testes, foram geradas dezoito amostras de emulsão concentrada para uso na bancada experimental, sendo quatorze do óleo NH-10 e quatro do 500PS.

Vale ressaltar, que algumas das amostras do NH-10 não geraram resultado no experimento, duas por conta da significativa presença de óleo livre quando a configuração do cilindro previa saída da emulsão pela parte superior deste, e três que geraram resultados inconclusivos tendo sido necessária a repetição da avaliação do orifício em questão.

$\mathrm{Na}$ Tabela 7 estão representadas as emulsões concentradas utilizadas nos experimentos com resultados validados, com a indicação do tipo de tamanho de gotas e o teor água/óleo $(\mathrm{A} / \mathrm{O})$ da emulsão concentrada. Este teor $\mathrm{A} / \mathrm{O}$ foi calculado através de uma relação volumétrica após a drenagem da água livre resultante do tempo de segregação.

Tabela 7 - Emulsões concentradas utilizadas no experimento

\begin{tabular}{|c|c|c|c|}
\hline Óleo & $\mathrm{N}^{\mathrm{o}}$ da Amostra & Teor A/O & Tipo de Gota \\
\hline \multirow{9}{*}{ NH-10 } & 5 & $24 / 76$ & Pequena \\
\hline & 6 & $20 / 80$ & Grande \\
\hline & 8 & $20 / 80$ & Grande \\
\hline & 9 & $20 / 80$ & Pequena \\
\hline & 10 & $21 / 79$ & Grande \\
\hline & 11 & $24 / 76$ & Pequena \\
\hline & 12 & $20 / 80$ & Grande \\
\hline & 13 & $24 / 76$ & Pequena \\
\hline & 18 & $20 / 80$ & Grande \\
\hline \multirow{4}{*}{ 500PS } & 14 & $19 / 81$ & Grande \\
\hline & 15 & $19 / 81$ & Pequena \\
\hline & 16 & $18 / 82$ & Grande \\
\hline & 17 & $20 / 80$ & Pequena \\
\hline
\end{tabular}

Observa-se que há um número impar de amostras utilizadas do óleo NH-10, isto se deve ao fato que foi necessário utilizar as amostras 8 e 10, de gotas grandes, para a avaliação de um orifício. Para facilitar a identificação do tamanho 
de gota da amostra adotou-se a metodologia de atribuir às emulsões com gotas pequenas $\left(\mathrm{d}_{90} \sim 60 \mu \mathrm{m}\right)$ números ímpares, e às emulsões com gotas grandes $\left(\mathrm{d}_{90} \sim 100 \mu \mathrm{m}\right)$ números pares. No item que trata sobre os resultados obtidos, será mostrada em qual orifício cada uma das amostras acima foi utilizada.

Pelos teores água/óleo verificados na tabela acima para cada um dos dois óleos pode-se afirmar que o procedimento para geração de emulsão apresentou boa repetitividade com pequeno desvio entre os teores observados. Enquanto este teor variou entre 24/76 a 20/80 no NH-10, nas amostras do óleo 500PS a variação foi ainda menor entre $20 / 80$ e $18 / 82$, o que mostra que um pouco mais de água foi incorporada pela emulsão formada a partir do NH-10.

\subsection{1.}

\section{Procedimento experimental de preparação e caracterização morfológica da emulsão concentrada}

- Separar $750 \mathrm{ml}$ de água destilada;

- Adicionar à amostra de água o surfactante SDS na concentração de 1,5 g/l de água. Utilizar a balança de precisão, mostrada na Figura 40, para determinar a massa necessária, no caso, $1,1 \mathrm{~g}$;

- Levar a solução de água e surfactante para o misturador (Figura 40) e deixar a mistura ocorrer até que a solução alcance uma aparência homogênea;

- Utilizando uma proveta, dividir igualmente a amostra de água com surfactante em três volumes de $250 \mathrm{ml}$ e colocar cada um em um recipiente de 21 ;

- Coletar $750 \mathrm{ml}$ do óleo que será utilizado e, também, separá-lo em três amostras de $250 \mathrm{ml}$, utilizando uma proveta;

- Misturar cada uma das amostras de $250 \mathrm{ml}$ de óleo a um dos recipientes de 2 litros com água;

- Levar cada recipiente de água com óleo para o Ultrarrax (Figura 40) e submeter a amostra à agitação determinada para cada tipo de óleo e tamanho de gota que deseja-se obter, conforme Tabela 8: 
Tabela 8 - Tempo e Velocidade de agitação para formação das emulsões

\begin{tabular}{|c|c|c|c|c|}
\hline \multirow{2}{*}{$\begin{array}{c}\text { Óleo } \\
\text { Utilizado }\end{array}$} & \multicolumn{2}{|c|}{ Gotas Pequenas $(60 \mu \mathrm{m})$} & \multicolumn{2}{c|}{ Gotas Grandes $(100 \mu \mathrm{m})$} \\
\cline { 2 - 5 } & Tempo (s) & Rotação (rpm) & Tempo (s) & Rotação (rpm) \\
\hline NH-10 & 180 & 6500 & 20 & 6500 \\
\hline $500 P S$ & 180 & 13500 & 180 & 9500 \\
\hline
\end{tabular}

- Após mistura da água e do óleo, colocar a emulsão formada no funil de separação. As amostras separadas anteriormente podem ser postas no mesmo funil, a depender da capacidade do mesmo;
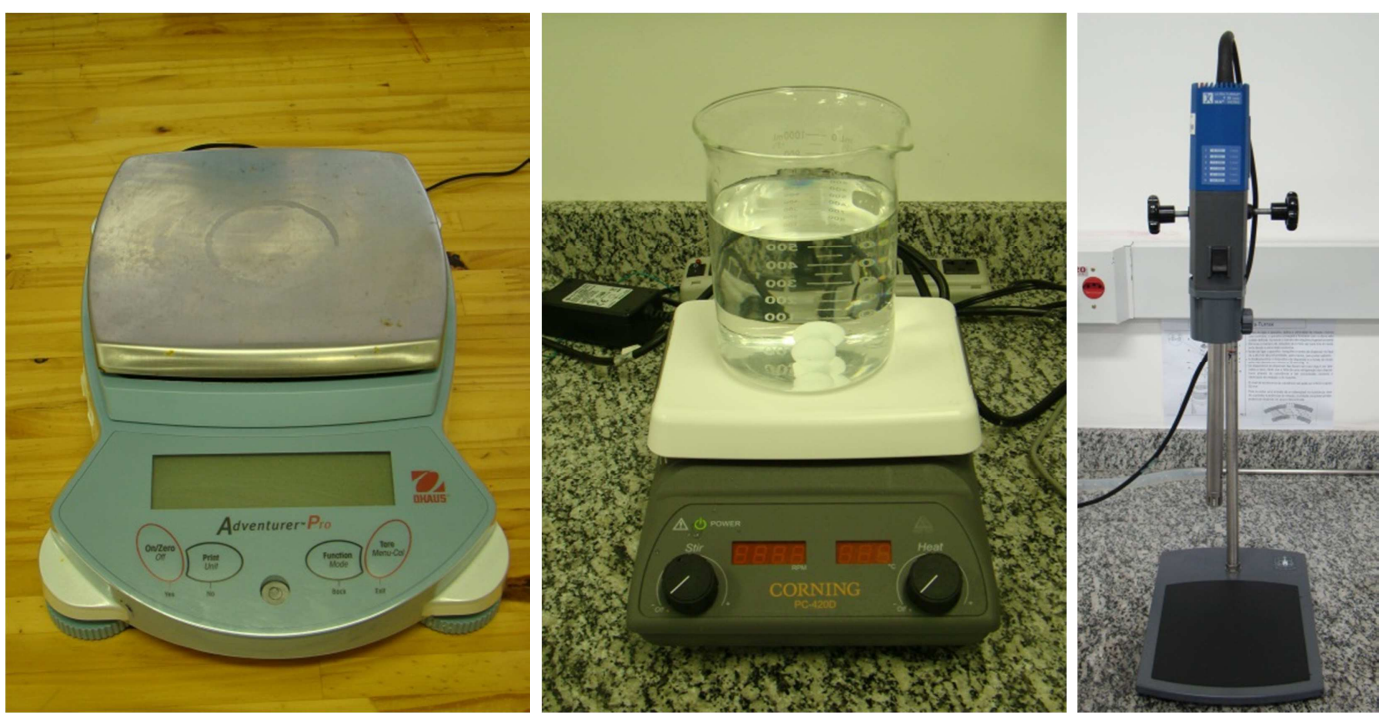

Figura 40 - Imagem dos equipamentos utilizados no procedimento de formação de emulsão - Balança de precisão, Misturador e Ultrarrax.

- Esperar a total separação entre a emulsão e a água livre. Esta estabilização normalmente se dá após 12 horas do preparo;

- Após segregação da água livre, drenar esta água e medir volume retirado para verificar teor água/óleo final da emulsão concentrada;

- Drenar a emulsão concentrada do funil em um único recipiente e leva-la ao Mastersizer 2000 para medição do tamanho de gotas;

- Medir tamanho de gotas, tomando uma amostra no topo e outra no fundo do bécher. Na Figura 41 segue medição feita no topo e no fundo para as amostras 3 e 4 ;

- Cobrir a amostra até utilização na bancada experimental. 


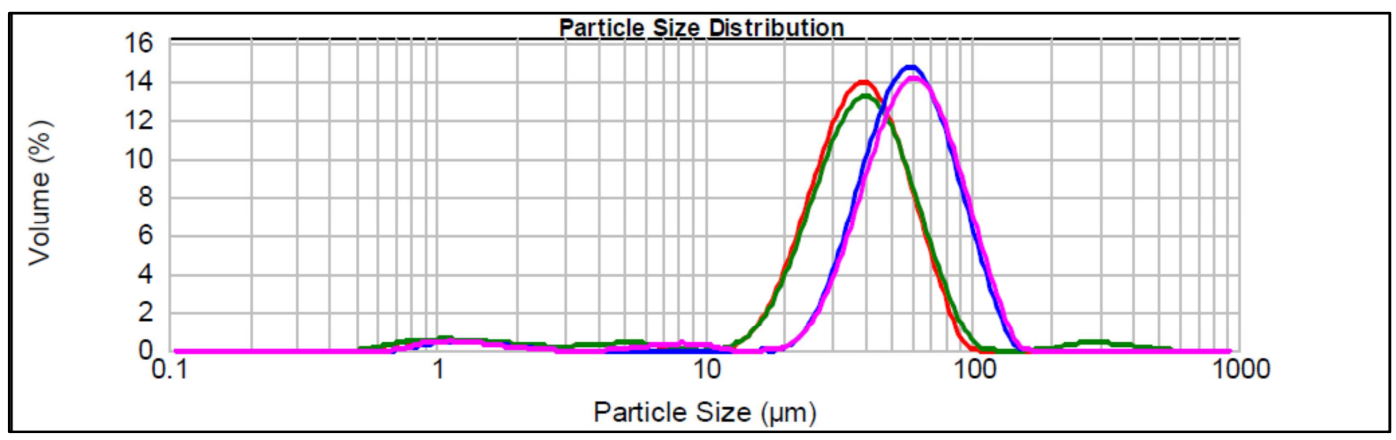

Figura 41 - Medição de tamanho de gotas. As linhas verde e vermelha são, respectivamente, as medições de fundo e topo da Amostra 3, e as linhas rosa e azul são, respectivamente, as de fundo e topo da Amostra 4. Observa-se homogeneidade nas duas amostras.

\section{4. \\ Obtenção dos Resultados}

Para geração dos resultados, primeiramente foi feita uma avaliação para verificar quais poderiam ser as vazões máximas no sistema para cada um dos orifícios construídos, a fim de que o limite de pressão diferencial do manômetro, que é de 100 psi, não fosse ultrapassado. Nesta avaliação foi utilizado o simulador de escoamento PIPESIM 2011, desenvolvido pela Schlumberger.

No modelo computacional, foram considerados os comprimentos e as condições de contorno aproximadas, pois no momento desta simulação a bancada de testes ainda não havia sido montada. Contudo, esta simulação orientou sobre quais as peças que não poderiam ser utilizadas com o limite de pressão imposto e quais seriam as mais interessantes para avaliar, pois gerariam o maior espectro de queda de pressão no orifício, e consequentemente uma faixa maior de potência dissipada. Posteriormente, durante a realização dos experimentos, observou-se uma boa concordância entre o valor de queda de pressão medido e o valor simulado computacionalmente no modelo simplificado.

Na simulação foi feita uma sensibilidade à vazão para cada tipo de orifício disponível e foi calculada a queda de pressão na restrição. O fluido utilizado para avaliação foi uma emulsão O/A com teor de óleo de 5\%. O óleo que forma a emulsão avaliada é o NH-10. Da Tabela 9 até a Tabela 12, estão indicados os valores simulados para a variação de pressão para cada orifício em função da vazão total do sistema. 
Tabela 9 - Variação de pressão, em psi; Comprimento do orifício $=30 \mathrm{~mm}$.

\begin{tabular}{|c|c|c|c|c|c|}
\hline \multirow{2}{*}{$\begin{array}{c}\text { Diâmetro } \\
(\mathrm{mm})\end{array}$} & \multicolumn{5}{|c|}{ Vazão do Sistema (1/min) } \\
\cline { 2 - 6 } & 0,25 & 0,5 & 1 & 1,5 & 2 \\
\hline 0,5 & 149,5 & 576,3 & 2780,6 & 6277,8 & 10192,6 \\
\hline 1 & 5,2 & 13,7 & 71,7 & 155,5 & 391,7 \\
\hline 2 & 1,6 & 2,1 & 4,2 & 7,8 & 19,7 \\
\hline 4 & 1,3 & 1,7 & 2,3 & 3,1 & 4,0 \\
\hline
\end{tabular}

Tabela 10 - Variação de pressão, em psi; Comprimento do orifício $=10 \mathrm{~mm}$.

\begin{tabular}{|c|c|c|c|c|c|}
\hline \multirow{2}{*}{$\begin{array}{c}\text { Diâmetro } \\
(\mathrm{mm})\end{array}$} & \multicolumn{5}{|c|}{ Vazão do Sistema (1/min) } \\
\cline { 2 - 6 } & 0,25 & 0,5 & 1 & 1,5 & 2 \\
\hline 0,5 & 54,4 & 242,2 & 946,3 & 2574,3 & 5143,4 \\
\hline 1 & 3,0 & 8,4 & 36,7 & 78,9 & 258,7 \\
\hline 2 & 1,2 & 1,8 & 3,6 & 6,0 & 15,8 \\
\hline 4 & 1,2 & 1,7 & 2,3 & 3,0 & 4,0 \\
\hline
\end{tabular}

Tabela 11 - Variação de pressão, em psi; Comprimento do orifício $=5 \mathbf{m m}$.

\begin{tabular}{|c|c|c|c|c|c|}
\hline \multirow{2}{*}{$\begin{array}{c}\text { Diâmetro } \\
(\mathrm{mm})\end{array}$} & \multicolumn{5}{|c|}{ Vazão do Sistema (1/min) } \\
\cline { 2 - 6 } & 0,25 & 0,5 & 1 & 1,5 & 2 \\
\hline 0,5 & 36,5 & 156,3 & 609,9 & 1603,3 & 3656,5 \\
\hline 1 & 2,6 & 7,1 & 27,8 & 59,7 & 225,5 \\
\hline 2 & 1,2 & 1,7 & 3,4 & 5,5 & 14,9 \\
\hline 4 & 1,2 & 1,6 & 2,3 & 3,0 & 3,9 \\
\hline
\end{tabular}

Tabela 12 - Variação de pressão, em psi; Comprimento do orifício = $1 \mathrm{~mm}$.

\begin{tabular}{|c|c|c|c|c|c|}
\hline \multirow{2}{*}{$\begin{array}{c}\text { Diâmetro } \\
(\mathrm{mm})\end{array}$} & \multicolumn{5}{|c|}{ Vazão do Sistema (1/min) } \\
\cline { 2 - 6 } & 0,25 & 0,5 & 1 & 1,5 & 2 \\
\hline 0,5 & 20,9 & 91,0 & 356,4 & 795,1 & 2449,8 \\
\hline 1 & 1,5 & 6,1 & 21,2 & 45,2 & 200,4 \\
\hline 2 & 1,3 & 1,7 & 3,3 & 5,2 & 14,2 \\
\hline 4 & 1,3 & 1,6 & 2,3 & 3,0 & 3,9 \\
\hline
\end{tabular}


Esta avaliação através da simulação computacional não foi feita para o óleo 500PS, pois mesmo sendo um óleo muito mais viscoso que o NH-10, a influência deste na viscosidade da mistura que circula na bancada experimental é muito pequena visto que a concentração volumétrica do óleo no fluido após a junção dos dois circuitos de injeção fica entre 3 e $5 \%$.

Através dos resultados das simulações acima, observou-se que não seria possível avaliar um orifício com diâmetro de $0,5 \mathrm{~mm}$ se o comprimento do orifício fosse $30 \mathrm{~mm}$. Como se desejava verificar o comportamento de quebra neste diâmetro, já que ele é apenas cinco vezes maior que o $\mathrm{d}_{90}$ da emulsão com gota maior, foi escolhido o orifício com comprimento de $10 \mathrm{~mm}$ (Orifício $\mathrm{n}^{\circ}$ 6), pois permitiria a avaliação da quebra de gotas em vazões reduzidas.

Outros orifícios escolhidos variavam o diâmetro, porém com mesmo comprimento. Foram escolhidas as peças 9 e 12 que possuíam diâmetro de 1,0 e 2,0 $\mathrm{mm}$ respectivamente. Após a escolha destes três orifícios, buscou-se avaliar o impacto do comprimento do orifício e optou-se pelo Orifício $\mathrm{n}^{\circ} 11$ que possui diâmetro e comprimento de 1,0 mm. A preferência pelo orifício com diâmetro de 1,0 mm se deu pelo fato de que este diâmetro era o que permitia, dado as limitações dos equipamentos, a maior faixa de vazão e de queda de pressão.

As primeiras avaliações foram feitas com as emulsões geradas a partir do óleo NH-10. Somente após as primeiras observações que foram utilizadas as amostras preparadas com o óleo 500PS. Estas amostras foram avaliadas apenas nas peças 9 e 11, tiveram seu comportamento de quebra de gotas comparado como o observado nas amostras com NH-10.

Para cada orifício escolhido era gerada uma matriz de teste que continha de três a cinco pontos para avaliar a variação da distribuição do tamanho das gotas da fase dispersa após passagem pelo orifício em diferentes vazões. Em cada ponto são indicados as vazões de injeção da emulsão, da água e o somatório destes dois valores. Nas tabelas 13 a 19 estão representadas as matrizes para cada orifício, e as emulsões que foram testadas nele. 
Tabela 13 - Matriz de teste do orifício no 6 - Amostras 5 e 6 (Óleo NH-10).

\begin{tabular}{|c|c|c|}
\hline Q Emulsão (ml/min) & Q Água (ml/min) & Q Total (ml/min) \\
\hline 20 & 292 & 312 \\
\hline 15 & 219 & 234 \\
\hline 10 & 146 & 156 \\
\hline
\end{tabular}

Tabela 14 - Matriz de teste do orifício no 9 - Amostra 9 (Óleo NH-10).

\begin{tabular}{|c|c|c|}
\hline Q Emulsão (ml/min) & Q Água (ml/min) & Q Total (ml/min) \\
\hline 48 & 1232 & 1280 \\
\hline 39 & 1001 & 1040 \\
\hline 30 & 770 & 800 \\
\hline 15 & 385 & 400 \\
\hline
\end{tabular}

Tabela 15 - Matriz de teste do orifício no 9 - Amostra 8 (Óleo NH-10).

\begin{tabular}{|c|c|c|}
\hline Q Emulsão (ml/min) & Q Água (ml/min) & Q Total (ml/min) \\
\hline 48 & 1232 & 1280 \\
\hline 39 & 1001 & 1040 \\
\hline 30 & 770 & 800 \\
\hline
\end{tabular}

Tabela 16 - Matriz de teste do orifício no 9 - Amostra 10 (Óleo NH-10).

\begin{tabular}{|c|c|c|}
\hline Q Emulsão (ml/min) & Q Água (ml/min) & Q Total (ml/min) \\
\hline 30 & 770 & 800 \\
\hline 24 & 616 & 640 \\
\hline 15 & 385 & 400 \\
\hline
\end{tabular}


Tabela 17 - Matriz de teste do orifício no 12 - Amostras 11 e 12 (Óleo NH-10).

\begin{tabular}{|c|c|c|}
\hline Q Emulsão (ml/min) & Q Água (ml/min) & Q Total (ml/min) \\
\hline 80 & 1920 & 2000 \\
\hline 70 & 1680 & 1750 \\
\hline 60 & 1440 & 1500 \\
\hline 40 & 960 & 1000 \\
\hline
\end{tabular}

Tabela 18 - Matriz de teste do orifício no 11 - Amostras 13 e 18 (Óleo NH-10), e Amostras 15 e 16 (Óleo 500PS).

\begin{tabular}{|c|c|c|}
\hline Q Emulsão (ml/min) & Q Água (ml/min) & Q Total (ml/min) \\
\hline 60 & 1540 & 1600 \\
\hline 51 & 1309 & 1360 \\
\hline 42 & 1078 & 1120 \\
\hline 30 & 770 & 800 \\
\hline 18 & 462 & 480 \\
\hline
\end{tabular}

Tabela 19 - Matriz de teste do orifício no 9 - Amostras 14 e 17 (Óleo 500PS).

\begin{tabular}{|c|c|c|}
\hline Q Emulsão (ml/min) & Q Água (ml/min) & Q Total (ml/min) \\
\hline 48 & 1232 & 1280 \\
\hline 39 & 1001 & 1040 \\
\hline 30 & 770 & 800 \\
\hline 24 & 616 & 640 \\
\hline 15 & 385 & 400 \\
\hline
\end{tabular}

Observa-se que a matriz proposta para a amostra 10 é uma complementação à proposta para a amostra 8. Isto porque durante a coleta de amostras para medição do tamanho de gotas, ocorreu uma inconformidade nos resultados da medição e os pontos tiveram que ser avaliados novamente. Com a nova avaliação, não havia volume de amostra suficiente para varrer toda a matriz proposta inicialmente. Por isso, foi necessário utilizar uma nova emulsão, com características similares, para completar a avaliação da quebra de gotas em emulsões com gotas grandes no orifício $\mathrm{n}^{\circ} 9$. 
Um ponto relevante nas matrizes é que as mesmas foram geradas prevendo a redução da vazão de um ponto para outro. Esta configuração objetivava reduzir o tempo necessário para a coleta das amostras e o volume de fluido que seria descartado. A redução do tempo do experimento ocorre, pois o número de operações de pressurização do sistema de injeção de emulsão é diminuído. Esta operação na linha de emulsão é muito demorada, e para cada ponto com aumento de vazão seria necessário aguardar a pressurização deste sistema. Com a progressão decrescente da vazão, apenas uma única operação de pressurização seria realizada, e nas demais vazões, a equalização entre os dois sistemas de injeção ocorreria de maneira mais rápida, já que a pressão requerida na junção dos circuitos diminuiria e a redução de pressão na linha de emulsão ocorreria de forma muito rápida.

Para cada ponto avaliado nas matrizes acima eram lidos cinco valores de pressão diferencial. Este procedimento visava reduzir o erro na leitura deste parâmetro. A média destes valores era combinada com a vazão total para calcular a potência dissipada no orifício sob uma determinada condição de escoamento.

Apenas após a leitura dos valores de queda de pressão que as amostras eram coletadas para avaliação do tamanho de gotas. A coleta se dava primeiro pelo ponto a jusante do orifício e depois no ponto a montante. Desta forma buscava-se que as coletas de amostra ocorressem sem causar impacto nas condições de escoamento impostas. Isto porque a realização da amostragem impacta todo o sistema a jusante do ponto de coleta. Caso a amostragem fosse feita primeira pelo ponto a montante do orifício, seria necessário aguardar o reequilíbrio do sistema, pois os sistemas de injeção não enxergariam a barreira de pressão no orifício, ocasionando uma queda na pressão de injeção da emulsão.

Nos itens a seguir serão apresentados os procedimentos desenvolvidos para a operação da bancada experimental com coleta de amostra, e para a medição do tamanho de gotas no Mastersizer 2000. 


\subsection{1. Procedimento para operação da bancada experimental e coleta de amostras}

- Para partida do sistema todas as válvulas devem estar abertas, exceto a válvula de saída do sistema, instalada no final do circuito experimental;

- Ligar a bomba de emulsão e, se necessário, encher o cilindro da bomba com água através da operação Refil do controlador. Para realizar esta operação é necessário fechar a válvula que conecta o cilindro da bomba com o cilindro da emulsão e abrir a válvula que é conectada ao reservatório de água.

- Após o término da operação de Refil, trocar as condições das válvulas do item anterior;

- Ligar a bomba de água;

- Abrir a válvula de saída do sistema em até $5 \mathrm{~s}$;

- Ajustar a rotação da bomba de água para obter a vazão desejada;

- Verificar a pressão que está indicada no manômetro. Se for superior a 100 psi, deve-se reduzir a vazão ou desligar para limpar o orifício.

- Regular no controlador a vazão desejada na bomba de emulsão e parti-la;

- Aguardar equalização de pressão do circuito de injeção de água e de injeção de emulsão;

- Ao equalizar a pressão, poderá ser visto pela mangueira transparente a montante da check valve, o início da injeção de emulsão concentrada;

- Após o início da injeção da emulsão, tomar cinco valores de pressão no manômetro;

- Coletar as amostras de fluido em recipientes separados para medição do tamanho de gotas;

- A coleta das amostras deve ser feita primeiramente no ponto a jusante do orifício, e depois no ponto a montante;

- Após a coleta, desligar a bomba de emulsão;

- Fechar a válvula de saída do sistema; 
- Desligar a bomba de água em até $5 \mathrm{~s}$ para evitar a pressurização excessiva do sistema.

O segundo e o terceiro itens do procedimento podem ser dispensados se for verificado pelo display da bomba de seringa, que ainda há um volume disponível para efetuar a avaliação do próximo ponto. Para estimativa da quantidade necessária de emulsão para uma avaliação, considerar que a emulsão será injetada durante 5 minutos, que é o tempo de estabilização do sistema, leitura das pressões e coleta das amostras.

\subsection{2.}

\section{Procedimento para medição do tamanho de gotas no Mastersizer 2000}

- Após desligamento da bancada experimental, proceder imediatamente a medição do tamanho de gotas;

- Colocar um bécher de vidro de $1000 \mathrm{ml}$, com um volume aproximado de $700 \mathrm{ml}$ de agua destilada, na unidade de dispersão e bombeio Hydro 2000MU;

- Habilitar a janela de medição Manual do software do Mastersizer 2000 e realizar o procedimento de Measure Background;

- Verificar se a intensidade do laser está acima de $80 \%$. Durante as medições, o limite mínimo da intensidade é 70\%;

- Adicionar, através de um conta-gotas, a amostra coletada ao bécher com água. A amostra deve ser posta na água até que o nível de obscurecimento do laser fique entre 5 e $20 \%$;

- Proceder a leitura do tamanho de gotas. O programa irá medir automaticamente a mesma amostra três vezes e gerará a média das três medidas. Para os ajustes e análises do experimento, utilizou-se a média gerada;

- Realizar, em outro bécher, a medida do tamanho de gotas da outra amostra coletada. Para isso, repetir o Measure Background, verificando a intensidade do laser, e adicionar a nova amostra até o obscurecimento indicado; 
- Se a intensidade do laser estiver menor que $70 \%$ após o Measure Background, será necessário trocar a água do bécher. Se não for suficiente para a intensidade retornar ao valor de $80 \%$, será preciso limpar o equipamento ótico;

- Repetir o procedimento de medição do tamanho de gotas mais duas vezes para cada amostra.

Para cada amostra coletada, a medição do tamanho de gotas foi feita três vezes de forma alternada entre as duas amostras. Isto visa reduzir erros devido a um procedimento de coleta da amostra inadequado com o conta-gotas, aumentando assim a confiança nos resultados obtidos. O procedimento de medição não deve ser interrompido, ou seja, as seis medições devem ser realizadas em sequência.

Vale ressaltar que a repetição da leitura do tamanho de gotas não está relacionada às três medições automáticas realizadas pelo Mastersizer 2000 para obtenção da média. Cada média gerada é considerada uma leitura efetuada.

Ao realizar três leituras, é possível verificar a estabilidade da amostra ao longo do tempo da medição através das três médias do tamanho de gotas disponíveis. Todo o procedimento de medição do tamanho de gotas, considerando as seis leituras totais, três para cada amostra, leva aproximadamente 30 minutos. 


\section{4 \\ Resultados Experimentais}

Neste capítulo serão apresentados os resultados obtidos nos experimentos conduzidos com base nas condições de escoamento propostas no capítulo anterior. Serão mostrados os tamanhos de gota resultantes do processo de quebra, nas condições apresentadas nas matrizes de teste indicadas no capítulo anterior. Por fim, será apresentado o melhor ajuste obtido para representar a quebra de gotas dos dois óleos nas condições de escoamento utilizadas.

\section{1. Resultados Obtidos}

Como mencionado, os experimentos foram conduzidos em um primeiro instante com as emulsões formadas a partir do óleo NH-10 nos orifícios $n^{\circ} 6,9,12$ e 11. Posteriormente, para avaliar a influência da viscosidade no processo de quebra de gotas, foram testadas as emulsões do óleo 500PS nas peças $\mathrm{n}^{\circ} 9$ e 11 . As tabelas a seguir mostram, para cada óleo e orifício testado, as leituras de pressão feitas para as condições de escoamento apresentadas no item 3.4, e a distribuição do tamanho de gotas das emulsões após a quebra. Os resultados serão apresentados na ordem em que foram obtidos.

\subsection{1. \\ Óleo $\mathrm{NH}-10$}

\subsubsection{1. \\ Orifício n6 ( $D=0,5 \mathrm{~mm} / \mathrm{L}=10 \mathrm{~mm})$}

Na Tabela 20 e na Tabela 21 são mostrados os resultados de queda de pressão lidos para as duas emulsões. Foi elaborada também a Tabela 22 com o cálculo da Potência dissipada, do número de Reynolds no duto e no orifício para cada uma das condições de vazão e queda de pressão, e o valor do d50 obtido pelo 
Mastersizer 2000 para as condições de tanque, que é o tamanho de gotas após o preparo, para o ponto antes do orifício e após a passagem do orifício.

A potência dissipada, $\mathrm{P}$, pode ser calculada conforme a Eq. 20, abaixo:

$$
\mathrm{P}=\mathrm{Q} \cdot \Delta \mathrm{p}
$$

Onde Q é a vazão total do sistema e $\Delta p$ é a variação de pressão sofrida pelo fluido durante a passagem no orifício. Como a vazão do sistema é dada em $\mathrm{ml} / \mathrm{min}$ e a variação de pressão em psi, faz-se necessária a adição de um termo à Eq. 20 para adequação da unidade da potência ao SI. Logo esta equação pode ser reescrita da seguinte forma:

$$
\mathrm{P}(\mathrm{W})=1,15 \times 10^{-4} \cdot \mathrm{Q}(\mathrm{ml} / \mathrm{min}) \cdot \Delta \mathrm{p}(\mathrm{psi})
$$

Já para o cálculo do Reynolds, tanto no duto quanto no orifício, é utilizada a fórmula apresentada na Eq. 22:

$$
\operatorname{Re}=\frac{\rho_{\mathrm{m}} \cdot \mathrm{U} \cdot \mathrm{d}}{\mu_{\mathrm{m}}}
$$

Onde $\rho_{\mathrm{m}}$ é a massa específica da mistura água e emulsão e $\mu_{\mathrm{m}}$ é a viscosidade desta mistura. Estes valores são obtidos através da média ponderada das propriedades em função da fração volumétrica de água e óleo. Para o orifício 6, a composição é $95 \%$ de água e 5\% de óleo. Para os demais orifícios, o teor de água é de $97 \%$ e o de óleo é $3 \%$. O termo U é a velocidade do fluido, no duto ou orifício, e d é o diâmetro do duto ou do orifício, a depender do ponto onde está sendo calculado o Reynolds.

Tabela 20 - Variação de Pressão obtida com a Emulsão 5 (Gotas Pequenas).

\begin{tabular}{|c|c|c|c|c|c|c|c|c|}
\hline $\begin{array}{c}\text { Q } \\
\text { Emulsão } \\
(\mathrm{ml} / \mathrm{min})\end{array}$ & $\begin{array}{c}\text { Q Água } \\
(\mathrm{ml} / \mathrm{min})\end{array}$ & $\begin{array}{c}\text { Q Total } \\
(\mathrm{ml} / \mathrm{min})\end{array}$ & \multicolumn{5}{|c|}{$\Delta$ P Medido (psi) } & $\begin{array}{c}\Delta \mathrm{P} \\
\text { Médio } \\
(\mathrm{psi})\end{array}$ \\
\hline 20 & 292 & 312 & 71,6 & 67,1 & 68,8 & 71,6 & 72,5 & 70,3 \\
\hline 15 & 219 & 234 & 42,1 & 42,5 & 42,6 & 42,2 & 42,5 & 42,4 \\
\hline 10 & 146 & 156 & 20,5 & 20,7 & 20,8 & 20,4 & 20,5 & 20,6 \\
\hline
\end{tabular}


Tabela 21 - Variação de Pressão obtida com a Emulsão 6 (Gotas Grandes).

\begin{tabular}{|c|c|c|c|c|c|c|c|c|}
\hline $\begin{array}{c}\text { Q } \\
\text { Emulsão } \\
(\mathrm{ml} / \mathrm{min})\end{array}$ & $\begin{array}{c}\text { Q Água } \\
(\mathrm{ml} / \mathrm{min})\end{array}$ & $\begin{array}{c}\text { Q Total } \\
(\mathrm{ml} / \mathrm{min})\end{array}$ & \multicolumn{5}{|c|}{$\Delta \mathrm{P}$ Medido (psi) } & $\begin{array}{c}\Delta \mathrm{P} \\
\text { Médio } \\
(\mathrm{psi})\end{array}$ \\
\hline 20 & 292 & 312 & 78,6 & 78,9 & 78,5 & 78,2 & 78,8 & 78,6 \\
\hline 15 & 219 & 234 & 43,8 & 43,9 & 43,7 & 43,8 & 44,0 & 43,8 \\
\hline 10 & 146 & 156 & 20,4 & 20,6 & 20,3 & 20,4 & 20,5 & 20,4 \\
\hline
\end{tabular}

Para exemplificar a determinação dos valores de potência dissipada, e do Reynolds no duto e no orifício, será mostrado o cálculo destes parâmetros utilizando os dados coletados na condição de maior vazão na Amostra 5.

Utilizando a Eq. 21, calcula-se a potência dissipada:

$$
P=1,15 \times 10^{-4} \cdot 312(\mathrm{ml} / \mathrm{min}) \cdot 70,3(\mathrm{psi})=2,52 \mathrm{~W}
$$

Para calcular o Reynolds é necessário determinar a massa específica e a viscosidade da mistura. Para isso, utilizam-se as propriedades do óleo apresentadas na Tabela 6.

$$
\begin{gathered}
\boldsymbol{\rho}_{\boldsymbol{m}}=\boldsymbol{\rho}_{\boldsymbol{o}} \epsilon_{o}+\boldsymbol{\rho}_{w} \epsilon_{w}=889 * 0,03+1000 * 0,97=996,7 \mathrm{~kg} / \mathrm{m}^{3} \\
\mu_{m}=\mu_{o} \epsilon_{o}+\mu_{w} \epsilon_{w}=(19,06 / 0,889) * 0,03+1 * 0,97=1,6 \mathrm{mPa} . \mathrm{s}
\end{gathered}
$$

O próximo passo para a determinação do Reynolds é o cálculo das velocidades no duto, Up, e no orifício, Uo.

$$
\begin{gathered}
\boldsymbol{U}_{\boldsymbol{p}}=Q * \frac{\mathbf{4}}{\boldsymbol{\pi} \cdot \boldsymbol{d}_{\boldsymbol{p}}^{2}}=\frac{312}{6 \times 10^{7}} * \frac{4}{\pi \cdot\left(3,175 \times 10^{-3}\right)^{2}}=0,66 \mathrm{~m} / \mathrm{s} \\
\boldsymbol{U}_{\boldsymbol{o}}=Q * \frac{\mathbf{4}}{\boldsymbol{\pi} \cdot \boldsymbol{d}_{\boldsymbol{o}}^{2}}=\frac{312}{6 \times 10^{7}} * \frac{4}{\pi \cdot\left(5 \times 10^{-4}\right)^{2}}=26,48 \mathrm{~m} / \mathrm{s}
\end{gathered}
$$

Com os dados obtidos acima, calcula-se o Reynolds no duto, $\operatorname{Re}_{\mathrm{p}}$, e no orifício, $\mathrm{Re}_{\mathrm{o}}$. Estes valores são apresentados na Tabela 22 .

$$
\begin{gathered}
\boldsymbol{R}_{\boldsymbol{p}}=\frac{\rho_{m} \cdot U_{p} \cdot d_{p}}{\mu_{m}}=\frac{996,7 * 0,66 * 3,175 \times 10^{-3}}{1,6 \times 10^{-3}}=1290 \\
\boldsymbol{R}_{\boldsymbol{o}}=\frac{\rho_{m} \cdot U_{o} \cdot d_{o}}{\mu_{m}}=\frac{996,7 * 26,48 * 5 \times 10^{-4}}{1,6 \times 10^{-3}}=8193
\end{gathered}
$$


Tabela 22 - Potência Dissipada, Reynolds e valores medidos para o d d $_{50}$ das Amostras 5 e 6.

\begin{tabular}{|c|c|c|c|c|c|c|c|c|}
\hline \multirow{4}{*}{} & Q & DP & Pot. & Re & Re & \multicolumn{3}{|c|}{ d_50 } \\
\cline { 2 - 9 } & $\mathrm{ml} / \mathrm{min}$ & $\mathrm{psi}$ & $\mathrm{W}$ & Duto & Orifício & Tanque & Antes & Depois \\
\hline \multirow{2}{*}{$\begin{array}{c}\text { Amostra } \\
5\end{array}$} & 312 & 70,3 & 2,52 & 1290 & 8193 & 39,7 & 37,3 & 9,1 \\
\cline { 2 - 9 } & 234 & 42,4 & 1,14 & 968 & 6145 & 39,7 & 35,7 & 17,2 \\
\cline { 2 - 9 } & 156 & 20,6 & 0,37 & 645 & 4096 & 39,7 & 40,1 & 29,4 \\
\hline \multirow{2}{*}{$\begin{array}{c}\text { Amostra } \\
6\end{array}$} & 312 & 78,6 & 2,82 & 1290 & 8193 & 67,3 & 51,1 & 9,7 \\
\cline { 2 - 9 } & 234 & 43,8 & 1,18 & 968 & 6145 & 67,3 & 58,5 & 12,0 \\
\cline { 2 - 9 } & 156 & 20,4 & 0,37 & 645 & 4096 & 67,3 & 55,8 & 20,3 \\
\hline
\end{tabular}

Na Figura 42 e na Figura 43 estão as distribuições do tamanho de gotas medidas para as amostras 5 e 6 antes e após o orifício para vazão de $312 \mathrm{ml} / \mathrm{min}$. Neste cenário é possível observar na Figura 42 que quase não há quebra de gotas devido ao escoamento no duto para a amostra 5, linha azul para a condição inicial e vermelha para o ponto antes do orifício, e que mesmo com uma vazão muito baixa, a quebra de gotas após a passagem no orifício é significativa para as duas amostras. Outro ponto relevante é que mesmo com diâmetros diferentes, a distribuição do tamanho de gotas após o orifício é similar para as duas amostras, linha azul para a Amostra 5 e rosa para a 6 na Figura 43.

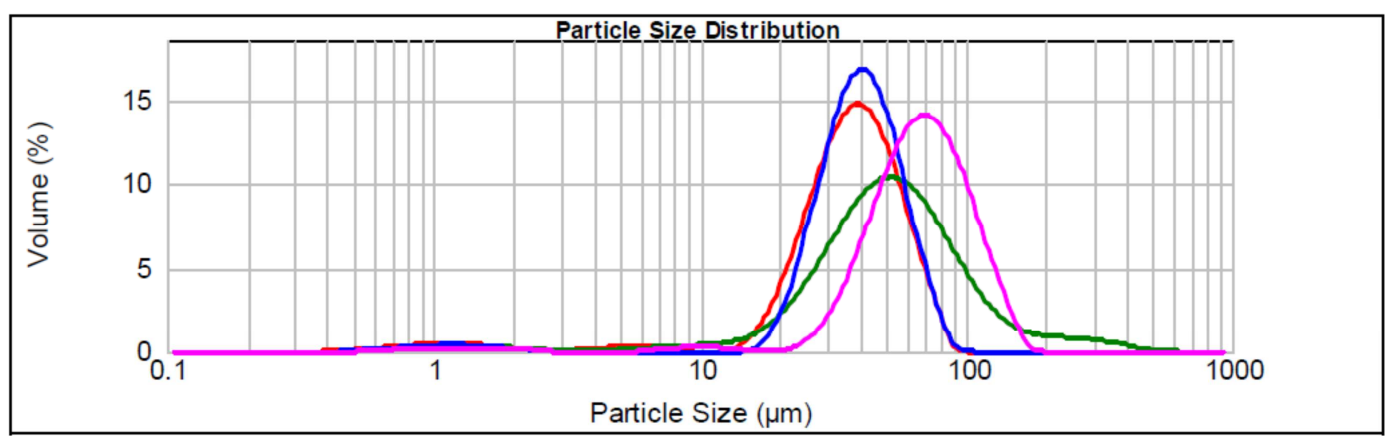

Figura 42 - Mudança do tamanho das gotas desde o tanque até o ponto antes do orifício, na vazão de $312 \mathrm{ml} / \mathrm{min}$, para a Amostra 5 (azul para vermelho) e Amostra 6 (rosa para o verde). 


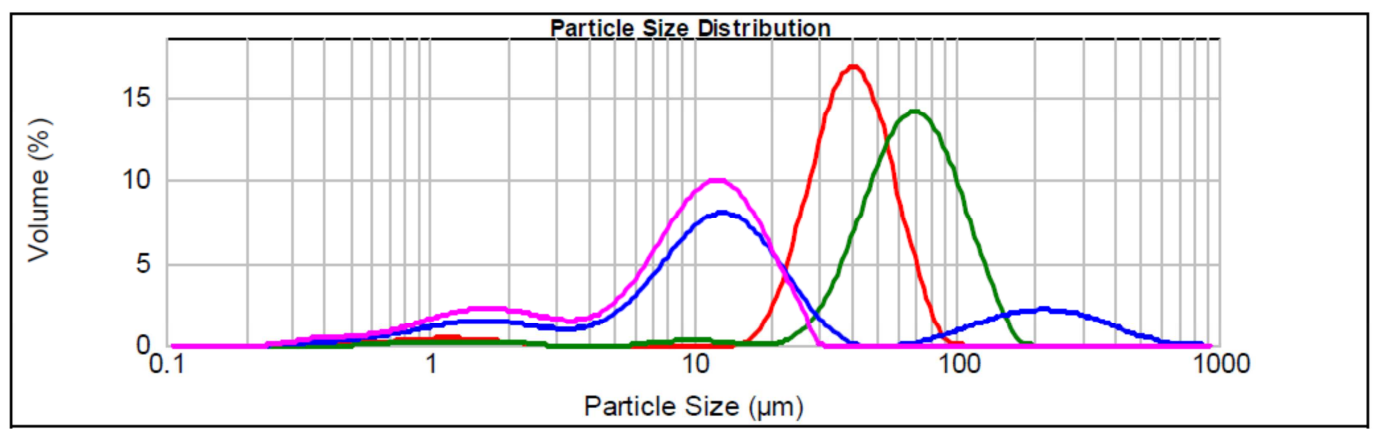

Figura 43 - Mudança do tamanho das gotas desde o tanque até o ponto após o orifício, na vazão de $312 \mathrm{ml} / \mathrm{min}$, para a Amostra 5 (vermelho para o azul) e Amostra 6 (verde para o rosa).

Na Tabela 22 é possível observar que na condição de menor vazão para a Amostra 5, o d 50 medido para a condição antes do orifício apresentou valor maior que o do tanque. Isso se deve à presença de pequenas quantidades de óleo não emulsionado que contamina a leitura com gotas de diâmetro maior. Contudo, na Figura 44 é possível constatar que a distribuição do tamanho de gotas nestas duas condições é similar (linhas azul e vermelha).

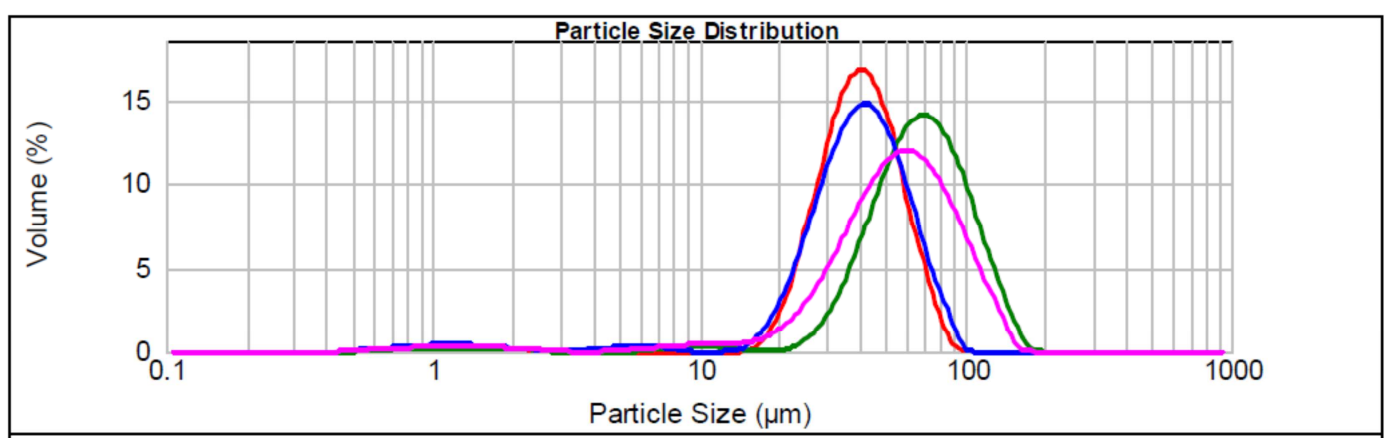

Figura 44 - Mudança do tamanho das gotas desde o tanque até o ponto antes do orifício, na vazão de $156 \mathrm{ml} / \mathrm{min}$, para a Amostra 5 (vermelho para o azul) e Amostra 6 (verde para o rosa).

\subsubsection{2.}

Orifício no $9(D=1 \mathrm{~mm} / \mathrm{L}=10 \mathrm{~mm})$

Para o orifício $\mathrm{n}^{\circ} 9$ uma nova matriz foi gerada para avaliação da queda de pressão. Nesta restrição foram utilizadas três emulsões para a medição da quebra de gotas, uma com gotas pequenas e duas com gotas grandes. Os resultados serão agrupados conforme o tamanho inicial das gotas da emulsão. 
Tabela 23 - Variação de Pressão obtida com a Emulsão 9 (Gotas Pequenas).

\begin{tabular}{|c|c|c|c|c|c|c|c|c|}
\hline $\begin{array}{c}\text { Q Emulsão } \\
(\mathrm{ml} / \mathrm{min})\end{array}$ & $\begin{array}{c}\text { Q Água } \\
(\mathrm{ml} / \mathrm{min})\end{array}$ & $\begin{array}{c}\text { Q Total } \\
(\mathrm{ml} / \mathrm{min})\end{array}$ & \multicolumn{5}{|c|}{$\Delta \mathrm{P}$ Medido (psi) } & $\begin{array}{c}\Delta \mathrm{P} \\
\text { Médio } \\
(\mathrm{psi})\end{array}$ \\
\hline 48 & 1232 & 1280 & 70,1 & 73,0 & 67,8 & 72,7 & 71,3 & 71,0 \\
\hline 39 & 1001 & 1040 & 46,8 & 48,5 & 47,6 & 46,4 & 48,3 & 47,5 \\
\hline 30 & 770 & 800 & 27,1 & 28,2 & 27,4 & 28,1 & 27,6 & 27,7 \\
\hline 15 & 385 & 400 & 7,1 & 7,6 & 7,0 & 6,7 & 7,3 & 7,1 \\
\hline
\end{tabular}

Tabela 24 - Variação de Pressão obtida com a Emulsão 8 (Gotas Grandes).

\begin{tabular}{|c|c|c|c|c|c|c|c|c|}
\hline $\begin{array}{c}\text { Q Emulsão } \\
(\mathrm{ml} / \mathrm{min})\end{array}$ & $\begin{array}{c}\text { Q Água } \\
(\mathrm{ml} / \mathrm{min})\end{array}$ & $\begin{array}{c}\text { Q Total } \\
(\mathrm{ml} / \mathrm{min})\end{array}$ & \multicolumn{5}{|c|}{$\Delta$ P Medido (psi) } & $\begin{array}{c}\Delta \text { P } \\
\text { Médio } \\
(\mathrm{psi})\end{array}$ \\
\hline 48 & 1232 & 1280 & 72,7 & 73,0 & 73,2 & 67,2 & 70,2 & 71,3 \\
\hline 39 & 1001 & 1040 & 46,3 & 45,9 & 46,1 & 44,4 & 46,5 & 45,8 \\
\hline 30 & 770 & 800 & - & - & - & - & - & - \\
\hline
\end{tabular}

Tabela 25 - Variação de Pressão obtida com a Emulsão 10 (Gotas Grandes).

\begin{tabular}{|c|c|c|c|c|c|c|c|c|}
\hline $\begin{array}{c}\text { Q Emulsão } \\
(\mathrm{ml} / \mathrm{min})\end{array}$ & $\begin{array}{c}\text { Q Água } \\
(\mathrm{ml} / \mathrm{min})\end{array}$ & $\begin{array}{c}\text { Q Total } \\
(\mathrm{ml} / \mathrm{min})\end{array}$ & \multicolumn{5}{|c|}{$\Delta$ P Medido (psi) } & $\begin{array}{c}\Delta \mathrm{P} \\
\text { Médio } \\
(\mathrm{psi})\end{array}$ \\
\hline 30 & 770 & 800 & 28,4 & 28,3 & 29,0 & 28,0 & 28,7 & 28,5 \\
\hline 24 & 616 & 640 & 18,5 & 18,9 & 18,2 & 18,6 & 18,9 & 18,6 \\
\hline 15 & 385 & 400 & 7,8 & 7,5 & 7,6 & 7,6 & 7,6 & 7,6 \\
\hline
\end{tabular}

As amostras 8 e 10, ambas de gotas grandes, apresentam uma pequena diferença no $\mathrm{d}_{50}$ de origem, $71 \mu \mathrm{m}$ e $60 \mu \mathrm{m}$ respectivamente, que pode ser verificada na Figura 45. 


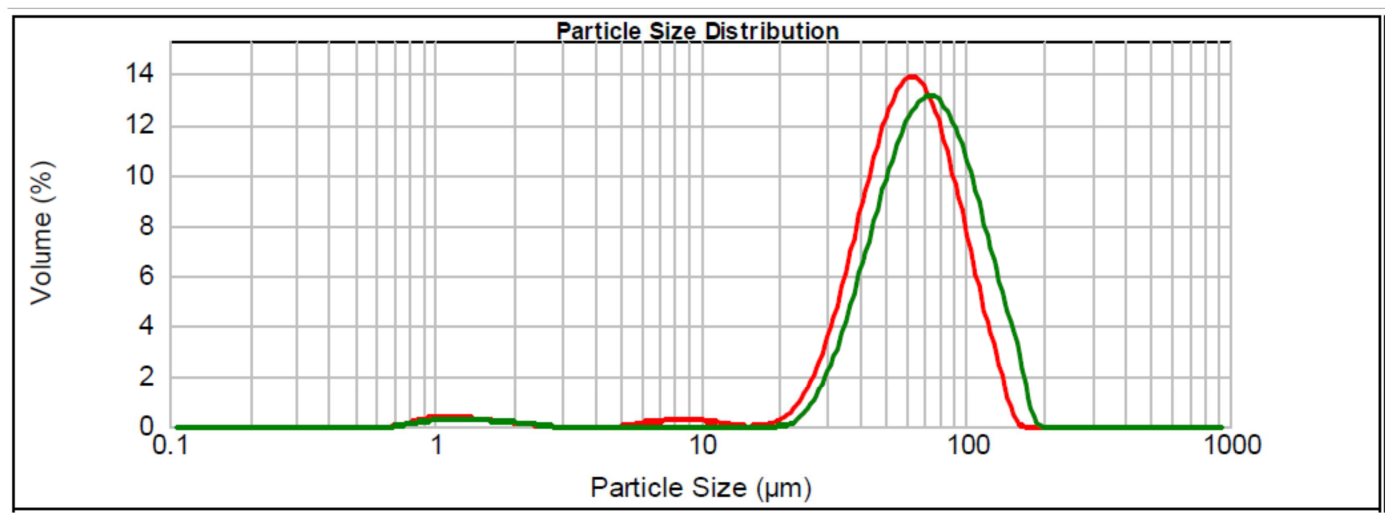

Figura 45 - Distribuição do tamanho de gotas após preparo das Amostras 8 (linha verde) e 10 (linha vermelha).

A matriz resumo com a potência dissipada, o Reynolds do escoamento no duto e no orifício, e o valor do $\mathrm{d}_{50}$ obtido pelo Mastersizer 2000 para as condições de tanque das três emulsões, para o ponto antes do orifício e após a passagem do orifício é apresentada na Tabela 26.

Tabela 26 - Potência Dissipada, Reynolds e valores medidos para o d50 das Amostras 8, 9 e 10.

\begin{tabular}{|c|c|c|c|c|c|c|c|c|}
\hline & Q & DP & Pot. & Re & Re & \multicolumn{3}{|c|}{ d_50 } \\
\cline { 2 - 9 } & $\mathrm{ml} / \mathrm{min}$ & $\mathrm{psi}$ & $\mathrm{W}$ & Duto & Orifício & Tanque & Antes & Depois \\
\hline \multirow{4}{*}{$\begin{array}{c}\text { Amostra } \\
9\end{array}$} & 1280 & 71,0 & 10,44 & 5294 & 16807 & 39 & 28 & 8,1 \\
\cline { 2 - 9 } & 1040 & 47,5 & 5,67 & 4301 & 13655 & 39 & 22,4 & 8,0 \\
\cline { 2 - 9 } & 800 & 27,7 & 2,55 & 3309 & 10504 & 39 & 22,0 & 17,7 \\
\cline { 2 - 9 } & 400 & 7,6 & 0,35 & 1654 & 5252 & 39 & 37,9 & 37,6 \\
\hline \multirow{4}{*}{8 e 10 } & 1280 & 71,3 & 10,48 & 5294 & 16807 & 71,3 & 37,0 & 6,8 \\
\cline { 2 - 9 } & 1040 & 45,8 & 5,47 & 4301 & 13655 & 71,3 & 51,3 & 9,6 \\
\cline { 2 - 9 } & 800 & 28,5 & 2,62 & 3309 & 10504 & 60,6 & 43,1 & 12,6 \\
\cline { 2 - 9 } & 400 & 18,6 & 1,37 & 2647 & 8403 & 60,6 & 52,8 & 13,6 \\
\hline
\end{tabular}

A diferença no tamanho inicial de gotas gerou uma aparente inconsistência no valor do diâmetro de gotas no ponto antes do orifício, pois a quebra devida à vazão de $1040 \mathrm{ml} / \mathrm{min}$ deveria gerar gotas menores que as obtidas quando a vazão fosse $800 \mathrm{ml} / \mathrm{min}$. Verificando os valores de $\mathrm{d}_{50}$ no tanque e antes do orifício para 
as duas vazões citadas, observa-se que a quebra ocorrida na vazão mais alta foi maior que a detectada na vazão menor. Isto significa que os valores medidos são válidos e representam adequadamente a quebra devido ao escoamento no duto.

Entretanto, no ponto a jusante do orifício não foi observada este comportamento, ou seja, o tamanho $\mathrm{d}_{50}$ medido após o orifício na vazão maior é menor que o da vazão de $800 \mathrm{ml} / \mathrm{min}$. Isso leva a crer que o diâmetro de entrada não teve influência no tamanho de gota resultante após a passagem na restrição. $\mathrm{Na}$ Figura 46 e na Figura 47, é possível observar a quebra de gotas ocorrida nas amostras 8 e 10, nas vazões de 1040 e 800 ml/min, respectivamente.

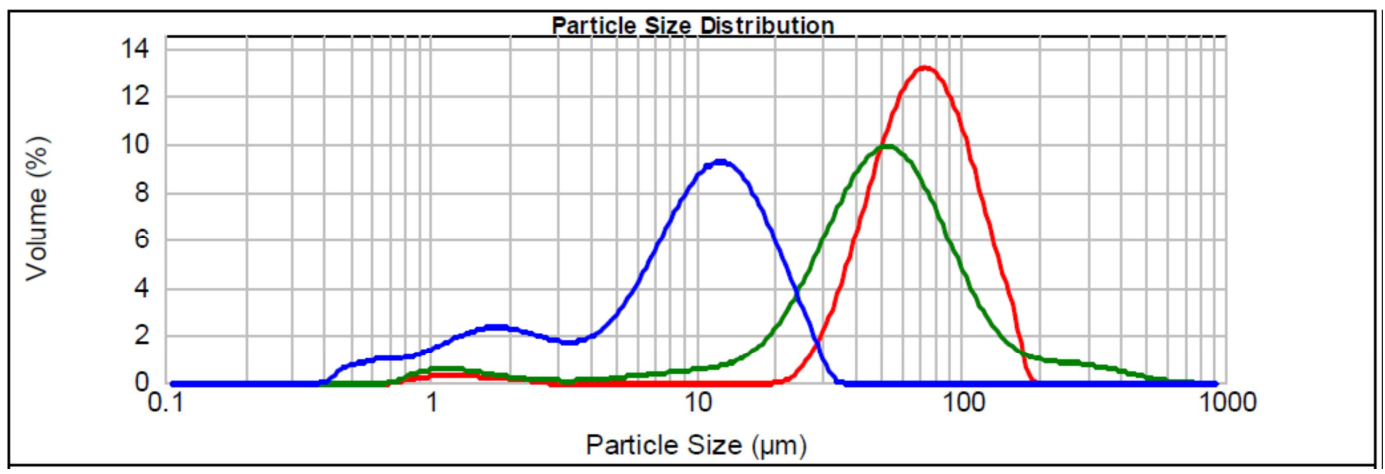

Figura 46 - Distribuição do tamanho de gotas para a Amostra 8 na vazão de $1040 \mathrm{ml} / \mathrm{min}$, na condição de tanque (linha vermelha), antes do orifício (linha verde) e após o orifício (linha azul).

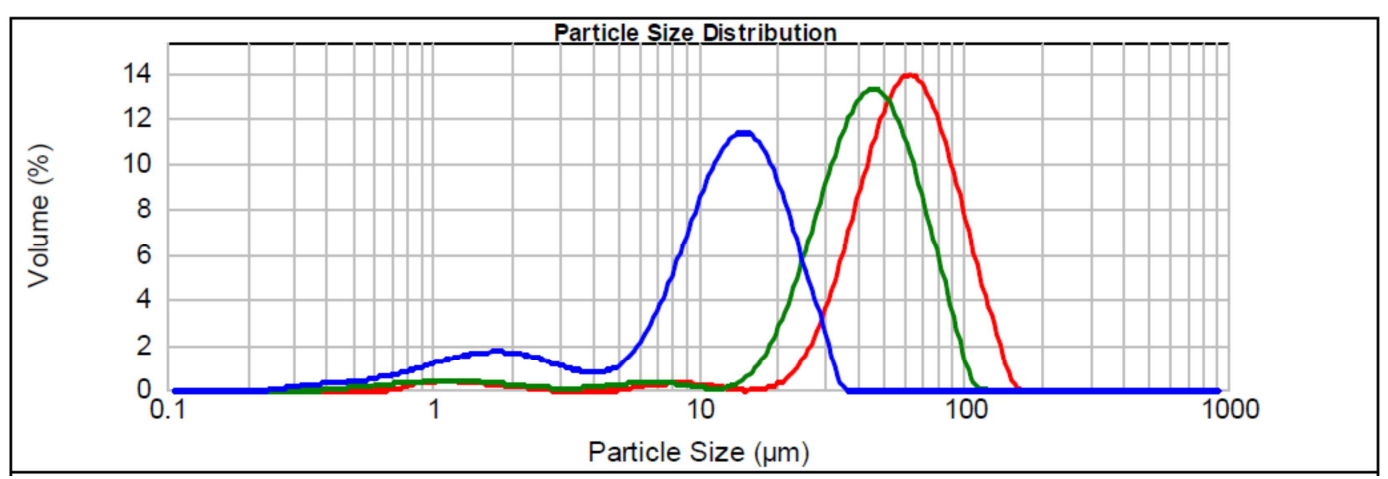

Figura 47 - Distribuição do tamanho de gotas para a Amostra 10 na vazão de $800 \mathrm{ml} / \mathrm{min}$, na condição de tanque (linha vermelha), antes do orifício (linha verde) e após o orifício (linha azul). 


\subsubsection{3.}

\section{Orifício no $12(D=2 \mathrm{~mm} / \mathrm{L}=10 \mathrm{~mm})$}

No Orifício $\mathrm{n}^{\mathrm{o}} 12$ foi avaliado apenas emulsões geradas com o óleo NH-10, assim como no Orifício $n^{\circ}$ 6. Isto porque foi observado que as variações de pressão obtidas nesta restrição eram pequenas quando comparados a outros orifícios e com isso a faixa de potência dissipada avaliada nesta peça foi reduzida. O motivo para a pequena variação de pressão é a limitação do sistema quanto à vazão de injeção associada ao diâmetro maior do orifício da peça. Os valores medidos para a queda de pressão podem ser vistos na Tabela 27 e na Tabela 28.

Tabela 27 - Variação de Pressão obtida com a Emulsão 11 (Gotas Pequenas).

\begin{tabular}{|c|c|c|c|c|c|c|c|c|}
\hline $\begin{array}{c}\text { Q Emulsão } \\
(\mathrm{ml} / \mathrm{min})\end{array}$ & $\begin{array}{c}\text { Q Água } \\
(\mathrm{ml} / \mathrm{min})\end{array}$ & $\begin{array}{c}\text { Q Total } \\
(\mathrm{ml} / \mathrm{min})\end{array}$ & \multicolumn{5}{|c|}{$\Delta \mathrm{P}$ Medido (psi) } & $\begin{array}{c}\Delta \text { Médio } \\
(\mathrm{psi})\end{array}$ \\
\hline 80 & 1920 & 2000 & 15,1 & 14,8 & 14,6 & 14,1 & 15,0 & 14,7 \\
\hline 70 & 1680 & 1750 & 11,0 & 10,6 & 10,6 & 10,9 & 10,7 & 10,8 \\
\hline 60 & 1440 & 1500 & 8,1 & 8,1 & 8,2 & 8,1 & 8,2 & 8,1 \\
\hline 40 & 960 & 1000 & 3,5 & 3,6 & 3,7 & 3,6 & 3,7 & 3,6 \\
\hline
\end{tabular}

Tabela 28 - Variação de Pressão obtida com a Emulsão 12 (Gotas Grandes).

\begin{tabular}{|c|c|c|c|c|c|c|c|c|}
\hline $\begin{array}{c}\text { Q Emulsão } \\
(\mathrm{ml} / \mathrm{min})\end{array}$ & $\begin{array}{c}\text { Q Água } \\
(\mathrm{ml} / \mathrm{min})\end{array}$ & $\begin{array}{c}\text { Q Total } \\
(\mathrm{ml} / \mathrm{min})\end{array}$ & \multicolumn{5}{|c|}{$\Delta$ Medido (psi) } & $\begin{array}{c}\Delta \mathrm{P} \\
\text { Médio } \\
(\mathrm{psi})\end{array}$ \\
\hline 80 & 1920 & 2000 & 14,3 & 14,5 & 14,6 & 14,1 & 14,4 & 14,4 \\
\hline 70 & 1680 & 1750 & 11,2 & 11,1 & 10,9 & 10,8 & 11,2 & 11,0 \\
\hline 60 & 1440 & 1500 & 8,1 & 8,1 & 8,2 & 8,0 & 8,2 & 8,1 \\
\hline 40 & 960 & 1000 & 3,5 & 3,6 & 3,7 & 3,6 & 3,4 & 3,6 \\
\hline
\end{tabular}

Na Tabela 29, é possível verificar que a potência dissipada está com valores menores do que os determinados para outros orifícios. Apesar desta tendência, a avaliação deste orifício trouxe conclusões importantes no estudo que serão tratadas mais a frente neste trabalho. Observa-se também, que a quebra de gotas 
na passagem pelo orifício não foi tão significativa mesmo quando a vazão era máxima. O resultado do processo de quebra pode ser verificado através da distribuição do tamanho de gotas das duas emulsões, na maior vazão, representada na Figura 48 e na Figura 49.

Tabela 29 - Potência Dissipada, Reynolds e valores medidos para o d do das Amostras 11 e 12.

\begin{tabular}{|c|c|c|c|c|c|c|c|c|}
\hline \multirow{4}{*}{} & Q & DP & Pot. & Re & Re & \multicolumn{3}{|c|}{ d_50 } \\
\cline { 2 - 9 } & $\mathrm{ml} / \mathrm{min}$ & $\mathrm{psi}$ & $\mathrm{W}$ & Duto & Orifício & Tanque & Antes & Depois \\
\hline \multirow{4}{*}{$\begin{array}{c}\text { Amostra } \\
11\end{array}$} & 2000 & 14,7 & 3,38 & 8271 & 13130 & 40,7 & 27,1 & 20,8 \\
\cline { 2 - 9 } & 1750 & 10,8 & 2,16 & 7237 & 11489 & 40,7 & 27,3 & 20,3 \\
\cline { 2 - 9 } & 1500 & 8,1 & 1,40 & 6203 & 9847 & 40,7 & 33,2 & 26,4 \\
\cline { 2 - 9 } & 1000 & 3,6 & 0,42 & 4136 & 6565 & 40,7 & 37,4 & 36,8 \\
\hline \multirow{4}{*}{12} & 2000 & 14,4 & 3,30 & 8271 & 13130 & 68,8 & 29,9 & 27,5 \\
\cline { 2 - 9 } & 1750 & 11,0 & 2,22 & 7237 & 11489 & 68,8 & 37,9 & 27,9 \\
\cline { 2 - 9 } & 1500 & 8,1 & 1,40 & 6203 & 9847 & 68,8 & 46,4 & 34,4 \\
\cline { 2 - 9 } & 1000 & 3,6 & 0,41 & 4136 & 6565 & 68,8 & 58,0 & 52,3 \\
\hline
\end{tabular}

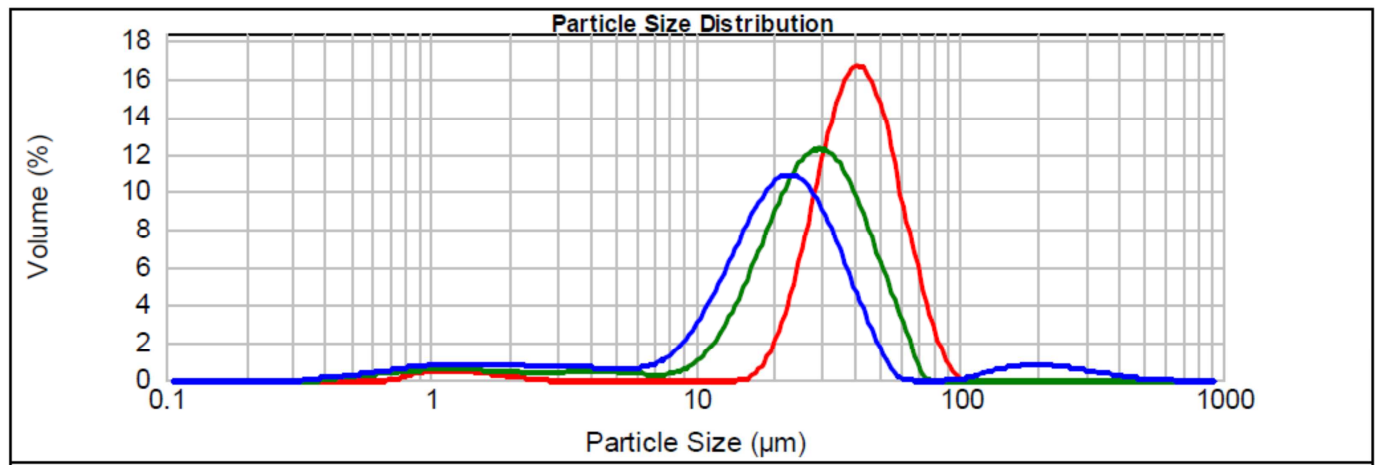

Figura 48 - Distribuição do tamanho de gotas para a Amostra 11 na vazão de $2000 \mathrm{ml} / \mathrm{min}$, na condição de tanque (linha vermelha), antes do orifício (linha verde) e após o orifício (linha azul). 


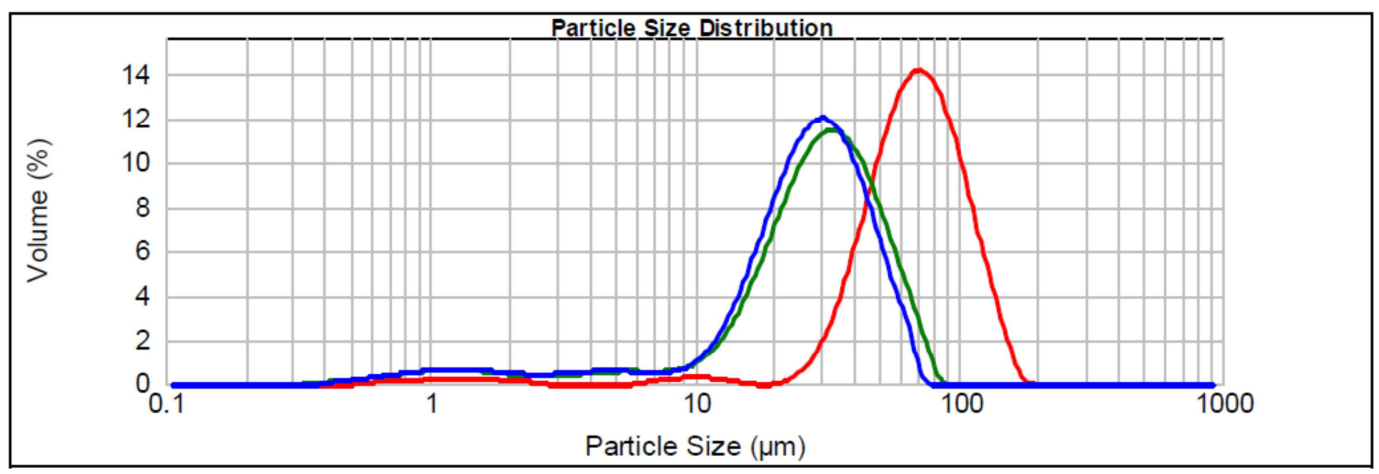

Figura 49 - Distribuição do tamanho de gotas para a Amostra 12 na vazão de $2000 \mathrm{ml} / \mathrm{min}$, na condição de tanque (linha vermelha), antes do orifício (linha verde) e após o orifício (linha azul).

Após a realização dos testes neste orifício, com a observação da quebra de gotas ocorrida, decidiu-se voltar a um orifício com diâmetro de 1,0 mm. Contudo, o comprimento do orifício deveria ser diferente, o que levou à escolha da peça $n^{\circ}$ 11, que possui restrição com comprimento de $1,0 \mathrm{~mm}$.

\subsubsection{4. \\ Orifício no $11(D=1 \mathrm{~mm} / \mathrm{L}=1 \mathrm{~mm})$}

No orifício $\mathrm{n}^{\circ} 11$ buscou-se avaliar a influência do comprimento da restrição no processo de quebra de gotas. Em relação ao orifício $n^{\circ}$, a redução do comprimento do orifício foi de 10 vezes. Nesta peça foi possível avaliar grande faixa de vazão e queda de pressão gerando assim uma massa de dados representativa de boa parte da capacidade de operação do sistema. Os valores medidos para a queda de pressão em função da vazão escoada podem ser verificados na Tabela 30 e na Tabela 31. 
Tabela 30 - Variação de Pressão obtida com a Emulsão 13 (Gotas Pequenas).

\begin{tabular}{|c|c|c|c|c|c|c|c|c|}
\hline $\begin{array}{c}\text { Q Emulsão } \\
(\mathrm{ml} / \mathrm{min})\end{array}$ & $\begin{array}{c}\text { Q Água } \\
(\mathrm{ml} / \mathrm{min})\end{array}$ & $\begin{array}{c}\text { Q Total } \\
(\mathrm{ml} / \mathrm{min})\end{array}$ & \multicolumn{5}{|c|}{$\Delta$ P Medido (psi) } & $\begin{array}{c}\Delta \mathrm{P} \\
\text { Médio } \\
(\mathrm{psi})\end{array}$ \\
\hline 60 & 1540 & 1600 & 91,9 & 92,0 & 94,3 & 91,0 & 95,4 & 92,9 \\
\hline 51 & 1309 & 1360 & 63,0 & 67,1 & 64,0 & 69,4 & 66,8 & 66,1 \\
\hline 42 & 1078 & 1120 & 45,4 & 45,8 & 46,0 & 44,7 & 45,0 & 45,4 \\
\hline 30 & 770 & 800 & 23,7 & 23,6 & 23,1 & 23,9 & 24,3 & 23,7 \\
\hline 18 & 462 & 480 & 8,3 & 8,6 & 8,5 & 8,3 & 8,4 & 8,4 \\
\hline
\end{tabular}

Tabela 31 - Variação de Pressão obtida com a Emulsão 18 (Gotas Grandes).

\begin{tabular}{|c|c|c|c|c|c|c|c|c|}
\hline $\begin{array}{c}\text { Q Emulsão } \\
(\mathrm{ml} / \mathrm{min})\end{array}$ & $\begin{array}{c}\text { Q Água } \\
(\mathrm{ml} / \mathrm{min})\end{array}$ & $\begin{array}{c}\text { Q Total } \\
(\mathrm{ml} / \mathrm{min})\end{array}$ & \multicolumn{5}{|c|}{$\Delta$ P Medido (psi) } & $\begin{array}{c}\Delta \mathrm{P} \\
\text { Médio } \\
(\mathrm{psi})\end{array}$ \\
\hline 60 & 1540 & 1600 & 91,4 & 89,9 & 92,6 & 92,1 & 92,9 & 91,8 \\
\hline 51 & 1309 & 1360 & 63,2 & 65,9 & 65,5 & 67,8 & 64,5 & 65,4 \\
\hline 42 & 1078 & 1120 & 45,2 & 44,2 & 45,5 & 46,3 & 45,4 & 45,3 \\
\hline 30 & 770 & 800 & 22,6 & 22,8 & 23,5 & 23,0 & 23,1 & 23,0 \\
\hline 18 & 462 & 480 & 8,3 & 8,5 & 8,4 & 8,6 & 8,4 & 8,4 \\
\hline
\end{tabular}

Como comentado, a variação de pressão chegou a 93 psi, que é próximo ao limite do manômetro de 100 psi, e a vazão chegou a $1600 \mathrm{ml} / \mathrm{min}$, que é $80 \%$ da vazão nominal da bomba. Com isso, uma grande faixa de potência dissipada pode ser avaliada e desta forma foi possível obter valores de tamanho de gotas representativos para diversas condições de operação. A potência dissipada, o Reynolds no duto e no orifício, e os valores de d50 medidos a partir das condições acima estão representados na Tabela 32. 
Tabela 32 - Potência Dissipada, Reynolds e valores medidos para o d $\mathrm{d}_{50}$ das Amostras 13 e 18.

\begin{tabular}{|c|c|c|c|c|c|c|c|c|}
\hline & Q & DP & Pot. & Re & Re & \multicolumn{3}{|c|}{ d_50 } \\
\cline { 2 - 9 } & $\mathrm{ml} / \mathrm{min}$ & $\mathrm{psi}$ & $\mathrm{W}$ & Duto & Orifício & Tanque & Antes & Depois \\
\hline \multirow{4}{*}{$\begin{array}{c}\text { Amostra } \\
13\end{array}$} & 1600 & 92,9 & 17,07 & 6617 & 21008 & 37,8 & 26,0 & 6,4 \\
\cline { 2 - 10 } & 1360 & 66,1 & 10,32 & 5624 & 17857 & 37,8 & 27,4 & 8,5 \\
\cline { 2 - 9 } & 1120 & 45,4 & 5,84 & 4632 & 14706 & 37,8 & 33,3 & 10,8 \\
\cline { 2 - 9 } & 800 & 23,7 & 2,18 & 3308 & 10504 & 37,8 & 37,1 & 15,0 \\
\cline { 2 - 9 } & 480 & 8,4 & 0,46 & 1985 & 6302 & 37,8 & 34,8 & 29,2 \\
\hline \multirow{4}{*}{18} & 1600 & 91,8 & 16,86 & 6617 & 21008 & 66,9 & 26,3 & 6,9 \\
\cline { 2 - 9 } & 1360 & 65,4 & 10,21 & 5624 & 17857 & 66,9 & 34,1 & 7,4 \\
\cline { 2 - 9 } & 1120 & 45,3 & 5,83 & 4632 & 14706 & 66,9 & 42,4 & 10,9 \\
\cline { 2 - 9 } & 800 & 23,0 & 2,11 & 3308 & 10504 & 66,9 & 47,3 & 16,9 \\
\cline { 2 - 8 } & 480 & 8,4 & 0,47 & 1985 & 6302 & 66,9 & 50,9 & 36,6 \\
\hline
\end{tabular}

Na Tabela 32, observa-se que o tamanho de gotas medido após o orifício para as duas emulsões, só apresenta uma diferença significativa para o caso em que a vazão é igual a $480 \mathrm{ml} / \mathrm{min}$. Para os outros pontos, o tamanho de gotas medido para as duas emulsões apresenta valores similares. Na Figura 50 e na Figura 51 são comparadas as distribuições do tamanho de gotas após o orifício para os casos de maior e menor vazão.

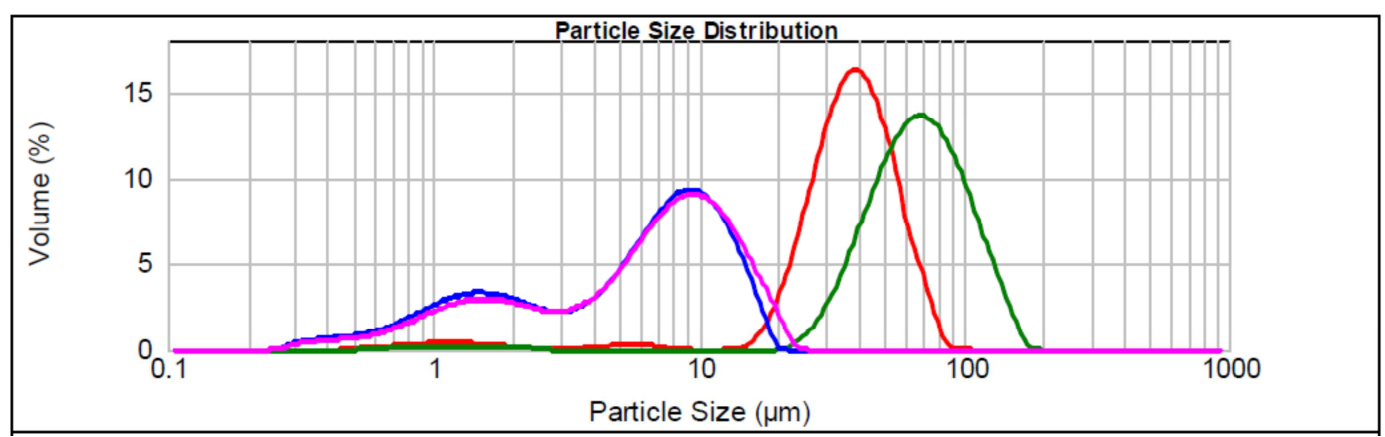

Figura 50 - Mudança do tamanho das gotas desde o tanque até o ponto após o orifício, na vazão de $1600 \mathrm{ml} / \mathrm{min}$, para a Amostra 13 (vermelho para o azul) e Amostra 18 (verde para o rosa). 


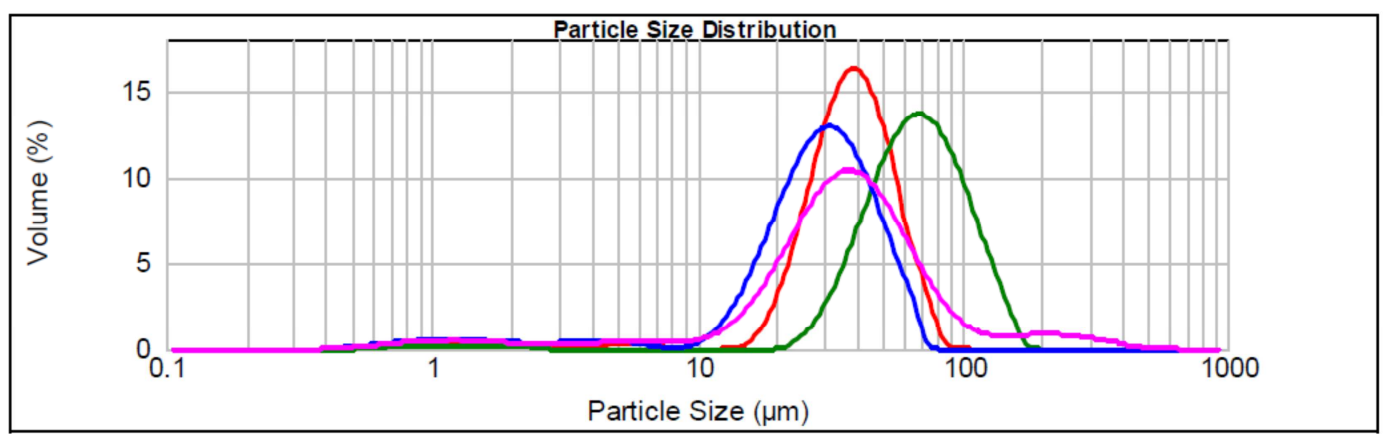

Figura 51 - Mudança do tamanho das gotas desde o tanque até o ponto após o orifício, na vazão de $480 \mathrm{ml} / \mathrm{min}$, para a Amostra 13 (vermelho para o azul) e Amostra 18 (verde para o rosa).

\subsection{2. \\ Óleo 500PS}

\subsubsection{1. \\ Orifício no $9(D=1 \mathrm{~mm} / \mathrm{L}=10 \mathrm{~mm})$}

Após testes com as emulsões formadas a partir do óleo NH-10 foi feita a avaliação da quebra de gotas com amostras geradas com o óleo 500PS. Este óleo possui viscosidade muito superior a do $\mathrm{NH}-10$ e consequentemente seria possível verificar o impacto da viscosidade do óleo no mecanismo de quebra de gotas.

Os orifícios escolhidos para avaliação das emulsões com o 500PS foram o $\mathrm{n}^{\circ} 9$ e 11. Isto porque, como visto nos itens anteriores, nestes orifícios é possível avaliar uma grande faixa de potência dissipada. Logo, para o orifício $n^{\circ} 9$ foi gerada uma matriz de teste que é a junção das condições utilizadas para as amostras 8 e 10. Na Tabela 33 e na Tabela 34 são apresentados os resultados de variação de pressão obtidos para as amostras 14 e 17, que foram as avaliadas neste orifício. 
Tabela 33 - Variação de Pressão obtida com a Emulsão 14 (Gotas Grandes).

\begin{tabular}{|c|c|c|c|c|c|c|c|c|}
\hline $\begin{array}{c}\text { Q Emulsão } \\
(\mathrm{ml} / \mathrm{min})\end{array}$ & $\begin{array}{c}\text { Q Água } \\
(\mathrm{ml} / \mathrm{min})\end{array}$ & $\begin{array}{c}\text { Q Total } \\
(\mathrm{ml} / \mathrm{min})\end{array}$ & \multicolumn{5}{|c|}{$\Delta \mathrm{P}$ Medido (psi) } & $\begin{array}{c}\Delta \mathrm{P} \\
\text { Médio } \\
(\mathrm{psi})\end{array}$ \\
\hline 48 & 1232 & 1280 & 70,8 & 74,3 & 73,6 & 70,5 & 74,2 & 72,7 \\
\hline 39 & 1001 & 1040 & 48,6 & 49,3 & 48,3 & 49,0 & 47,7 & 48,6 \\
\hline 30 & 770 & 800 & 28,1 & 28,6 & 28,7 & 29,5 & 28,1 & 28,6 \\
\hline 24 & 616 & 640 & 17,9 & 18,9 & 18,6 & 18,9 & 18,9 & 18,6 \\
\hline 15 & 385 & 400 & 7,1 & 7,3 & 7,4 & 7,3 & 7,2 & 7,3 \\
\hline
\end{tabular}

Tabela 34 - Variação de Pressão obtida com a Emulsão 17 (Gotas Pequenas).

\begin{tabular}{|c|c|c|c|c|c|c|c|c|}
\hline $\begin{array}{c}\text { Q Emulsão } \\
(\mathrm{ml} / \mathrm{min})\end{array}$ & $\begin{array}{c}\text { Q Água } \\
(\mathrm{ml} / \mathrm{min})\end{array}$ & $\begin{array}{c}\text { Q Total } \\
(\mathrm{ml} / \mathrm{min})\end{array}$ & \multicolumn{5}{|c|}{$\Delta$ M Medido (psi) } & $\begin{array}{c}\Delta \mathrm{P} \\
\text { Médio } \\
(\mathrm{psi})\end{array}$ \\
\hline 48 & 1232 & 1280 & 71,3 & 74,1 & 72,9 & 73,0 & 72,7 & 72,8 \\
\hline 39 & 1001 & 1040 & 48,3 & 49,1 & 49,7 & 48,4 & 48,5 & 48,8 \\
\hline 30 & 770 & 800 & 29,1 & 29,1 & 29,5 & 29,0 & 29,5 & 29,2 \\
\hline 24 & 616 & 640 & 18,6 & 18,3 & 17,6 & 18,9 & 18,6 & 18,4 \\
\hline 15 & 385 & 400 & 7,4 & 7,4 & 7,4 & 7,5 & 7,4 & 7,4 \\
\hline
\end{tabular}

Pode-se observar que a presença de uma emulsão formada a partir de um óleo mais viscoso, não alterou a variação de pressão medida no orifício. Isto se deve ao baixo teor de óleo presente na mistura, que é entre 3 e $5 \%$. Contudo, comparando os diâmetros medidos nesta configuração com os apresentados na Tabela 26, observa-se que há um comportamento diferente deste óleo durante o processo de quebra de gotas. A Potência dissipada, o Reynolds no duto e no orifício, e o valor do d50 para as duas emulsões nas condições de tanque, no ponto antes do orifício e após a passagem do orifício, são apresentadas na Tabela 35. 
Tabela 35 - Potência Dissipada, Reynolds e valores medidos para o d $\mathbf{d}_{50}$ das Amostras 14 e 17.

\begin{tabular}{|c|c|c|c|c|c|c|c|c|}
\hline \multirow{4}{*}{} & Q & DP & Pot. & Re & Re & \multicolumn{3}{|c|}{ d_50 } \\
\cline { 2 - 9 } & $\mathrm{ml} / \mathrm{min}$ & $\mathrm{psi}$ & $\mathrm{W}$ & Duto & Orifício & Tanque & Antes & Depois \\
\hline \multirow{4}{*}{\begin{tabular}{c} 
Amostra \\
\cline { 2 - 9 }
\end{tabular}} & 1280 & 72,7 & 10,68 & 1250 & 3968 & 53,0 & 42,5 & 11,6 \\
\cline { 2 - 9 } & 1040 & 48,6 & 5,80 & 1016 & 3224 & 53,0 & 45,9 & 11,0 \\
\cline { 2 - 9 } & 800 & 28,6 & 2,63 & 781 & 2480 & 53,0 & 46,5 & 29,6 \\
\cline { 2 - 9 } & 640 & 18,6 & 1,37 & 625 & 1984 & 53,0 & 46,2 & 36,2 \\
\hline \multirow{4}{*}{17} & 400 & 7,3 & 0,33 & 391 & 1240 & 53,0 & 52,4 & 42,5 \\
\cline { 2 - 9 } & 1280 & 72,8 & 10,70 & 1250 & 3968 & 37,7 & 37,0 & 13,7 \\
\cline { 2 - 9 } & 1040 & 48,8 & 5,83 & 1016 & 3224 & 37,7 & 37,5 & 22,6 \\
\cline { 2 - 9 } & 800 & 29,2 & 2,69 & 781 & 2480 & 37,7 & 37,9 & 33,1 \\
\cline { 2 - 9 } & 640 & 18,4 & 1,35 & 625 & 1984 & 37,7 & 36,4 & 35,4 \\
\cline { 2 - 9 } & 400 & 7,4 & 0,34 & 391 & 1240 & 37,7 & 37,2 & 35,6 \\
\hline
\end{tabular}

Observa-se uma diferença significativa no tamanho de gotas após o orifício entre as duas amostras para a vazão de $1040 \mathrm{ml} / \mathrm{min}$ e uma pequena variação quando a vazão é igual a $800 \mathrm{ml} / \mathrm{min}$. A diferença entre os valores se deve ao fato que a amostra com gotas maiores (Amostra 14) possui gotas mais instáveis, logo mais suscetíveis à quebra que a emulsão com gota menor.

$\mathrm{Na}$ vazão de $1280 \mathrm{ml} / \mathrm{min}$ a potência gerada é grande o suficiente para quebrar igualmente as gotas das duas amostras. Já na vazão imediatamente menor, o sistema está numa zona de transição, logo o efeito sobre cada tipo de gota é diferenciado. Com a redução da vazão, a potência disponível não quebra significativamente a gota.

Na Figura 52 e na Figura 53 é possível observar as distribuições resultantes da quebra de gota na emulsão com gotas grandes, linha azul do gráfico, e da quebra na emulsão com gotas pequenas, linha rosa, quando as vazões do sistema são iguais a 1040 e $800 \mathrm{ml} / \mathrm{min}$. 


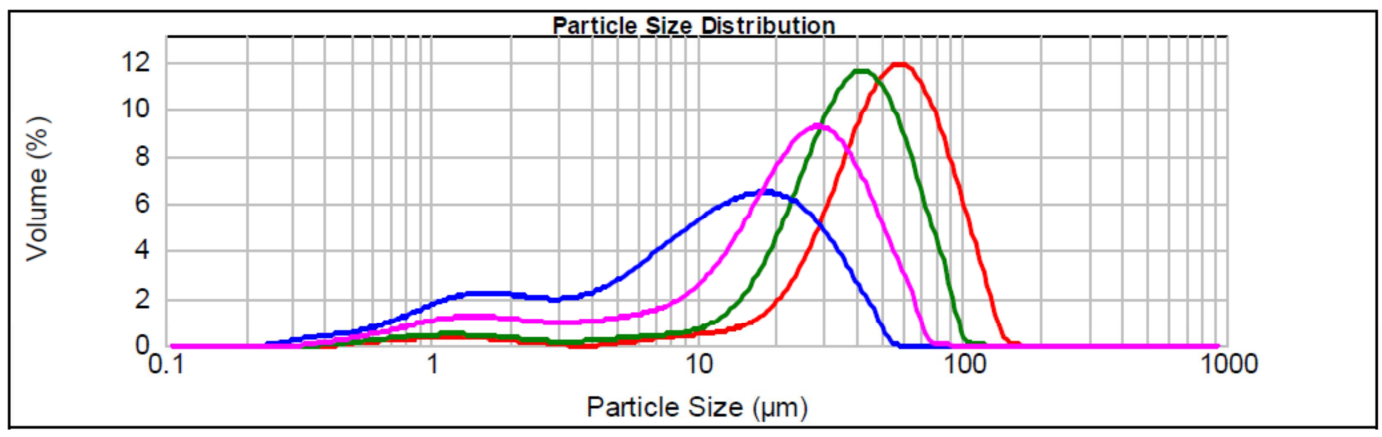

Figura 52 - Mudança do tamanho das gotas desde o tanque até o ponto após o orifício, na vazão de $1040 \mathrm{ml} / \mathrm{min}$, para a Amostra 14 (vermelho para o azul) e Amostra 17 (verde para o rosa).

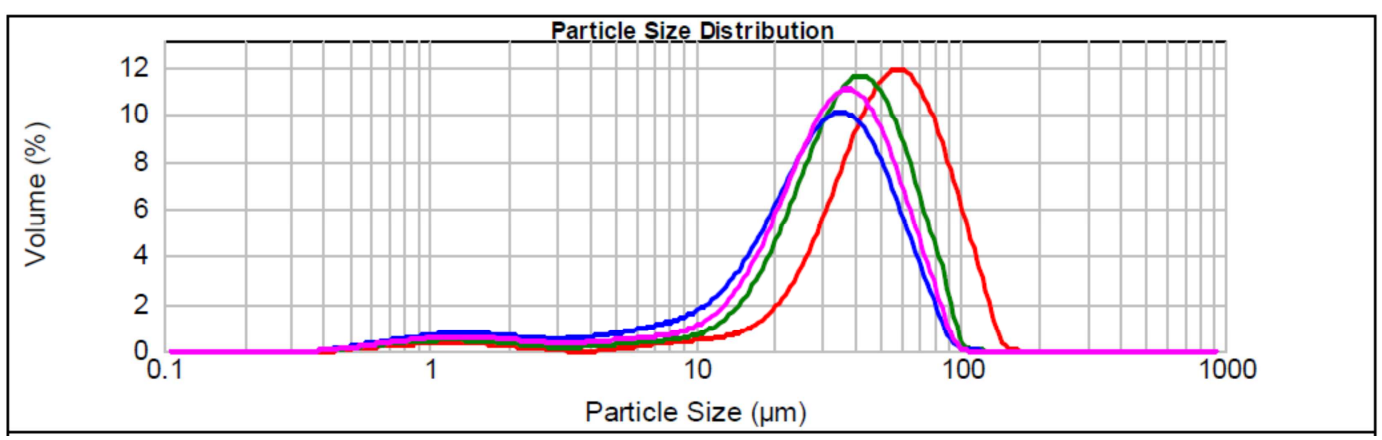

Figura 53 - Mudança do tamanho das gotas desde o tanque até o ponto após o orifício, na vazão de $800 \mathrm{ml} / \mathrm{min}$, para a Amostra 14 (vermelho para o azul) e Amostra 17 (verde para o rosa).

\subsubsection{2. \\ Orifício $\mathrm{n} \times 11(D=1 \mathrm{~mm} / \mathrm{L}=1 \mathrm{~mm})$}

A combinação deste orifício com as emulsões 15 e 16 foi a última a ser avaliada neste trabalho. Como visto para as amostras 13 e 18, neste orifício há grande possibilidade de variação da potência dissipada. A matriz de teste para as amostras 15 e 16 foi similar à apresentada para as emulsões formadas com o óleo NH-10. As leituras de pressão feitas para estas duas amostras estão representadas na Tabela 36 e na Tabela 37. 
Tabela 36 - Variação de Pressão obtida com a Emulsão 15 (Gotas Pequenas).

\begin{tabular}{|c|c|c|c|c|c|c|c|c|}
\hline $\begin{array}{c}\text { Q Emulsão } \\
(\mathrm{ml} / \mathrm{min})\end{array}$ & $\begin{array}{c}\text { Q Água } \\
(\mathrm{ml} / \mathrm{min})\end{array}$ & $\begin{array}{c}\text { Q Total } \\
(\mathrm{ml} / \mathrm{min})\end{array}$ & \multicolumn{5}{|c|}{$\Delta$ P Medido (psi) } & $\begin{array}{c}\Delta \mathrm{P} \\
\text { Médio } \\
(\mathrm{psi})\end{array}$ \\
\hline 60 & 1540 & 1600 & 90,0 & 93,1 & 94,3 & 90,2 & 89,1 & 91,3 \\
\hline 51 & 1309 & 1360 & 66,9 & 68,5 & 68,6 & 66,3 & 67,2 & 67,5 \\
\hline 42 & 1078 & 1120 & 46,0 & 47,0 & 44,9 & 46,8 & 45,8 & 46,1 \\
\hline 30 & 770 & 800 & 24,3 & 24,0 & 23,3 & 24,1 & 24,0 & 23,9 \\
\hline 18 & 462 & 480 & 8,6 & 8,9 & 8,8 & 8,6 & 8,8 & 8,7 \\
\hline
\end{tabular}

Tabela 37 - Variação de Pressão obtida com a Emulsão 16 (Gotas Grandes).

\begin{tabular}{|c|c|c|c|c|c|c|c|c|}
\hline $\begin{array}{c}\text { Q Emulsão } \\
(\mathrm{mL} / \mathrm{min})\end{array}$ & $\begin{array}{c}\text { Q Água } \\
(\mathrm{mL} / \mathrm{min})\end{array}$ & $\begin{array}{c}\text { Q Total } \\
(\mathrm{mL} / \mathrm{min})\end{array}$ & \multicolumn{5}{|c|}{$\Delta$ Pedido (psi) } & $\begin{array}{c}\Delta \mathrm{P} \\
\text { Médio } \\
(\mathrm{psi})\end{array}$ \\
\hline 60 & 1540 & 1600 & 88,3 & 95,5 & 94,4 & 90,6 & 91,2 & 92,0 \\
\hline 51 & 1309 & 1360 & 66,8 & 63,2 & 66,3 & 64,2 & 67,7 & 65,6 \\
\hline 42 & 1078 & 1120 & 45,7 & 46,1 & 46,7 & 44,9 & 46,7 & 46,0 \\
\hline 30 & 770 & 800 & 23,4 & 24,0 & 24,1 & 23,9 & 23,6 & 23,8 \\
\hline 18 & 462 & 480 & 8,3 & 8,2 & 8,3 & 8,3 & 8,3 & 8,3 \\
\hline
\end{tabular}

Assim como verificado nos estudos do orifício anterior, não houve variação significativa nos valores medidos de queda de pressão quando há mudança na viscosidade do óleo. A matriz resumo para as amostras 15 e 16 com a potência dissipada calculada, o Reynolds no duto e no orifício, e o valor do d50 obtido para as duas emulsões nas condições de tanque, no ponto antes do orifício e após a passagem do orifício, são apresentadas na Tabela 38. 
Tabela 38 - Potência Dissipada, Reynolds e valores medidos para o d $\mathbf{d}_{50}$ das Amostras 15 e 16.

\begin{tabular}{|c|c|c|c|c|c|c|c|c|}
\hline \multirow{5}{*}{} & Q & DP & Pot. & Re & Re & \multicolumn{3}{|c|}{ d_50 } \\
\cline { 2 - 9 } & $\mathrm{ml} / \mathrm{min}$ & $\mathrm{psi}$ & $\mathrm{W}$ & Duto & Orifício & Tanque & Antes & Depois \\
\hline \multirow{4}{*}{$\begin{array}{c}\text { Amostra } \\
15\end{array}$} & 1600 & 91,3 & 16,78 & 1563 & 4961 & 41,7 & 36,5 & 8,3 \\
\cline { 2 - 9 } & 1360 & 67,5 & 10,54 & 1328 & 4216 & 41,7 & 38,9 & 14,7 \\
\cline { 2 - 9 } & 1120 & 46,1 & 5,93 & 1094 & 3472 & 41,7 & 39,0 & 26,6 \\
\cline { 2 - 9 } & 800 & 23,9 & 2,20 & 781 & 2480 & 41,7 & 41,3 & 36,7 \\
\cline { 2 - 9 } & 480 & 8,7 & 0,48 & 469 & 1488 & 41,7 & 42,8 & 42,7 \\
\cline { 2 - 9 } Amostra & 1600 & 92,0 & 16,90 & 1563 & 4961 & 51,0 & 34,6 & 11,4 \\
\cline { 2 - 9 } 16 & 1360 & 65,6 & 10,25 & 1328 & 4216 & 51,0 & 35,4 & 11,1 \\
\cline { 2 - 9 } & 800 & 23,8 & 2,19 & 781 & 2480 & 51,0 & 51,6 & 34,9 \\
\cline { 2 - 9 } & 480 & 8,3 & 0,46 & 469 & 1488 & 51,0 & 51,4 & 41,1 \\
\hline
\end{tabular}

Assim como observado para as Amostras 14 e 17, há uma faixa de avaliação que gera diferença significativa no tamanho de gotas após o orifício entre as duas amostras avaliadas neste orifício. Para a condição testada, o ponto com maior diferença nos diâmetros ocorre quando a vazão é igual a $1120 \mathrm{ml} / \mathrm{min}$. As gotas menores são geradas a partir da amostra com maior tamanho de gotas, pois estas são mais instáveis durante o escoamento sendo mais suscetíveis à quebra que as gotas menores.

Na vazão de $1120 \mathrm{ml} / \mathrm{min}$ o sistema está numa zona de transição, com Reynolds de 3500 no orifício, logo o efeito sobre cada tipo de gota é diferenciado. Com vazões maiores, a turbulência tende a quebrar as gotas para um diâmetro limite, e para vazões menores, a quebra tende a ser reduzida já que o fluido está sujeito a um escoamento laminar.

Na Figura 54 e na Figura 55 é possível observar as distribuições resultantes da quebra de gota na emulsão com gotas grandes, linha azul do gráfico, e na com gotas pequenas, linha rosa, quando as vazões do sistema são iguais a 1360 e 1120 $\mathrm{ml} / \mathrm{min}$. Na segunda vazão nota-se a diferença entre as distribuições resultantes da passagem pelo orifício. 


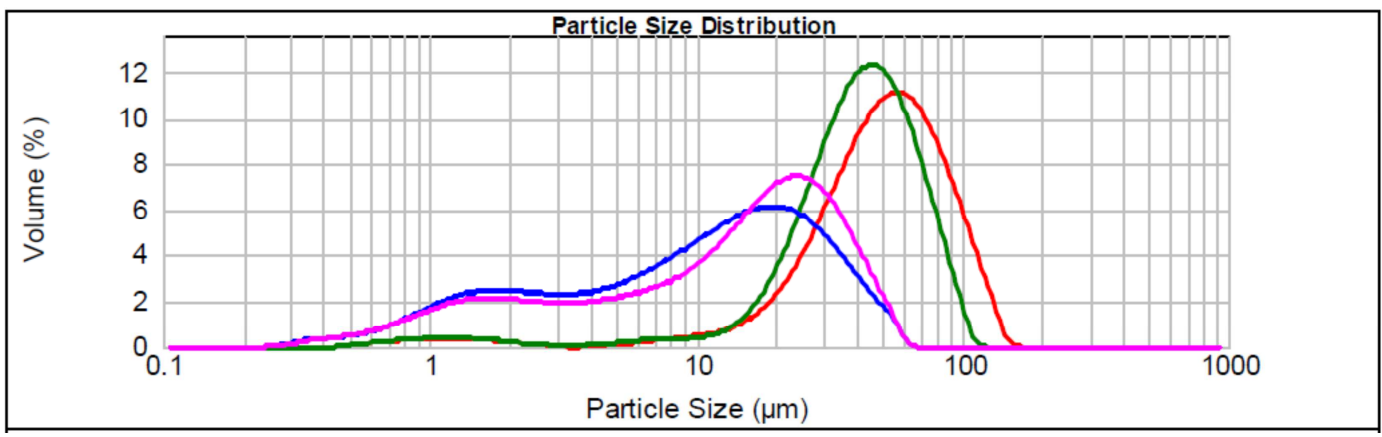

Figura 54 - Mudança do tamanho das gotas desde o tanque até o ponto após o orifício, na vazão de $1360 \mathrm{ml} / \mathrm{min}$, para a Amostra 15 (verde para o rosa) e Amostra 16 (vermelho para o azul).

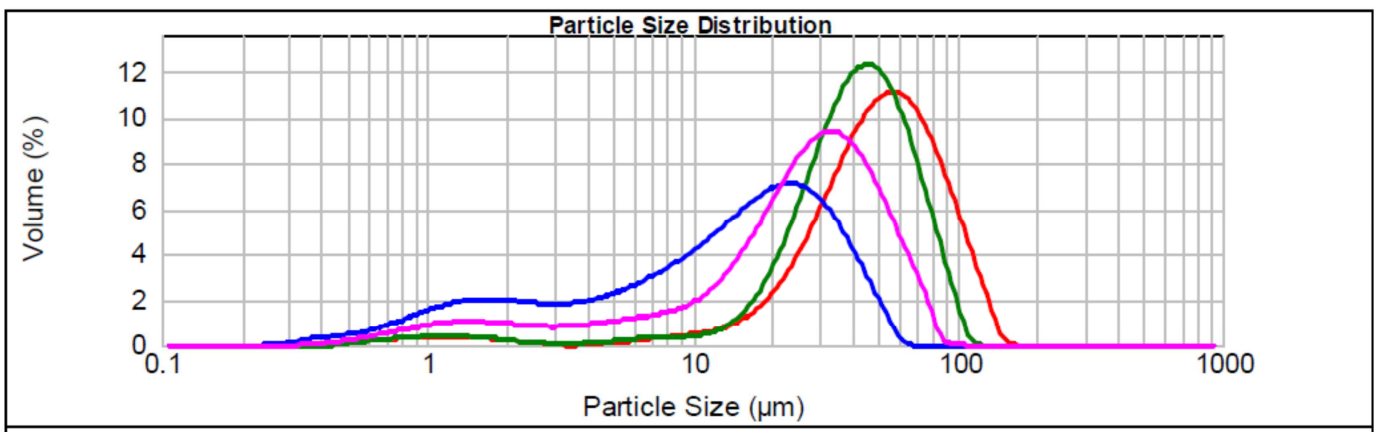

Figura 55 - Mudança do tamanho das gotas desde o tanque até o ponto após o orifício, na vazão de $1120 \mathrm{ml} / \mathrm{min}$, para a Amostra 15 (verde para o rosa) e Amostra 16 (vermelho para o azul).

\section{2. \\ Discussão dos Resultados}

Após a coleta dos dados experimentais apresentados, buscou-se a melhor correlação que determina o tamanho das gotas em função das condições do escoamento e propriedade dos fluidos. Numa primeira tentativa, utilizou-se a potência dissipada como parâmetro de ajuste, pois segundo as conclusões de van der Zande e van den Broek [4] este termo representou adequadamente o processo de quebra de gotas nos experimentos realizados por eles.

Para avaliação deste parâmetro gerou-se um gráfico com os diâmetros $\mathrm{d}_{50}$ medidos após o orifício em função das potências dissipadas obtidas nos experimentos com as emulsões formadas a partir do óleo NH-10. A Figura 56 apresenta esta relação. O número ao lado da letra $\mathrm{O}$ representa o orifício utilizado 
com o diâmetro e comprimento deste entre parênteses, já ao lado da letra E está representada a emulsão utilizada.

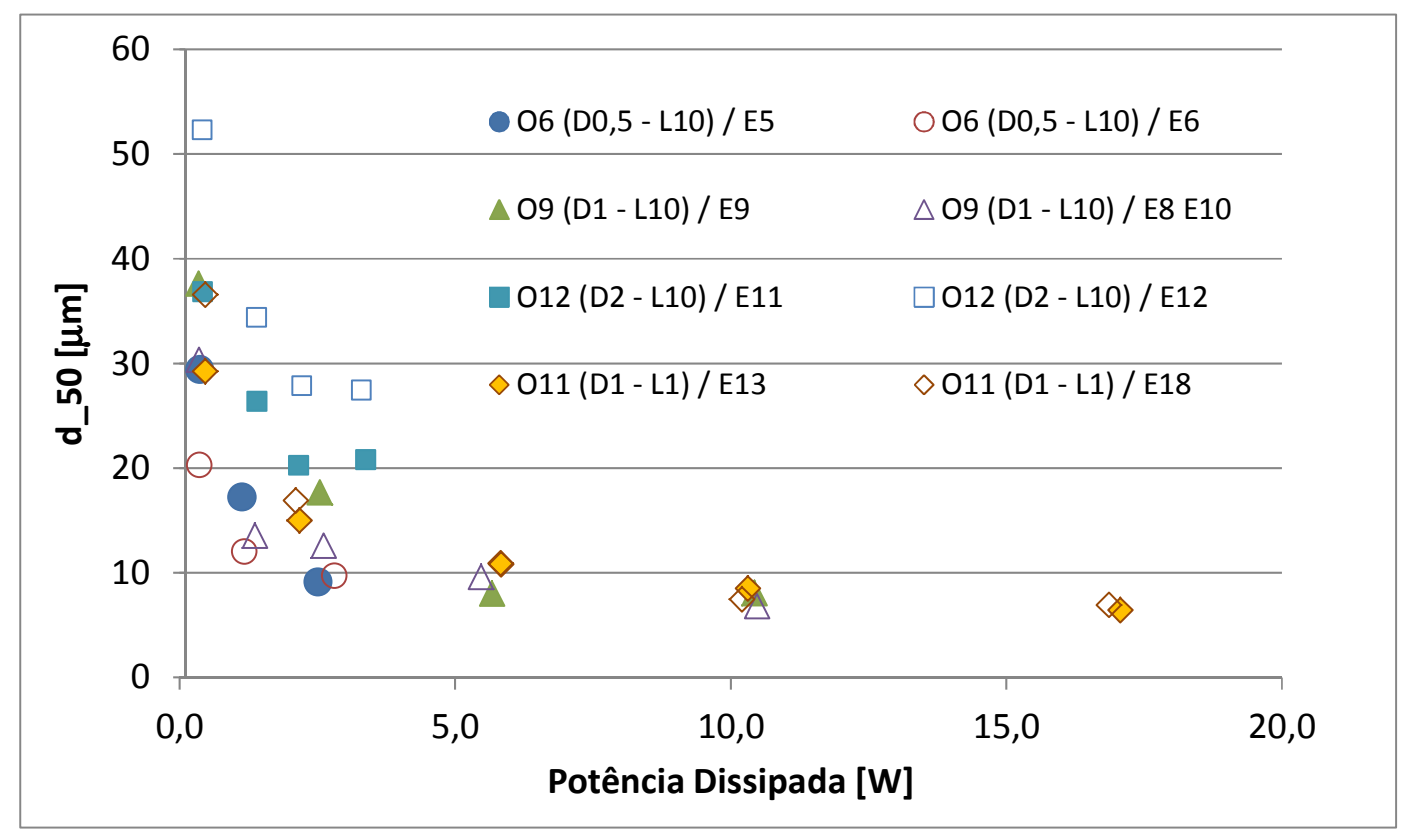

\section{Figura 56 - Diâmetro $d_{50}$ a jusante do orifício em função da Potência Dissipada.}

A partir deste gráfico é possível observar que as emulsões avaliadas no Orifício 12, que possui diâmetro de $2,0 \mathrm{~mm}$, apresentaram comportamento diferente das demais emulsões testadas nas peças 6,9 e 11 . Verifica-se que para estes três orifícios o tamanho de gotas a jusante da restrição é pouco influenciado pelo diâmetro da gota a montante do orifício (gotas grandes com marcadores vazados e gotas pequenas com marcadores cheios). Para potências dissipadas maiores, observa-se que esta independência é mais proeminente. Apenas no Orifício 12 o tamanho de gotas a montante afeta seu diâmetro à jusante da restrição. Como este orifício é o que possui diâmetro de 2,0 mm, o maior avaliado, isto pode indicar que há um limite na relação entre os diâmetros do orifício e de gotas $\left(\mathrm{d}_{\mathrm{o}} / \mathrm{d}_{\mathrm{g}}\right)$ em que é válida a consideração que o tamanho de gotas na saída independe do valor de entrada. Neste trabalho não foi avaliada esta hipótese pela limitação dos equipamentos instalados na bancada.

Na Figura 56 é mostrado também que o comprimento do orifício não impactou no tamanho de gotas observado após a quebra. Esta comparação é feita entre a peça $\mathrm{n}^{\circ} 11$, que possui comprimento de $1 \mathrm{~mm}$, e as peças $\mathrm{n}^{\circ} 6$ e 9 , que têm 
comprimento de $10 \mathrm{~mm}$. Mesmo com o Orifício $\mathrm{n}^{\mathrm{o}} 11$ sendo 10 vezes menor que o das outras peças testadas, é possível notar uma boa concordância no valor do diâmetro das gotas após a quebra entre este orifício e as outras duas peças citadas. $\mathrm{Na}$ comparação com o orifício $\mathrm{n}^{\circ}$ 9, que possui uma faixa de pressão avaliada similar, a diferença entre os diâmetros de gotas medidos a jusante do orifício é muito pequena. Isto pode indicar que a quebra das gotas não ocorre na passagem do orifício, mas sim num ponto imediatamente após a restrição.

Outro ponto relevante que pode ser observado neste gráfico é que apenas as gotas geradas pelo Orifício 12 não estão agrupadas com as obtidas através dos outros três orifícios. Como a bomba disponível não permitia um aumento de vazão, não foi possível testar outras condições que gerariam maior potência dissipada. Verifica-se que, neste orifício, pontos com potências dissipadas similares resultaram em gotas com diâmetros superiores. A avaliação deste orifício pôs em dúvida a adequabilidade da potência dissipada como parâmetro de ajuste do mecanismo de quebra de gotas já que para uma determinada condição avaliada experimentalmente foi observado um desvio significativo dos pontos medidos.

Na Figura 57 é possível verificar que os pontos obtidos no Orifício 12 não apresentam bom ajuste quando os pontos obtidos com as emulsões de tamanho de gotas diferentes são postos em uma mesma série, e que estes têm tendência diferente dos pontos gerados nos demais orifícios. Já para os orifícios 6, 9 e 11, mesmo com uma pequena diferença entre si, pode-se considerar que os pontos obtidos apresentaram bom ajuste com a potência dissipada, porém era necessário avaliar outro parâmetro que representasse totalmente o mecanismo de quebra de gotas observado no experimento.

$\mathrm{Na}$ Figura 57 os orifícios são representados pela letra $\mathrm{O}$ e o número correspondente junto com as dimensões de diâmetro e comprimento, ambas em milímetros. 


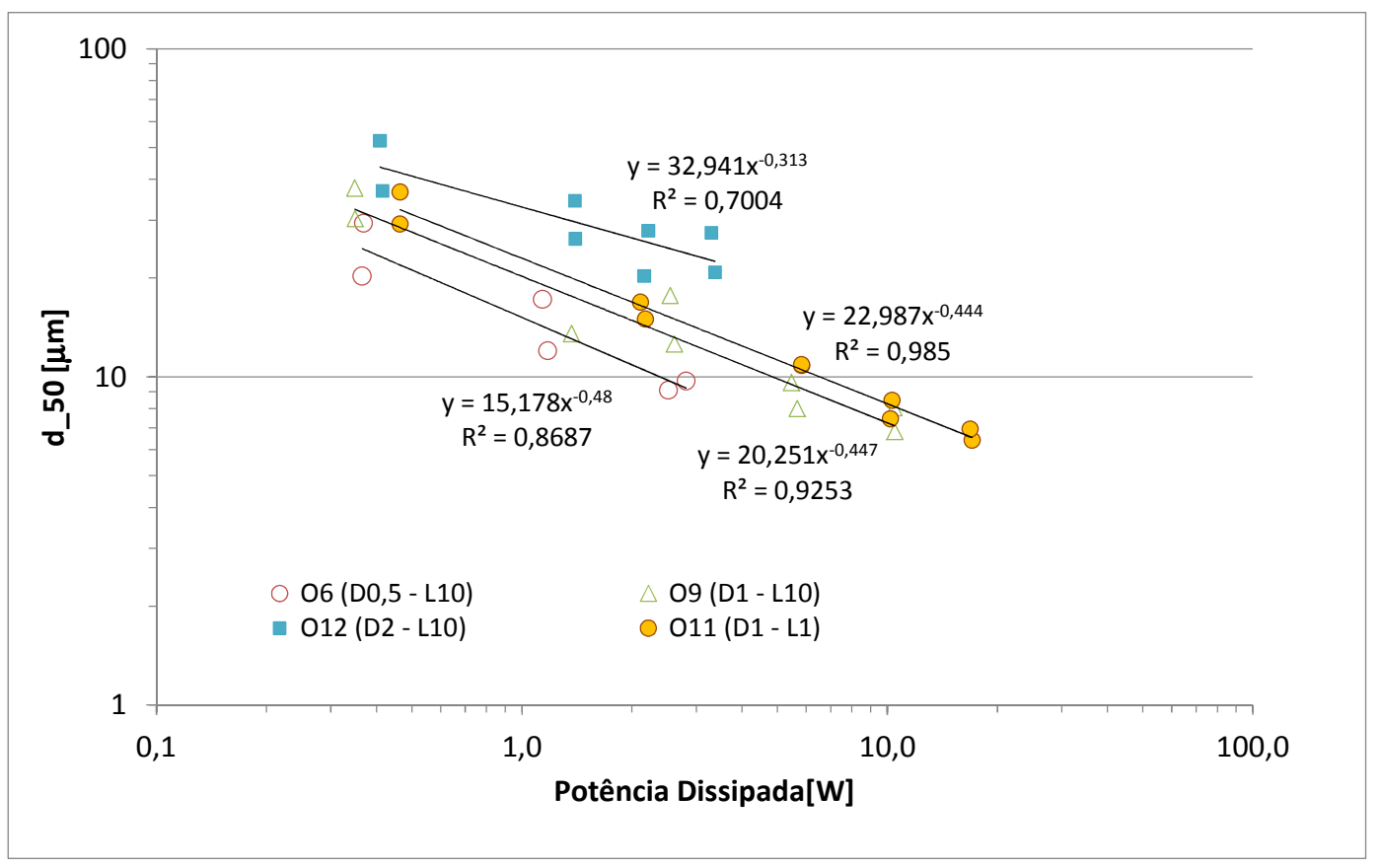

Figura 57 - Gráfico $\log$-log com o ajuste do diâmetro $d_{50}$ após a restrição em função da Potência Dissipada para cada orifício avaliado com o óleo NH-10.

Outro item avaliado para o ajuste da quebra de gotas foi o número de Reynolds. Calculou-se o valor do Re no orifício para cada uma das condições analisadas e fez-se a relação com o d $\mathrm{d}_{50}$ medido após a restrição. Este parâmetro também, não se mostrou adequado para representar o mecanismo de quebra, tendo inclusive apresentado, para todos os orifícios, uma dispersão maior dos dados coletados. A relação entre o número de Reynolds no orifício e o $\mathrm{d}_{50}$ pode ver vista na Figura 58. As séries de dados deste gráfico são indicadas seguindo o mesmo modelo apresentado na Figura 57. 


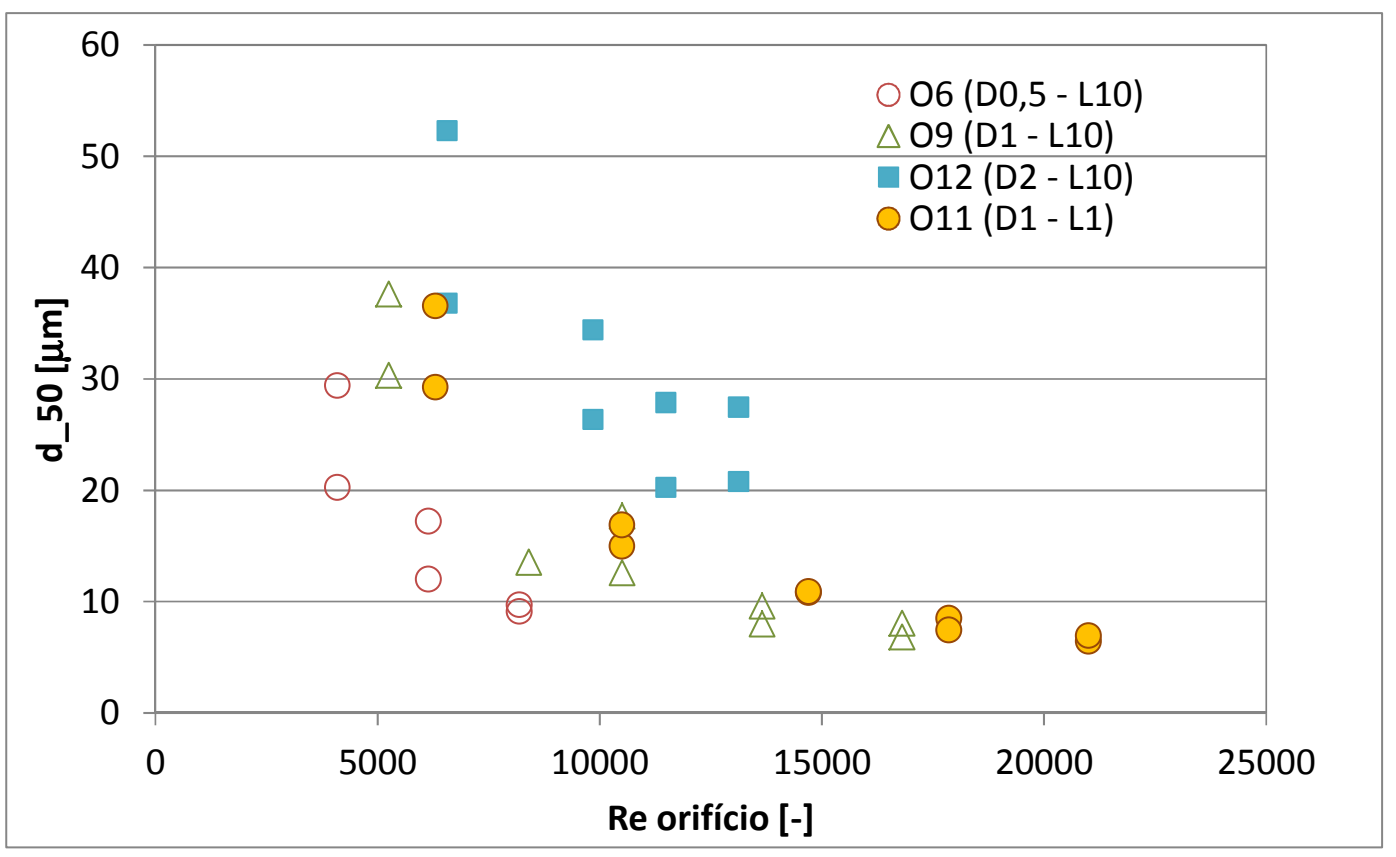

Figura 58 - Diâmetro d 50 após a quebra em função do Re em cada orifício.

Como visto, o ajuste em função do Reynolds não apresentou resultados satisfatórios para o conjunto de pontos coletados. A partir da definição do número de Reynolds, pode-se notar que o que diferenciava o ajuste entre os orifícios era, na realidade, o produto da velocidade do fluido no orifício com o diâmetro da peça, já que a massa específica e a viscosidade do fluido eram iguais para todas as condições analisadas até aqui.

Decidiu-se então desprezar o diâmetro do orifício no ajuste e realizar esta operação apenas em função da velocidade no orifício. Desta forma, apenas as condições de escoamento seriam consideradas no ajuste. Ao gerar o gráfico com estes dois termos, verificou-se uma boa correlação para todos os dados gerados, inclusive para os obtidos através do Orifício 12 , peça com maior diâmetro. $\mathrm{Na}$ Figura 59, a seguir, está mostrado como os pontos gerados em cada orifício seguem uma tendência e, na Figura 60, está mostrada a equação resultante do ajuste de potência com o coeficiente de determinação, quando os pontos medidos nos quatro orifícios são agrupados em uma única série. 


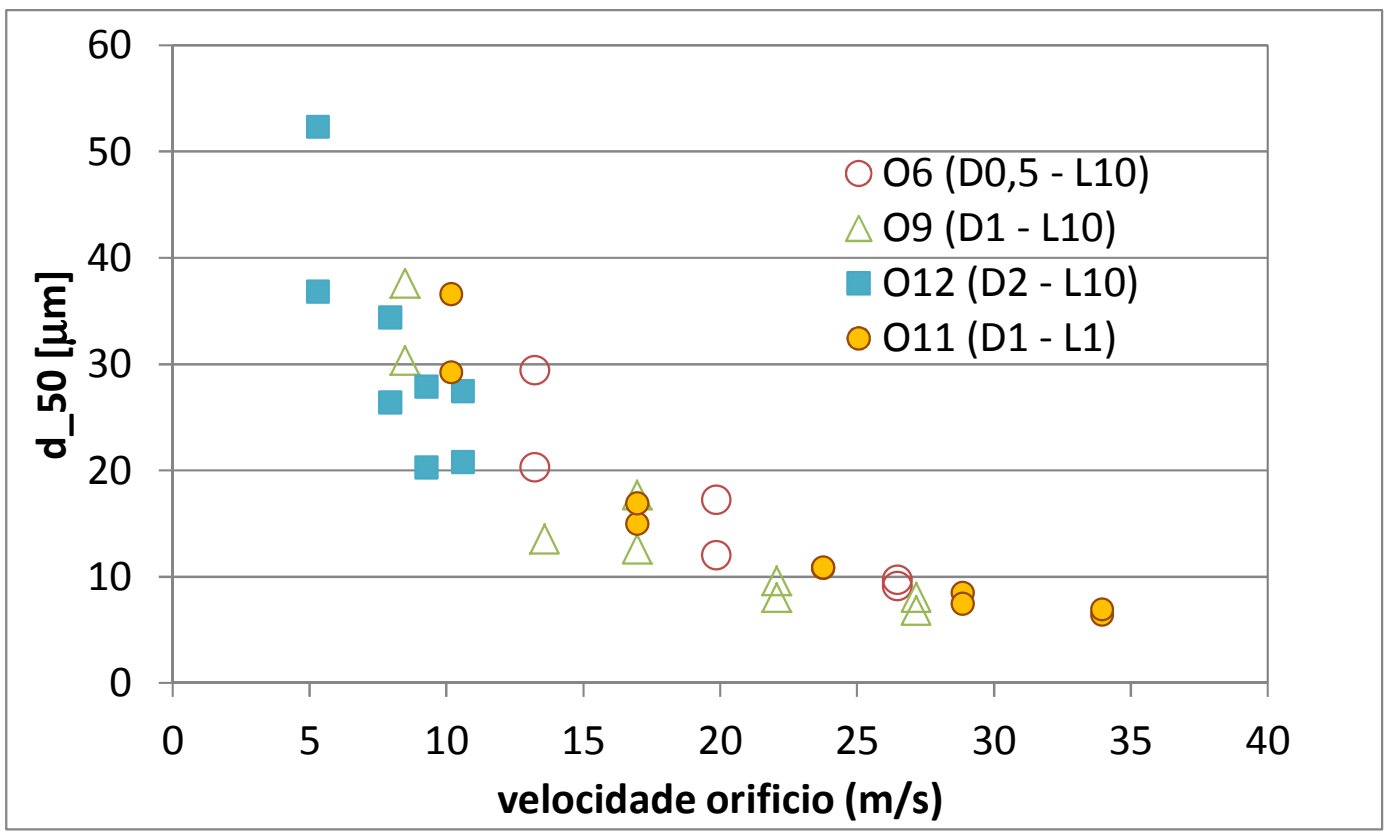

Figura 59 - Diâmetro d 50 após a quebra em função da velocidade no orifício.

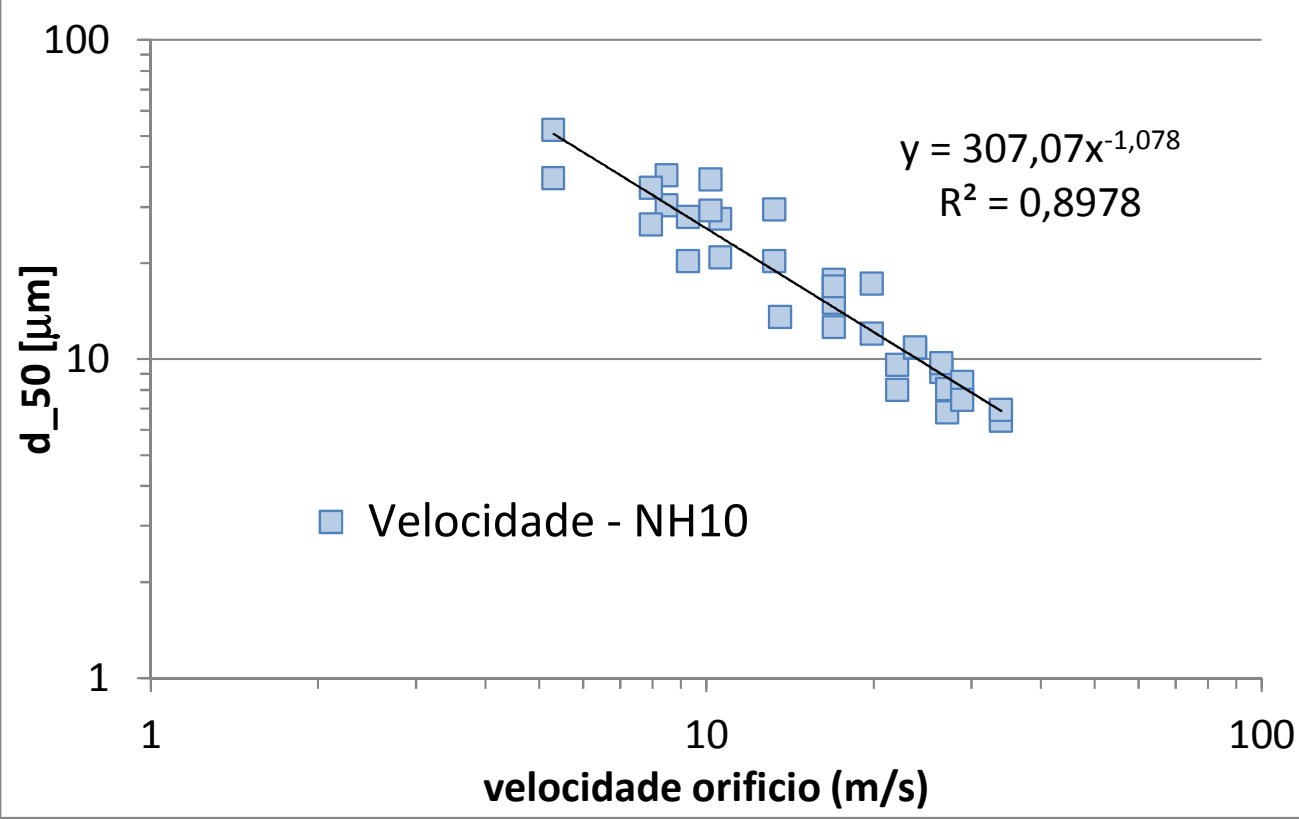

Figura 60 - Equação de ajuste do diâmetro $d_{50}$ após o orifício em função da velocidade no orifício.

Como mostrado na figura acima, o coeficiente de correlação $\left(R^{2}\right)$ da equação está próximo a 0,9 o que significa que a equação determinada representa adequadamente a amostra de pontos medidos. Até o momento, os ajustes foram testados apenas com as emulsões do óleo NH-10. 
Apesar de ter se mostrado um bom parâmetro para ajustar o modelo de quebra de gotas, a velocidade no orifício apresenta uma limitação para ser utilizada como termo determinante no modelo, que é a ausência de medição no experimento. Este termo é calculado através da soma das vazões das bombas de água e de emulsão, ou seja, não é determinado diretamente. Porém, como a velocidade tem relação direta com a perda de carga, verificou-se a possibilidade de realizar o ajuste através da variação de pressão observada no orifício.

Assim como feito no ajuste com a velocidade, todos os pontos medidos foram postos numa mesma série e foi gerado um gráfico do $\mathrm{d}_{50}$ a jusante do orifício em função da queda de pressão na restrição com a respectiva equação de ajuste. Na Figura 61 é possível observar a boa correlação existente entre estes dois parâmetros.

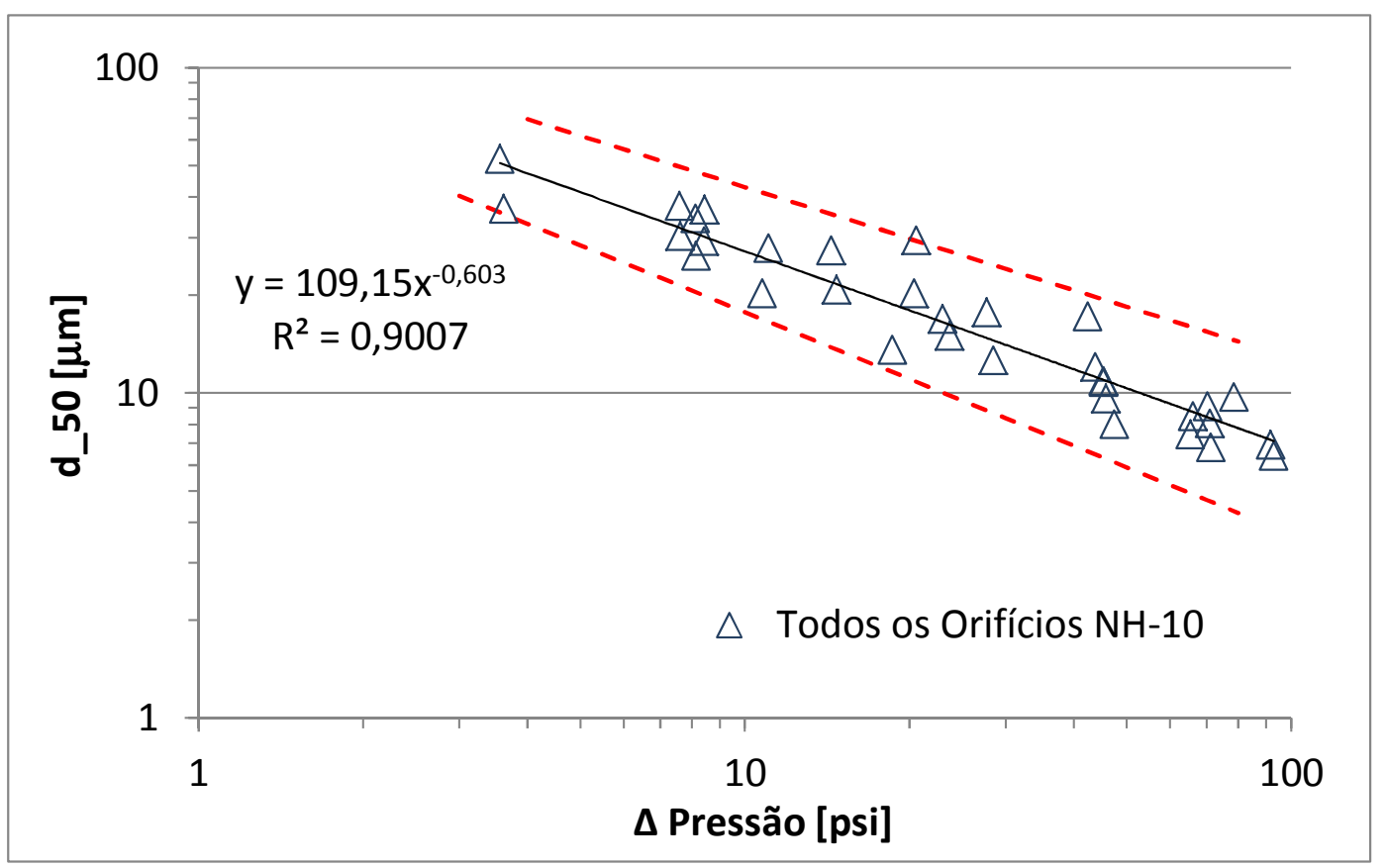

Figura 61 - Relação entre o diâmetro d $d_{50}$ após a quebra e a queda de pressão no orifício, com a equação de ajuste para as emulsões do óleo NH-10, e a faixa de confiança de $95 \%$.

Observa-se uma similaridade na forma entre os gráficos da velocidade e da queda de pressão. Ambos apresentaram um $\mathrm{R}^{2}$ de 0,9 , o que mostra que através destes termos pode-se obter uma representação do processo de quebra de gotas. Isto significa que é possível relacionar satisfatoriamente o valor medido para a queda de pressão com o diâmetro de gota resultante da quebra. As linhas 
pontilhadas representam um nível de confiança da amostra de 95\% utilizando a distribuição de probabilidade de $t$ student.

É importante lembrar que este ajuste foi obtido considerando orifícios com diferentes diâmetros e comprimentos, ou seja, a quebra da gota não ocorreu no orifício, mas sim num ponto a jusante da restrição. A relação entre a queda de pressão e o diâmetro da gota a jusante do orifício foi independente da característica do orifício avaliado. Os detalhes construtivos dos orifícios utilizados foram apresentados na Figura 23.

Entretanto, para validar a queda de pressão como parâmetro de ajuste, era necessário avaliar se este termo também representava adequadamente a quebra no outro óleo analisado, o 500PS, que possui viscosidade maior que o NH-10.

O procedimento para geração do gráfico de tamanho de gota em função da variação de pressão foi similar ao executado para as amostras de NH-10. Todos os pontos coletados nos experimentos com o óleo 500PS foram postos numa única série e foi gerada uma equação de ajuste para estes dois termos com os intervalos de confiança de $95 \%$. Na Figura 62 é mostrada a equação obtida através dos dados coletados nos ensaios com o óleo 500PS.

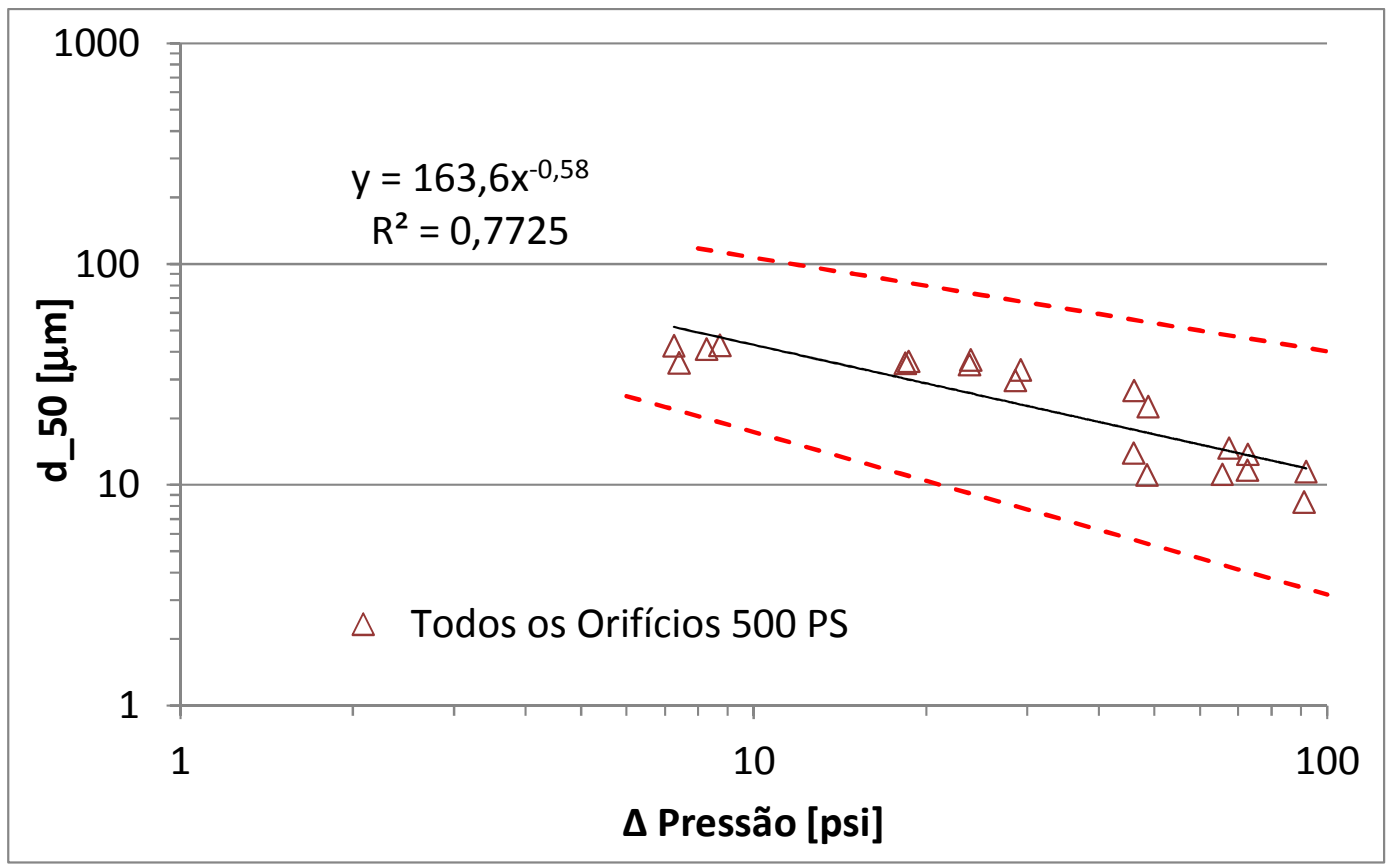

Figura 62 - Relação entre o diâmetro $d_{50}$ após a quebra e a queda de pressão no orifício, com a equação de ajuste para as emulsões do óleo 500PS, e a faixa de confiança de $95 \%$. 
Para o óleo 500PS o ajuste apresentou um coeficiente de determinação menor que o obtido para o óleo NH-10, nesta segunda análise este termo ficou próximo a 0,77 o que dá um grau razoável de representação dos dados pela função de potência. Contudo, mesmo com um ajuste mais desfavorável, era necessário que as funções de ajuste fossem iguais para que o agrupamento dos dados coletados fosse realizado.

\section{3.}

\section{Considerações Gerais}

Como detalhado no item anterior, a queda de pressão no orifício foi o parâmetro do experimento que melhor representou o mecanismo de quebra de gotas observado e medido nas amostras. Contudo, seria importante que houvesse uma única função que permitisse avaliar a quebra de gotas para as emulsões formadas a partir dos dois óleos. Desta forma, o modelo gerado seria mais amplo, sendo válido para óleos com diferentes características.

Na Figura 63, estão representados, de forma conjunta, os pontos gerados a partir dos dois óleos com os ajustes mostrados no item anterior. O objetivo é agrupar os pontos medidos, para que seja possível correlacionar o tamanho de gotas após a quebra através de uma única função.

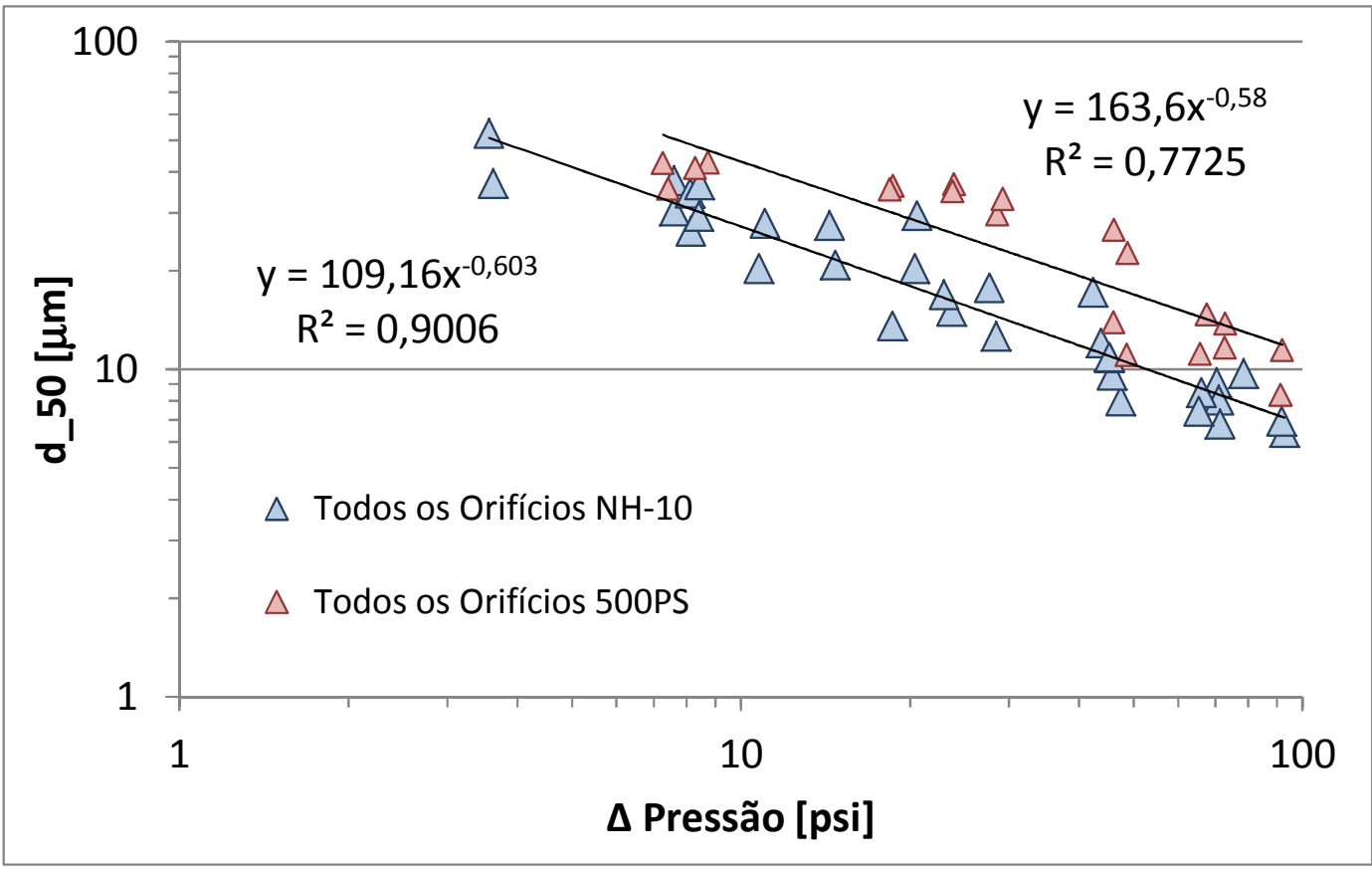

Figura 63 - Ajustes obtidos com os dois óleos testados no experimento. 
Pela Figura 63 observa-se que era necessário adicionar um termo à queda de pressão para que a relação que representa a quebra de gotas nos dois óleos fosse única. Em uma análise das informações disponíveis, verifica-se que o diferencial dos dois conjuntos de dados era a viscosidade dos óleos utilizados. Todos os demais parâmetros do teste foram iguais para as amostras oriundas dos dois óleos. A influência deste termo, contudo, ainda não havia sido implementada.

Seguindo a teoria de Reynolds, decidiu-se avaliar a divisão entre a parte referente aos esforços inerciais e a parcela viscosa. Desta forma, a quebra de gotas seria diretamente proporcional à variação de pressão no orifício e inversamente à viscosidade dinâmica do óleo utilizado na emulsão.

A aplicação deste conceito trouxe melhoria no ajuste global dos pontos gerados a partir dos dois tipos de emulsão, porém observou-se que era necessário inserir no termo da viscosidade um expoente, com valor entre 0 e 1 , para que o ajuste fino fosse feito. Foi realizada uma análise de sensibilidade para este expoente a fim de verificar qual valor traria o maior coeficiente de determinação para a série formada por todos os pontos medidos no experimento. O passo utilizado na variação do expoente foi de 0,1 , tendo sido obtido para este expoente o valor de 0,3 , com a função possuindo um $\mathrm{R}^{2}$ de 0,86 . Para a realização deste cálculo utilizou-se como base os valores de viscosidade dinâmica a $25^{\circ} \mathrm{C}$ calculados a partir da multiplicação do valor da viscosidade cinemática pela massa específica de cada óleo testado. Os valores medidos para estes dois termos estão apresentados na Tabela 6.

Sendo assim, o novo termo na abcissa do gráfico passa a ser $\Delta \mathrm{p} . \mu^{-0,3}$, onde a variação de pressão está em psi, e a viscosidade em cP. Na Figura 64 são mostradas as equações em função deste novo ajuste quando as séries são consideradas separadamente. 


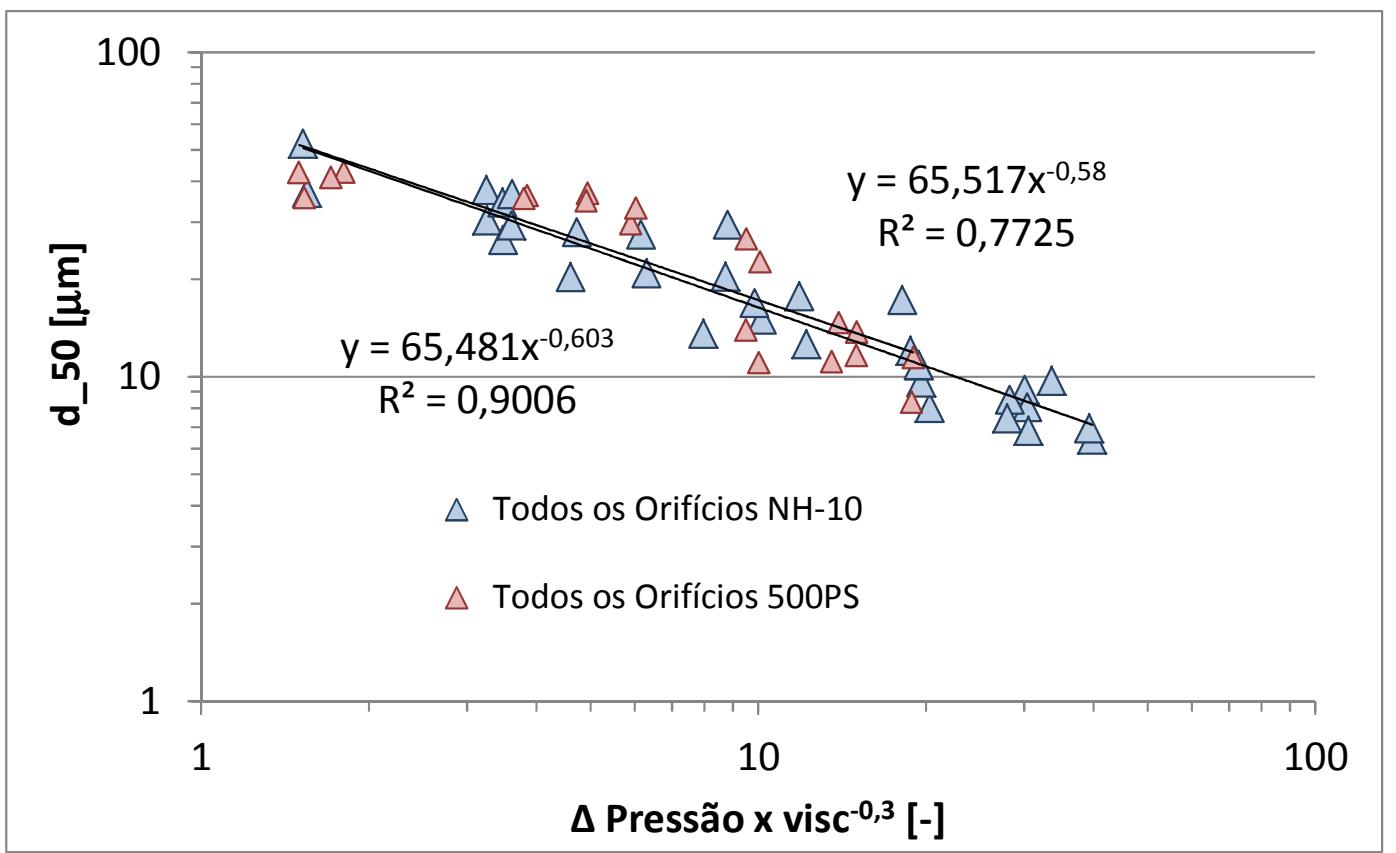

Figura 64 - Novo ajuste para os dois tipos de emulsão em função do termo de queda de pressão e viscosidade.

Como explicado anteriormente, para determinar o valor de 0,3 como expoente da viscosidade, buscou-se maximizar o coeficiente de determinação para a série formada por todos os pontos coletados. Na Figura 65 é apresentada a equação que melhor ajustou a todos os dados medidos, com as linhas de confiança de 95 e $99 \%$ calculadas a partir da distribuição de $t$ student, e o coeficiente de determinação resultante.

Com a relação apresentada na Figura $65, \mathrm{~d}_{50}=66,33 \cdot\left(\Delta \mathrm{p} \cdot \mu^{-0,3}\right)^{-0,601}$, acreditase que é possível representar a quebra de gotas de óleos que possuem viscosidade entre 17 e 192 mPa.s, que são os valores das amostras de NH-10 e de 500PS respectivamente, de forma adequada. Provavelmente, emulsões que possuam gotas com $\mathrm{d}_{90}>100 \mu \mathrm{m}$ não apresentarão um bom ajuste a esta função se a queda de pressão a que forem sujeitas for muito baixa $(\Delta \mathrm{p}<5$ psi). Já para elevadas variações de pressão no orifício é muito provável que os diâmetros resultantes estejam mais próximos ou iguais aos apresentados neste trabalho. 


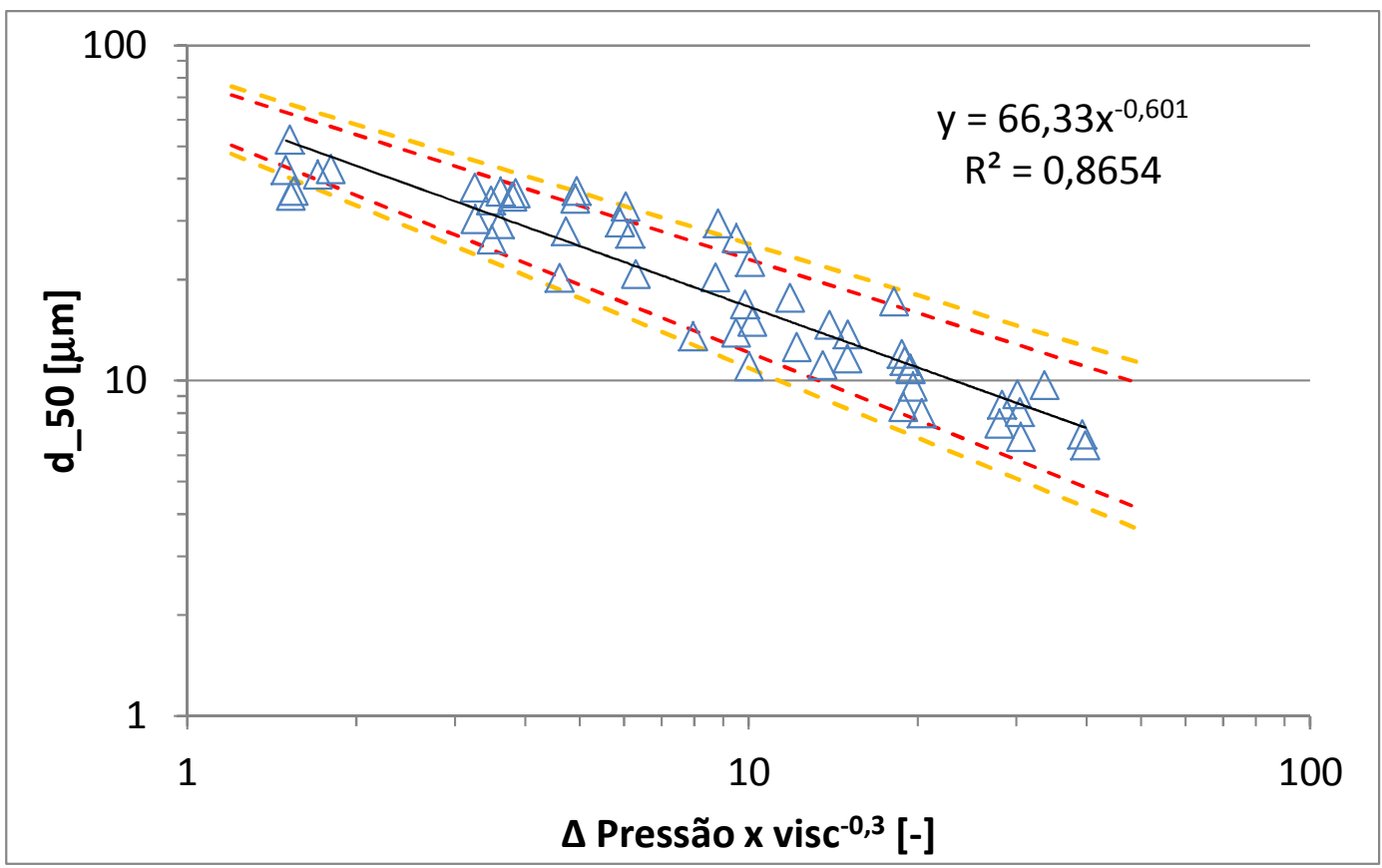

Figura 65 - Ajuste de todos os pontos coletados em função do parâmetro de queda de pressão e viscosidade, e as linhas de confiança de $95 \%$ (vermelha) e 99\% (amarela).

Um ponto a considerar, é que o termo proposto para correlacionar o diâmetro da gota após a quebra não é adimensional, é uma relação entre pressão, em psi, e viscosidade, em cP. Até o momento não há na literatura um termo com esta característica que consiga representar o fenômeno de quebra de gota. É importante salientar que há poucos trabalhos relacionados ao tema, o que mostra que ainda há muitos pontos que podem ser investigados. 


\section{5 \\ Conclusões e Recomendações}

\section{1. Conclusões}

Apesar dos estudos apresentados na literatura indicarem que o mecanismo de quebra de gotas é governado pela potência dissipada ocorrida em um orifício, foi observado nos experimentos conduzidos neste trabalho, que este parâmetro não apresentou bom ajuste para os valores gerados a partir das emulsões testadas no orifício de diâmetro igual a 2,0 mm, que é aproximadamente 20 vezes maior que o $\mathrm{d}_{90}$ da amostra com gotas maiores. Isto pode indicar que há um limite na relação entre os diâmetros das gotas e do orifício em que a potência dissipada se ajusta adequadamente a este fenômeno. Desta forma, foi necessário determinar um novo parâmetro para representar adequadamente a quebra de gotas em todos os orifícios testados.

Após algumas tentativas, foi detectado que a variação de pressão medida na restrição fornecia um bom ajuste com os diâmetros das gotas medidos nos testes com as emulsões formadas a partir do óleo NH-10. Numa verificação posterior, com fins de validação, foi possível observar uma boa correlação deste termo com as amostras preparadas com o óleo 500PS, que é mais viscoso. Nos ajustes realizados em ambos os óleos, não foi detectada nenhuma influência do comprimento do orifício no mecanismo de quebra de gotas.

Após o ajuste realizado em função da queda de pressão para as amostras de cada óleo separadamente, foi inserido o efeito da viscosidade do óleo para que uma única função pudesse representar o mecanismo de quebra independentemente do tipo de óleo que fosse utilizado. A inserção deste efeito foi feita através da divisão da queda de pressão pela viscosidade do óleo elevada ao valor de 0,3 $\left(\Delta \mathrm{p} / \mu^{0,3}\right)$, que foi determinado através de sensibilidade numérica. Este novo termo conseguiu agrupar os pontos medidos em cada amostra, gerando assim uma nova função, única para os dois tipos de óleo, com coeficiente de determinação de 0,86 e elevado grau de confiança. 
Sendo assim, acredita-se que este novo termo poderá ser utilizado para correlacionar adequadamente o mecanismo de quebra de gotas em orifícios com diferentes diâmetros e comprimentos, e em óleos que possuam viscosidade dinâmica intermediária aos valores medidos para os utilizados no ensaio.

Este estudo não esgota o assunto, mas mostra uma abordagem diferente do fenômeno de quebra de gotas que poderá ser pesquisado e validado em futuros trabalhos acadêmicos. No item a seguir estão listadas algumas recomendações para futuras análises que poderão ajudar na investigação mais profunda de alguns pontos que não foram avaliados neste experimento devido a alguma limitação.

\section{2. \\ Recomendações}

Neste item serão apresentadas sugestões que poderão ser implementadas em futuros testes e avaliações do fenômeno de quebra de gotas. Estas recomendações são o resultado de observações feitas durante o desenvolvimento deste trabalho. Estas buscam solucionar restrições detectadas no experimento e aumentar a robustez dos testes até aqui realizados.

- Utilização de uma bomba de água com vazão nominal superior a 2 1/min para avaliar a perda de pressão nos orifícios com maior diâmetro. No caso do experimento, os orifícios com diâmetro igual a $2 \mathrm{~mm}$ poderiam ter uma maior faixa de avaliação para a potência dissipada, sendo possível traçar uma comparação mais ampla com os outros orifícios. Vale lembrar que foram confeccionadas peças com diâmetro de $4 \mathrm{~mm}$ que não foram utilizadas no experimento, e que poderiam ser com uma vazão maior na bomba de água.

- Avaliação de óleos com viscosidade intermediária entre as medidas para o NH-10 e o 500PS visando validar o modelo proposto em função da viscosidade dinâmica. Esta nova análise daria mais robustez ao modelo proposto. Há ainda a possibilidade de testar um óleo mais viscoso que o 500PS com a mesma finalidade. Para validação do modelo, todos os demais procedimentos e variáveis de escoamento devem ser mantidos constantes. 
- Preparo de emulsões com diâmetro de gotas maior para verificar o comportamento na quebra e se há a necessidade de inserir um novo parâmetro no ajuste de quebra de gotas. Para o preparo de emulsões com $\mathrm{d}_{90}$ maior que $100 \mu \mathrm{m}$ um novo procedimento deve ser testado, provavelmente utilizando outro misturador que não seja o Ultrarrax. Esta nova emulsão serviria para averiguar se a relação entre os diâmetros do orifício e da gota é realmente significativa no processo de quebra de gotas como visto nos testes com o orifício $\mathrm{n}^{\mathrm{o}} 12$.

- Utilização de um manômetro com capacidade de leitura superior a 100 psi para a realização dos experimentos nos orifícios com comprimento de $30 \mathrm{~mm}$. Assim como foi feita a avaliação da quebra de gotas reduzindo o comprimento do orifício, seria realizado o teste em orifícios mais compridos que geram maior tempo de residência da gota na restrição. O resultado confirmaria, ou não, a observação feita que o comprimento do orifício não altera o tamanho da gota após o orifício. Já há um manômetro, do mesmo fabricante utilizado no experimento, que tem como limite 500 psi, contudo este não estava disponível para uso no laboratório. Como ponto de atenção, vale lembrar que a bomba de emulsão tem limite de pressão de 260 bar, ou seja, o aumento da pressão no sistema deve ser avaliado em função dos equipamentos instalados na bancada. 
6

\section{Referência Bibliográfica}

1 ROSA, A.; CARVALHO, R.; XAVIER, J. Engenharia de Reservatórios de Petróleo, Rio de Janeiro: Interciência, 2006.

2 Blog EPN Engeprojnews, EPN Engeprojnews, 1 Julho 2007. Disponível em: http://engeprojnews.blogspot.com.br/. Acesso em 31 Out. 2013.

3 JANSSEN, P.; VAN DEN BROEK, W.; VAN DIJK, K.; CRAS, R.; KLAUER, H. Characterization of Near-Wellbore Oil/Water Morphology. Proceedings of the 2nd International Seminar in Pratices of Oil and Gas Exploration, Lima, Peru, 1996.

4 VAN DER ZANDE, M.; VAN DEN BROEK, W. The Effect of Tubing and Choke Valve on Oil-Droplet Break-up. Proceedings of the 1st North American Conference on Multiphase Technology, Banff, Canada, 1998.

5 VAN DER ZANDE, M.; VAN DEN BROEK, W. Break-up of Oil Droplets in the Production System. Proceedings of the Energy Sources Technology Conference and Exhibition, Houston, 1998.

6 GAlinAT, S.; MASBERNAT, O.; GUIRAUD, P.; DALMAZZONE, C.; NOÏK, C. Drop break-up in turbulent pipe flow downstream of a restriction. Chemical Engineering Science, n. 60, p. 6511-6528, 2005.

7 VAN DER ZANDE, M.; MUNTINGA, J.; VAN DEN BROEK, W. The Effects of Production Rate and Choke Size on Emulsion Stability, em INGEPET, Lima, Peru, 1999.

8 CENTRO DE PESQUISA E DESENVOLVIMENTO LEOPOLDO A. MIGUEZ DE MELLO. Avaliação Reológica do Petróleo e suas Emulsões CT TEE 066/13. Rio de Janeiro, 2013.

9 ONEGUMAS, Wikimedia Commons, 21 Março 2011. Disponível em: http://commons.wikimedia.org/wiki/File:Simple_emulsion.jpg. Acesso em 31 Out. 2013.

10 WALSTRA, P. Principles of Emulsion Formation. Chemical Engineering Science, vol. 48, p. 333-349, 1993. 
11 DAVIES, J. Turbulent Phenomena. Academic Press, 1972.

12 WALSTRA, P. Formation of Emulsions. Encyclopedia of Emulsion Technology, Dekker, NY, Becher, 1983, p. 57-127.

13 WALSTRA, P. Influence of Rheological Properties of both phases on droplet size of $\mathrm{O} / \mathrm{W}$ obtained by homogenization and similar processes. Dechema Monogr., p. 87-94, 1974.

14 VANKOVA, N.; TCHOLAKOVA, S.; DENKOV, N.; IVANOV, I.; VULCHEV, V.; DANNER, T. Emulsification in turbulent flow - Mean and maximum drop diameters in inertial and viscous regimes. Journal of Colloid and Interface Science, n. 312, p. 363-380, 2007.

15 DAVIES, J. Drop sizes of emulsions related to turbulent energy dissipation rates. Chemical Engineering Science, n. 40, p. 839-842, 1985.

16 PRINCEN, H. Encyclopedia of Emulsion Technology, Dekker, NY: J.Sjöblom, 2001.

17 BARNES, H. The Flow of Suspensions. A Handbook of Elementary Rheology. Aberystwyth, University of Wales, 2000, p. 119-140.

18 BARNES, H. Dispersion Rheology 1980, a survey of industrial problems and academic progress. London: Royal Society of Chemistry, 1981.

19 GHANNAM, M.; ESMAIL, N. Flow Enhancement of Medium Viscosity Crude Oil. Petroleum Science and Technology, n. 24, p. 985-999, 2006.

20 CENTRO DE PESQUISA E DESENVOLVIMENTO LEOPOLDO A. MIGUEZ DE MELLO. Avaliação reológica das emulsões e do petróleo do poço Alpha. Rio de Janeiro, 2009.

$21 \mathrm{XU}, \mathrm{X}$. Study on oil-water two-phase flow in horizontal pipelines. Journal of Petroleum Science and Engineering. n. 59, p. 43-58, 2007.

22 ARIRACHAKARN, S.; OGLESBY, K.; BRILL, J. An Analysis of Oil/Water Flow Phenomena in Horizontal Pipes. SPE, 1989.

23 OGLESBY, K. An experimental study on the effect of oil viscosity mixture, velocity and water fraction on horizontal oil-water flow. MS Thesis, University of Tulsa, 1979.

24 ANGELI P.; HEWITT, G. Pressure gradient in horizontal liquid-liquid flows. International Journal of Mutiphase Flow, n. 24, p. 1183-1203, 1998.

25 OTSWALD, W. Beitrage zur Denntris der Emulsionen. Kolloid-Z., n. 6, p. $103,1910$. 
26 BRAUNER, N.; ULLMANN, A. Modeling of phase inversion phenomenon in the two-phase flows. International Journal of Multiphase Flow, n. 28, p. 1177-1204, 2002.

27 DUKLER, A.; WICKS III, M.; CLEVELAND, R. Frictional pressure drop in two phase flow. AIChE Journal, vol. 1, n. 10, p. 44-51, 1964.

28 RONNINGSEN, H. Correlation for predicting viscosity of W/O emulsions based on North Sea crude oils. Procedures of the SPE International Symposium Oil Field Chemistry, Houston, TX, 1995.

29 BROUGHTON G.; SQUIRES, L. The viscosity of oil-water emulsions. Journal of Physical Chemistry, n. 42, p. 253-263, 1938.

30 HINZE, J. Fundamentals of the Hydrodynamic Mechanism of Splitting in Dispersion Processes. AIChE Journal, vol. 1, n. 3, p. 289-295, 1955.

31 ANGELI P.; HEWITT, G. Drop size distributions in horizontal oil-water dispersed flows. Chemical Engineering Science, vol. 55, p. 3133-3143, 2000 .

32 McCABE, W.; SMITH, J. Unit Operations of Chemical Engineering. McGraw-Hill Chemical Engineering Series, 1976.

33 TEYSSANDIER, R.; HUSAIN, Z. Experimental Investigation of an Orifice Meter Pressure Gradient. Journal of Fluids Engineering, vol. 109, p. 144$148,1987$.

34 MORISSON, G.; DeOTTE, R.; NAIL, G.; PANAK, D. Mean Velocity and Turbulence Fields Inside a Beta=0,5 Orifice Flowmeter. American Institute of Chemical Engineers Journal, vol. 39, n. 5, p. 744-756, 1993.

35 PERCY, J.; SLEICHER, C. Drop Breakup in the Flow of Immiscible Liquids through an orifice in a pipe. American Institute of Chemical Engineers Journal, vol. 29, n. 1, p. 161-164, 1983. 